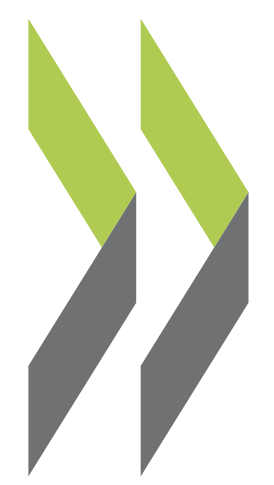

OECD Working Papers on Public Governance No. 26

\title{
Social Media Use
}

by Governments: A Policy Primer to Discuss Trends,

\section{Arthur Mickoleit}

\section{Identify Policy Opportunities and Guide Decision Makers}


OECD Working Papers should not be reported as representing the official views of the OECD or of its member countries. The opinions expressed and arguments employed are those of the authors.

Working Papers describe preliminary results or research in progress by the author(s) and are published to stimulate discussion on a broad range of issues on which the OECD works. Comments on Working Papers are welcomed, and may be sent to the Public Governance and Territorial Development Directorate, OECD, 2 rue André-Pascal, 75775 Paris Cedex 16, France.

OECD Working Papers on Public Governance No. 26

SOCIAL MEDIA USE BY GOVERNMENTS: A POLICY PRIMER TO DISCUSS TRENDS, IDENTIFY POLICY OPPORTUNITIES AND GUIDE DECISION MAKERS

Validated for publication by Rolf Alter, Director, Public Governance and Territorial Development Directorate 
WORKING PAPER

SOCIAL MEDIA USE BY GOVERNMENTS:

\title{
A POLICY PRIMER TO DISCUSS TRENDS, IDENTIFY POLICY OPPORTUNITIES AND GUIDE DECISION MAKERS
}

\author{
Arthur Mickoleit
}

\begin{abstract}
This working paper takes a comparative snapshot of social media use in and by OECD governments. The focus is on government institutions, as opposed to personalities, and how they manage to capture the opportunities of new social media platforms to deliver better public services and to create more open policy processes. The analysis is based on a large amount of empirical data, including a survey of OECD governments on policies and objectives in this area. Major challenges are discussed, notably those related to the uncertainty of institutions on how to best leverage social media beyond "corporate" communications. The paper proposes tools to guide decision makers: a checklist of issues to be considered by government institutions, a set of potential indicators to appraise impacts, and a range of options for more in-depth policy analysis.
\end{abstract}




\section{EXECUTIVE SUMMARY}

Presence and activity on social media is no longer a question of choice for most governments as those new platforms empower individuals and non-traditional interest groups. Politicians were first to react to these changes by using platforms such as Twitter, Facebook and blogs to rally support. Government institutions are slowly catching up and increasingly experiment with social media.

- Governments are witnessing how social media empower individuals, as well as traditional and newly-formed interest groups to influence political agendas and policy processes. Most prominent topics discussed on social media include elections and political campaigns, disaster and emergency situations, political unrest. But social media are more than just a global place for discussions, they have become a vehicle for the organisation of collective action.

- Political personalities, e.g. heads of state or heads of government, quickly adapted to these changes. Social media are today a standard component of a politicians' toolkit for campaigning, rallying and fund-raising. Some state or government leaders are very successful, as illustrated by high levels of popularity on social media achieved by the President of the United States (@BarackObama) or the President of Ecuador (@MashiRafael) - both interact with communities of Twitter followers that correspond to more than $10 \%$ of the domestic population.

- Government institutions are slowly becoming more represented and active on social media. The main executive institutions in 26 out of 34 OECD member countries operate a Twitter account; and they maintain a Facebook page in 21 out of 34 countries. Many ministries and specialised agencies operate on social media; as do institutions at regional and local levels of government.

- Data suggests that some of the social media activities by government institutions are met with interest. For example the top executive institutions in Ecuador (@Presidencia_Ec), the United Kingdom (@Number10gov) and Chile (@GobiernodeChile) managed to build a community of Twitter followers that is equivalent to over $4 \%$ of the domestic population. Tweets by the United States White House (@WhiteHouse) are re-tweeted over 270 times on average, which can be interpreted as a sign of interest and perceived relevance by social media users.

The purpose and returns of social media use by institutions are not as clear as they are for political personalities. This leads to uncertainty among government institutions about how to best leverage social media and about the implications for strategic objectives and day-to-day operations.

- Political leaders, i.e. heads of state and heads of government, are more popular on social media than the institutions they represent. On Twitter the average government leader counts at least four times more followers than the average institutional account for the head of state or government.

- Higher social media popularity of personalities versus institutions relates to the expectation of many social media users to interact with "real", i.e. identifiable, people. But it also illustrates uncertainty and a lack of creativity on the side of institutions. Political leaders are able to reap measurable returns on social media use, e.g. through social media campaigns that lead to more funds, support or votes. Many government institutions in turn are still looking for the right "recipe" among the options for using social media: providing public information, providing 
corporate information, promoting public services in general or promoting specific delivery channels, consulting and involving the population.

- Good practices of purposeful and mission-oriented institutional use of social media exist. The Spanish national police (@Policia) has for example become a global reference for police work on and with social media. Such cases provide guidance on how social media help transform public services and help build trusted relationships with citizens.

- But the overall uncertainty is confirmed by the fact that few national governments in OECD countries have a dedicated strategy or overarching plan for institutional use of social media. Among those governments that do, most consider social media as being mainly an additional tool to improve public communications. Only few governments try to genuinely leverage social media for more advanced purposes like involving citizens in public policy processes or transforming and re-designing public service delivery.

Social media have the potential to make policy processes more inclusive and thereby rebuild some confidence between governments and citizens. But there are no "one size fits all" approaches and government strategies need to seriously consider context and demand factors to be effective.

- Social media offer new opportunities to reduce political exclusion, e.g. by allowing ad-hoc and diffuse interest groups to place items on the political agenda. Especially when combined with petitions, empirical evidence and on-the-ground actions, social media have proven their potential to "escalate" issues and alter original decisions made by established actors in the political system.

- Governments can leverage this potential to design public policies and services in more iterative, collaborative and responsive ways. It does, however, require dedicating resources to participative development and establishing credible follow-up procedures to integrate feedback received via new channels and platforms.

- Empirical evidence suggests that social media can bridge access and take-up gaps still faced by many traditional online government services. But the characteristics of social media users and non-users can be very different from country to country, as well as within countries.

- Social media do not automatically "level the playing field" in the sense of empowering all societal groups equally. This might be the case in some countries, e.g. in Germany, Austria or some Nordic ones where social media take-up and use do not depend on educational attainment. But in countries like Spain, the United Kingdom, Hungary, Portugal, Greece and Turkey social media use is much more prominent among parts of the population with high education levels than among those with no or low levels of education. The uptake gap can be as large as 50 percentage points.

- Neither do social media guarantee more attention or participation of younger, disenchanted people. General social media use is of course very high among young people in almost all OECD countries. But just over $30 \%$ of young Dutch seem to use social media to discuss political or civic issues. The Netherlands in fact lead this European comparison, which is trailed by Austria where less than 10\% of 16-24 year olds report using social media that way.

- Low rates of young people using social media to discuss political or civic issues are not just an expression of disinterest. They also result from low levels of capacity and commitment by many government institutions to use this channel to engage young people. This is particularly worrisome in about a dozen European countries that also suffer from very high rates of voter abstention among young people. Governments in those countries are not able to realise the potential of social media to make processes more inclusive of young people. Non-government 
actors often fill the gap by showing creative options and using social media to foster inclusion, as for example the "Bite the Ballot" campaign for young voter registration in the United Kingdom.

Social media drive innovation in public service delivery and government operations. They amplify some of the "democratisation" effects of the Internet on public information and services; and they provide opportunities to deliver on expectations that are not met by traditional online government services. But institutions need to be aware of risks, for instance in terms of protection of privacy, quality of information and public perception.

- Social media allow governments to "crowd-source" ideas, suggestions and critical remarks. Public institutions increasingly create or participate on collaborative platforms. One such example is GitHub, an open source collaboration platform that holds re-usable source codes for www.data.gov (United States), www.gov.uk (United Kingdom) and many other projects. The "government" category of the platform's repository has seen rapid growth since 2011.

- Where governments fail to or are slow to use those platforms to improve and deliver public services, people and organisations step in and pressure for change. The impacts of "bottomup" processes tend to increase where social media are combined with online petitions, mobile applications, open (government) data analytics, crowd-funding initiatives, and collective "offline" action such as protests.

- Better targeted and more efficient public service delivery is one of the expectations governments have towards social media. That expectation echoes the early days of "e-government". It is therefore important to make sure institutional use of social media is directed towards the realization of tangible benefits for users, society and government. Analysis of specific government sectors helps illustrate the potential, e.g. in healthcare or employment services.

- Digital opportunities in healthcare are a priority for many countries. But even in the most advanced countries only $50-60 \%$ of people use the Internet as a source for healthcare-related information. This has to do with the importance of interpersonal relationships between practitioners and patients. But it is also an illustration of the perceived lack of reliable and credible information. Seniors (over 65 year olds) are for example a fast-growing group of Internet and social media users - more than half of them are Internet users in Japan and the United States; and at least one in five seniors are social media users in Korea, Iceland, Norway and the United Kingdom. Public healthcare providers are still hesitant to use Internet forums or social media applications to accompany this segment of the population and to better integrate healthcare information into elderly people's daily lives.

- Looking for employment has long been transformed by the Internet and is under full transformation by social media. In some countries public employment services and commercial online service providers complement each other well, e.g. in Germany or Sweden where the majority of job seekers use the Internet to look for a job and consult the national employment agency. Germany's Bundesagentur für Arbeit for example supports job seekers and employers by collaborating with the online professional network Xing. In several other countries, however, the perceived relevance of public employment agencies is declining, which should give the concerned institutions incentives to re-invent their service delivery in this new context.

- As social media become more pervasive, they allow governments to use new sources of information to understand people's needs and behaviours. Governments can mine social media activities to obtain insights for better quality of services across all policy areas. But this is also an area of growing public attention, resentment to privacy breaches and perceived surveillance 
by governments. The number of government requests about individual users' information from platforms such as Facebook, Twitter and Google is steadily growing. While these requests are, in principle, in line with national legislation and often concern criminal investigations, the numbers and reasons are not always well communicated by governments and can lead to unfavourable public perception.

Government institutions need to better understand the impacts they can achieve through social media in order to help prioritise targets and establish effective policies. They need to adapt to, learn from and preferably shape the ways in which social media transform public value creation.

- Social media can help governments improve communications, both regular and emergency. But much potential is still undiscovered when it comes to using social media to transform policy processes, make decisions more transparent and processes more inclusive, and develop more responsive and more efficient public services. Few "recipes" are ready off the shelf but iterative interactions with users can start a process of mutual learning on how to best apply social media in a given area.

- There is little guidance on how government institutions can appraise the impact of social media on people's satisfaction with public services, on efficiency of government operations and on greater openness overall. Only a small minority of governments systematically monitor or measure the impacts. Some quantifiable information can be utilised to measure presence or popularity of an institution on social media. But more qualitative information, e.g. case stories about a better outcome for an individual or a community, are needed to appraise penetration, perception and purpose-orientation of institutional social media use.

- Some government institutions take up the challenge of developing skills and capacities. This includes developing programmes to attract, develop and retain the skills sets needed among civil servants. The Australian Public Service has long had a systematic approach to developing skills and capacities for digital government reforms; and the framework is being adapted to include social media and collaborative approaches.

- Governments need to build communities of interest around their social media experiences. There are some centrally coordinated exchange mechanisms, e.g. the "Social Media Community of Practice" supported by the United States GSA. Such communities help overcome some of the hesitation and uncertainty that individual ministries or agencies express when it comes to questions about if and how to take up social media in their work.

- The wide variety of practices mentioned in this report point to the benefits of further analysing the policy implications of social media, identifying good examples and developing missionoriented guidance for the public sector. A checklist for institutions is proposed below. The report develops a set of potential metrics and indicators for impact measurement; and it outlines options for more in-depth analysis. 
A checklist for purpose-oriented use of social media in the public sector

\begin{tabular}{|c|c|}
\hline Issue & Questions to be raised and answered \\
\hline $\begin{array}{l}\text { Objectives and } \\
\text { expectations }\end{array}$ & $\begin{array}{l}\text { What is the core mission of my institution? } \\
\circ \text { What are the most important information and services provided by my institution? } \\
\circ \text { How important is public communication for achieving my institution's core objectives? } \\
\circ \text { How can social media support my institution's core mission? What are examples from similar } \\
\text { institutions domestically or internationally? } \\
\text { Can social media enable outside actors to support selected activities of my institution, e.g. } \\
\text { intermediaries or individuals for which my institution can provide a platform for collaboration? }\end{array}$ \\
\hline $\begin{array}{l}\text { Governance } \\
\text { modes and } \\
\text { guidelines }\end{array}$ & $\begin{array}{l}\text { Is there a central oversight body for social media use across government or is the preferred } \\
\text { operating mode one of dispersed innovation? } \\
\text { How can different organisational units in my institution leverage social media, e.g. the public } \\
\text { relations department, the IT department, the policy making department, the service delivery } \\
\text { department? } \\
\circ \quad \text { Is there a need for social media guidelines for civil servants, including for personal use? } \\
\circ \quad \text { Is there a need for social media guidelines for official institutional accounts, e.g. Facebook } \\
\text { presence of a given ministry? } \\
\text { Who, if anybody, sets guidelines for social media use by politicians or appointed high-ranking } \\
\text { civil servants representing an institution? }\end{array}$ \\
\hline Legal compliance & $\begin{array}{l}\text { What are the specific legal and regulatory provisions that may have an impact on how my } \\
\text { institution uses social media? } \\
\text { - Are social media covered or excluded from official record-keeping? } \\
\text { - What disclaimers should be added to the social media presence? } \\
\text { - What information is my institution allowed to re-use when it comes to privacy protection or } \\
\text { compliance with intellectual property laws? } \\
\text { How to ensure that my institution's social media use meets requirements for accessibility of } \\
\text { information and services? }\end{array}$ \\
\hline $\begin{array}{l}\text { Skills and } \\
\text { resources }\end{array}$ & $\begin{array}{l}\text { What human resources are available or can be mobilized to achieve sustainable impacts? } \\
\text { Are social media skills addressed by wider (digital) skills strategies at my institution or } \\
\text { government? } \\
\text { How are social media expenses accounted for? Can they be extracted from overall } \\
\text { communications expenses in order to calculate specific costs? }\end{array}$ \\
\hline $\begin{array}{l}\text { Collaboration and } \\
\text { community- } \\
\text { building }\end{array}$ & $\begin{array}{l}\text { Do government communities exist where l can exchange social media experiences? } \\
\text { What coordination or collaboration mechanisms would help my institution understand and } \\
\text { maximize the impact of social media? }\end{array}$ \\
\hline $\begin{array}{l}\text { Managing risks of } \\
\text { social media use }\end{array}$ & $\begin{array}{ll}\circ & \text { How damaging would reputational risks be for my institution? } \\
\circ & \text { Does my institution need to worry about unintentional disclosure of information? } \\
\circ & \text { What share of civil servants uses social media in their personal capacity? } \\
\circ & \begin{array}{l}\text { Are social media risks addressed by overarching strategies for managing risks in my } \\
\text { institution or government? }\end{array}\end{array}$ \\
\hline $\begin{array}{l}\text { Monitoring and } \\
\text { measuring social } \\
\text { media impacts }\end{array}$ & $\begin{array}{l}\text { How advanced are my social media indicators? What do they actually measure: presence, } \\
\text { popularity, penetration, perception or purpose? } \\
\text { Does my institution use indicators that evaluate the contribution to actual core objectives? } \\
\circ \text { What would be an ideal set of metrics for my institution's use of social media? } \\
\circ \text { What information sources can I use to move from the current metrics to an ideal set of } \\
\text { purpose-oriented indicators? }\end{array}$ \\
\hline
\end{tabular}


TABLE OF CONTENTS

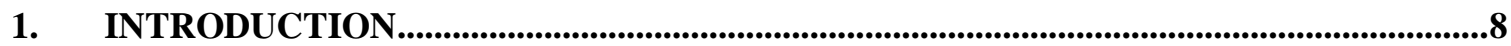

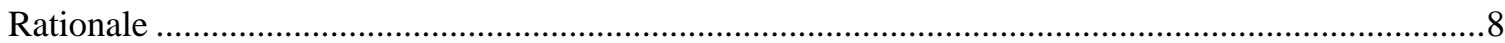

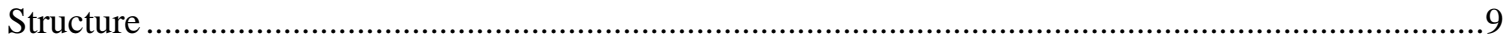

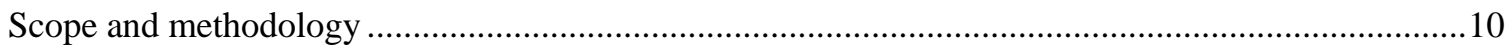

2. TAKING STOCK OF SOCIAL MEDIA USE IN GOVERNMENT ......................................12

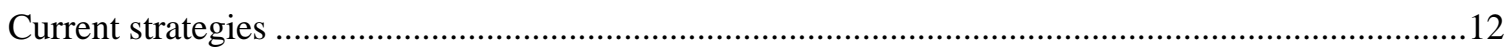

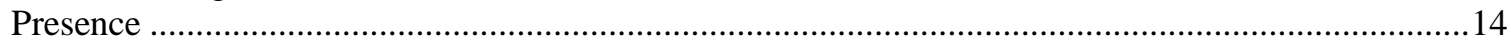

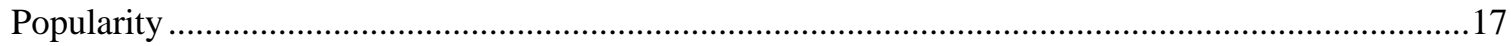

Comparing government institutions to government leaders ……...................................................19

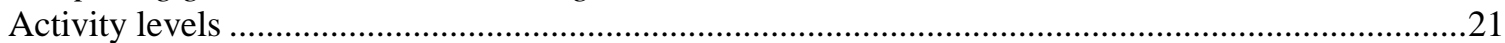

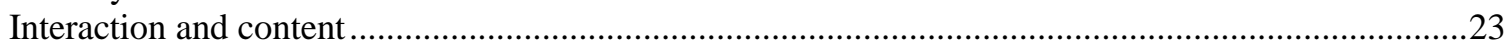

3. POTENTIAL AND CHALLENGES OF SOCIAL MEDIA USE IN GOVERNMENT.....27

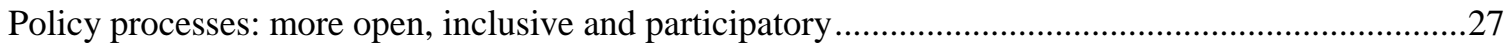

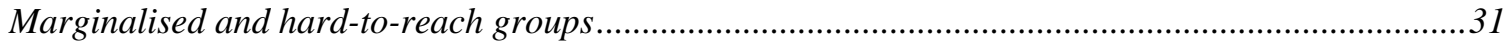

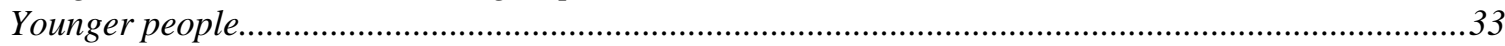

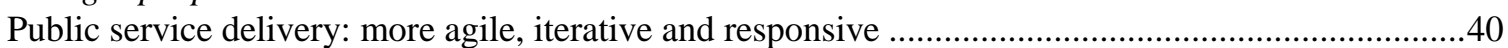

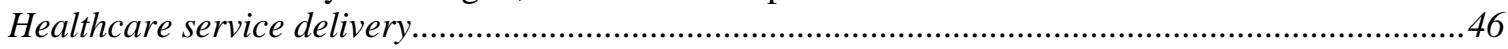

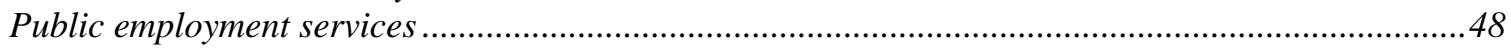

4. MANAGING THE NECESSARY CHANGE IN GOVERNMENT TO CREATE

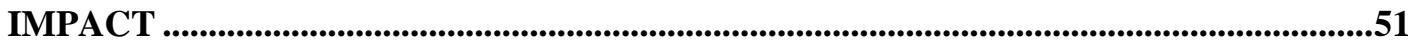

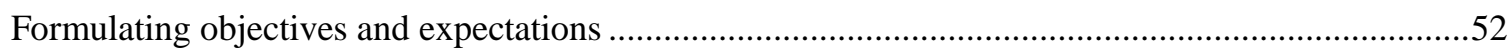

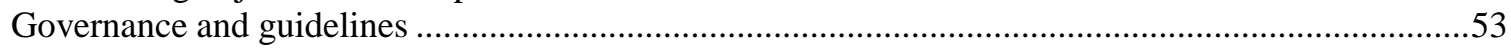

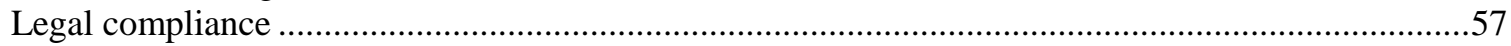

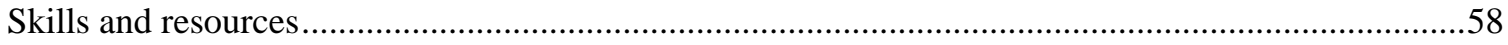

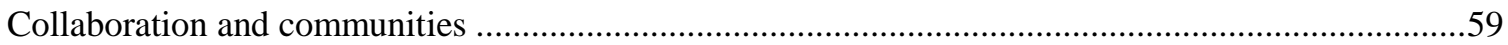

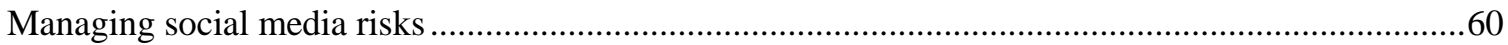

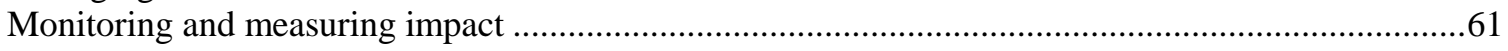

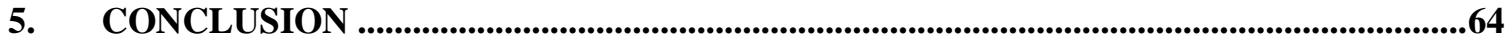

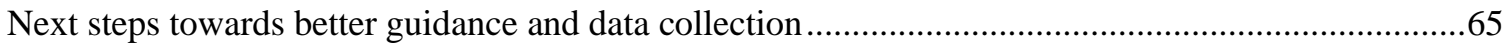




\section{INTRODUCTION}

\section{Rationale}

Governments all over the world are using social media. There are a multitude of cases for any country, any sector and any level of government. New government representatives and institutions are joining every day, mainly because the entry costs are relatively low and because the lost opportunities of "not being there" are perceived as being high.

But what is actually the added value for governments of embracing social media? Is it a technology trend likely to end up as "hype" or is it a societal development that requires full attention? Experimentation is surely an option since initial entry costs are low. At the same time sustainable operations and tangible impacts do require dedicated resources - human, financial, organisational. And at times when demands for governments to be more open, transparent and accountable coincide with demands to be more efficient and effective in the provision of public goods and services - the freedom to experiment is more often than not limited by the need to show explicit returns.

It is relatively undisputed that social media make communications more effective. This includes regular communications by politicians, civil servants and government institutions. And it also includes communications in sudden crisis and emergency situations, e.g. in response to natural disasters, where each new crisis in the recent past showed the world new aspects of how social media can and cannot make a difference (cf. Wendling et al., 2013).

But public sector institutions need and want to go beyond improving communications. More and more institutions are making the effort to re-think the ways in which they provide information and deliver services, the ways in which they let stakeholders participate in policy processes, the ways in which they source ideas, respond to requests and collaborate with internal and external partners. Digital technologies, including social media, have today become a cornerstone of such reforms and governments find guidance for purpose-oriented use in the OECD Recommendation on Digital Government Strategies (OECD, 2014).

But the full potential and the risks of social media use for government are not yet fully understood, let alone proven. That is different in the private sector where the contribution of social media to drive revenues or reduce costs is quite clearly articulated, measured and exposed (see Figure 1 for commercial value propositions by Facebook and Google+). Take the example of Blendtec, a manufacturer of professional food blenders. The company's YouTube campaign of blending household items like mobile phones, laptops and golf balls became viral on social media and let to a $700 \%$ sales increase over a year (SocialMediaToday, 2013). 
Figure 1. Commercial value propositions for social media use, Facebook and Google+

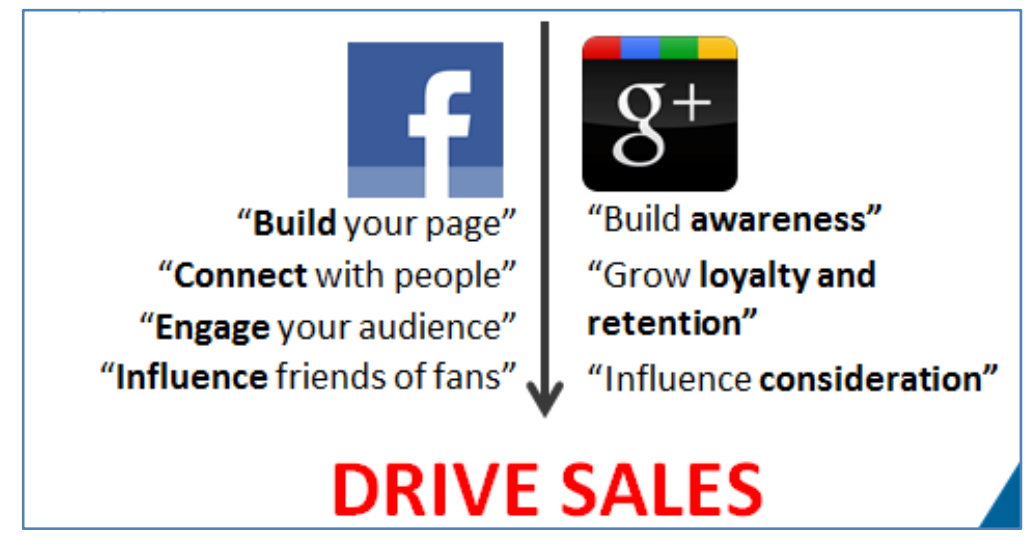

Source: Adapted by author, based on information retrieved from Facebook and Google websites, October 2013.

Such sales-oriented value propositions might actually apply to those parts of government where communications and "selling" of some sort is a primary objective. Think of political leaders that need to convince voters, funders and other partners of their policies. Social media have indeed become mainstream in these areas.

But the starting point is quite different for most public sector institutions. There are certainly institutions whose main function is to provide the public with credible and high-quality information. This is part of regular operations and can also incur costs on users of that information, e.g. access to data held by national registries or statistical offices. It is also part of information management during emergency operations, e.g. that of law enforcement agencies during a crisis (cf. Wendling et al., 2013). In many of these areas, social media can be utilised as a tool for information diffusion and oneway communications.

But the functions of public sector institutions go wider than that and therefore require a more sophisticated approach to social media to exploit its potential. Many institutions actually give services away without direct payments in return where this complies with policy and with individual needs. Other institutions primarily collect payments without any direct returns, e.g. agencies collecting taxes or social security contributions. Still other government departments' services focus on providing services in the "back-office" of the state administration, e.g. agencies responsible for public procurement, human resources and infrastructure management.

Just these few examples illustrate that business case approaches for social media use in the commercial area do not easily transfer to the public sector. The challenge is therefore one of establishing methodologies that allow public sector decision makers to identify which social media investments lead to expected returns. Despite much enthusiasm for government experimentation in this area, tough questions are already being asked about whether resources spent on social media contribute to achievement of mission-oriented objectives.

\section{Structure}

This paper aims to support decision-makers in creating solid value propositions for the diverse areas where social media have the potential to support core government objectives. Making references to work done elsewhere, this paper explores and - to the degree this is possible at this stage compares trends in government use of social media according to the following structure: 
Chapter 2 uses empirical information to depict the current international landscape of government use of social media. It compares and analyses the strategies formulated by government, the levels of activity on selected social networks, the interest and feedback these activities trigger within the general population.

Chapter 3 analyses the opportunities and challenges of social media to help re-build mutual trust between governments and their citizens, and to improve government responsiveness to demands for more effective and efficient public services. The chapter draws on empirical evidence around the inclusion of marginalised people and younger people. It also discusses specific application opportunities in the sectors of healthcare and public employment service provision.

Chapter 4 then outlines what governments are doing to manage the changes necessary to adapt to the rapid diffusion of social media into all spheres of public, personal and commercial life. The chapter cites government practices where they exist and where they can inspire similar initiatives in other countries.

The conclusion develops a preliminary checklist for government institutions to follow when designing social media strategies. This checklist is the starting point of a comprehensive analytical framework and data collection methodology presented in the concluding chapter. The framework structures further analytical work around government use of social media.

\section{Scope and methodology}

To clearly frame this paper two key terms need to be qualified right away: social media and government.

Social media today encompass a vast array of platforms with different purposes, features and target audiences. Different taxonomies and categorisations exist, but their use would add no major value to this analysis. This paper takes the pragmatic approach of focusing on the leading generalist platforms today instead of attempting to be exhaustive in its coverage of social media platforms. Reference to purpose-specific platforms will be made where this adds value.

Facebook and Twitter are by far the most popular social media platforms worldwide. In 2014 Facebook had over 1 billion active users worldwide, which is the equivalent of around $15 \%$ of the world's population. ${ }^{1}$ Twitter's more than 270 million active users emit more than half a billion Twitter messages ("tweets") per day. ${ }^{2}$ To facilitate research and mining of this vast reserve of data, the US Library of Congress agreed to archive all public tweets starting 2006 and into the future. ${ }^{3}$

Regional differences in the popularity of social networks certainly exist. Google+, for example, is much more popular in the United States and in India than in the rest of the world. Naver applications have great popularity in Korea. Qzone and Weibo are the leading social networks in China, where access to Facebook, Twitter and Google+ is severely limited. Orkut is a leading social media platform in Brazil, vKontakte an important one in Russia.

\footnotetext{
${ }^{1}$ For more information see http://news.cnet.com/8301-1023 3-57566550-93/facebook-by-the-numbers-1.06-billion-monthlyactive-users.

${ }^{2}$ For more information see https://about.twitter.com/company.

${ }^{3}$ For more information see http://blogs.loc.gov/loc/2013/01/update-on-the-twitter-archive-at-the-library-of-congress.
} 
There are also platforms that focus on a very specific functionality such as YouTube for sharing videos, Pinterest for web content curation, Instagram for sharing pictures, WhatsApp for instant messaging. Their offer and character is, however, constantly in flux as new functions are being added and as companies are being merged or acquired.

Blogs can be considered a social media category of its own. They have democratised creation of written content similar to the way that YouTube democratised creation of filmed content. Wordpress, a leading blogging service, each months sees over 400 million visitors each month to over 70 million registered blogs (http://en.wordpress.com/stats/).

Social media trends are of course mutually reinforcing with other major technology developments. In particular, the mobile Internet and open data trends are important drivers and beneficiaries of social media diffusion, including for government (cf. OECD \& ITU, 2011; Ubaldi, 2013). Other technology trends such as cloud computing, machine-to-machine communications and big data are closely related as well (cf. OECD, 2012a).

Government in this paper primarily refers to the highest executive institutions in the national public administration: the offices of the president, prime minister or government as a whole. Political leaders, as well as intermediary organisations such as parties, trade unions or business associations, will only be discussed sporadically where comparisons provide specific insights. So the analysis in this paper focuses on the social media activities of offices rather than the personalities holding the office, e.g. on @WhiteHouse rather than@BarackObama or on @Number10Gov rather than @David_Cameron.

The focus on institutions enables better comparability across countries. But there are also reasons pertaining to the subject matter itself that speak in favour of comparing what public sector institutions, rather than individual personalities, do with social media. For one, institutions constitute the main interface with the state in the day-to-day lives of individuals, organisations, and businesses. The institutional focus will help identify policy opportunities that are more directly linked to the core mission of the state. Moreover, institutions typically remain longer in place than the people holding an office, which makes over-time comparisons more meaningful.

So the objective is to contribute to the relatively scarce body of analysis available about the impacts of government institutions' use of social media. To support the analysis the OECD conducted a survey of social media use among central government institutions. During September and October 2013, 24 out of 34 member countries (i.e. a 70\% return rate) plus one partner country, Colombia, provided information that for the first time allows a cross-country comparison of objectives, strategies, policies and rules set by national centres of government in this area. 


\section{TAKING STOCK OF SOCIAL MEDIA USE IN GOVERNMENT}

This section takes stock of empirical data to establish a first set of baselines on government social media use. The main sources for comparison are the OECD survey of social media use in governments and publicly available data from the main social networking platforms. ${ }^{4}$

\section{Current strategies}

The current use of social media at national governments is largely one of "laissez faire" and experimentation. Only one quarter of the responding governments (7 out of 25) have a dedicated social media strategy (Figure 2): Australia, Austria, Belgium, Chile (see Box 1), Colombia, Korea and the Netherlands. Other well-known examples are of course the United States where social media is an integral part of the government strategy to "engage and connect" and the United Kingdom where social media are deeply embedded in the government's digital strategy. ${ }^{5}$

Figure 2. A minority of governments have a dedicated social media strategy, OECD, 2013

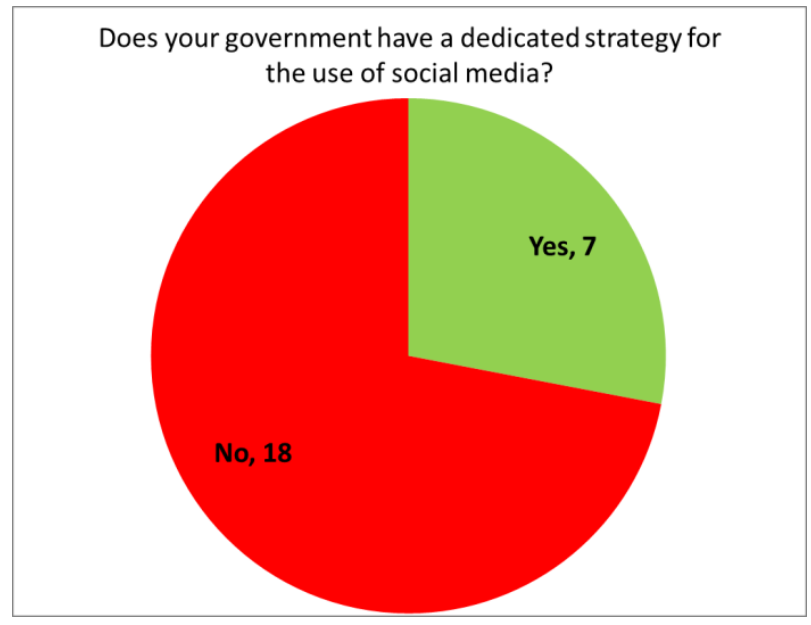

Source: OECD (2013b), "Survey on government use of social media".

\footnotetext{
${ }^{4}$ There is a slight bias towards using Twitter data in this section because a very exhaustive dataset on government activities is periodically collected and made public by Burson-Marsteller under the Twiplomacy label (www.twiplomacy.com). No such data collection exists for Facebook yet.

${ }^{5}$ For more information see www.whitehouse.gov/engage/social-hub and www.gov.uk/government/publications/governmentdigital-strategy.
} 


\section{Box 1. Chile's social media strategy: hitting the right buttons}

@Gobiernodechile enjoys a relatively high popularity on Twitter with over 550,000 followers, which translates into roughly $3 \%$ of the population (cf. Mickoleit, 2013). The government early on developed a proactive strategy towards social media. Key elements to get the strategy going were:

- An official circular in 2010 that explicitly encouraged the use of social media across the Chilean government (archived at http://2010-2014.gob.cl/comunicacion-digital/instrucciones-sobre-lineamientoscomunicacionales-de-plataformas-digitales-y-sitios-electronicos-del//).

- Integration of social media as a key component in the national e-government strategy 2011-2014 and its three pillars: "open government", "government close to its constituents", and "efficient government" (www.modernizacion.gob.cl/nuestra-agenda/plan-estrategico-de-gobierno-electronico.html).

- A digital guide (Guía digital) that provides strategic and technical assistance on government use of new technologies. It includes information on the preconditions, capacities and skills necessary to make the best use of social media (http://www.guiadigital.gob.cl/plataformas-sociales).

The Chilean government reports that the collaborative and iterative development of these documents was critical for their production. Stakeholders are engaged in the evolution of the strategy and development of key documents. The e-government strategy, for example, went through several public iterations before it reached its final state in 2012. Social media facilitated these iterative and collaborative efforts.

If not full-fledged strategies, around half of the responding governments (12 out of 25) formulate explicit objectives or expectations for the use of social media (Figure 3): Australia, Austria, Belgium, Canada, Chile, Colombia, Finland, France, Ireland, Korea, Netherlands, Turkey.

Figure 3. Around half of governments have specific objectives or expectations for social media use, OECD, 2013

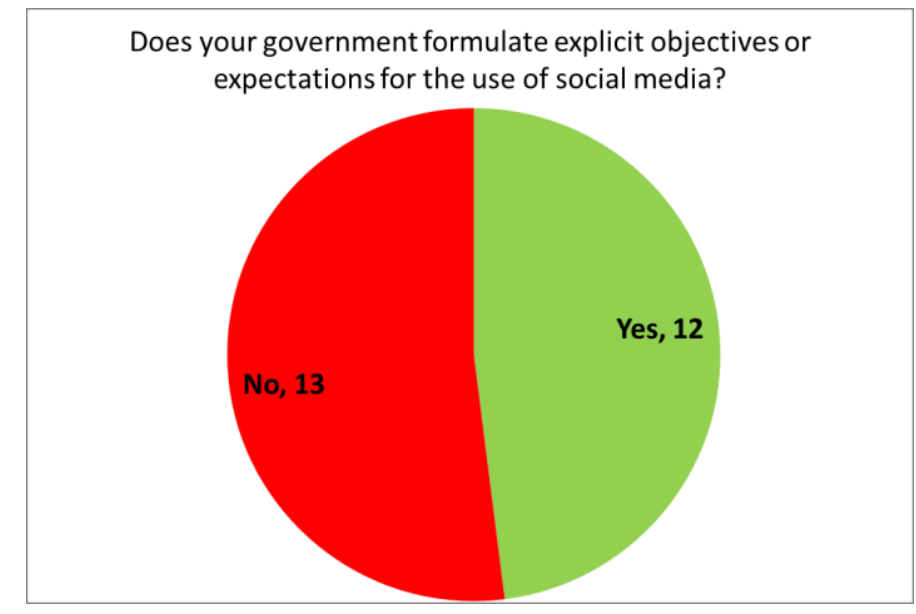

Source: OECD (2013b), "Survey on government use of social media".

The primary objective for governments is to improve communications, followed by stakeholder engagement and service delivery improvements (Figure 4). In a sense this illustrates that social media are as of today still mainly regarded as means to diffuse information and only secondarily to improve consultation or even active participation as part of better government-citizen relations (cf. OECD, 2001). 
Figure 4. Improving public communications is the most prominent objective, OECD, 2013

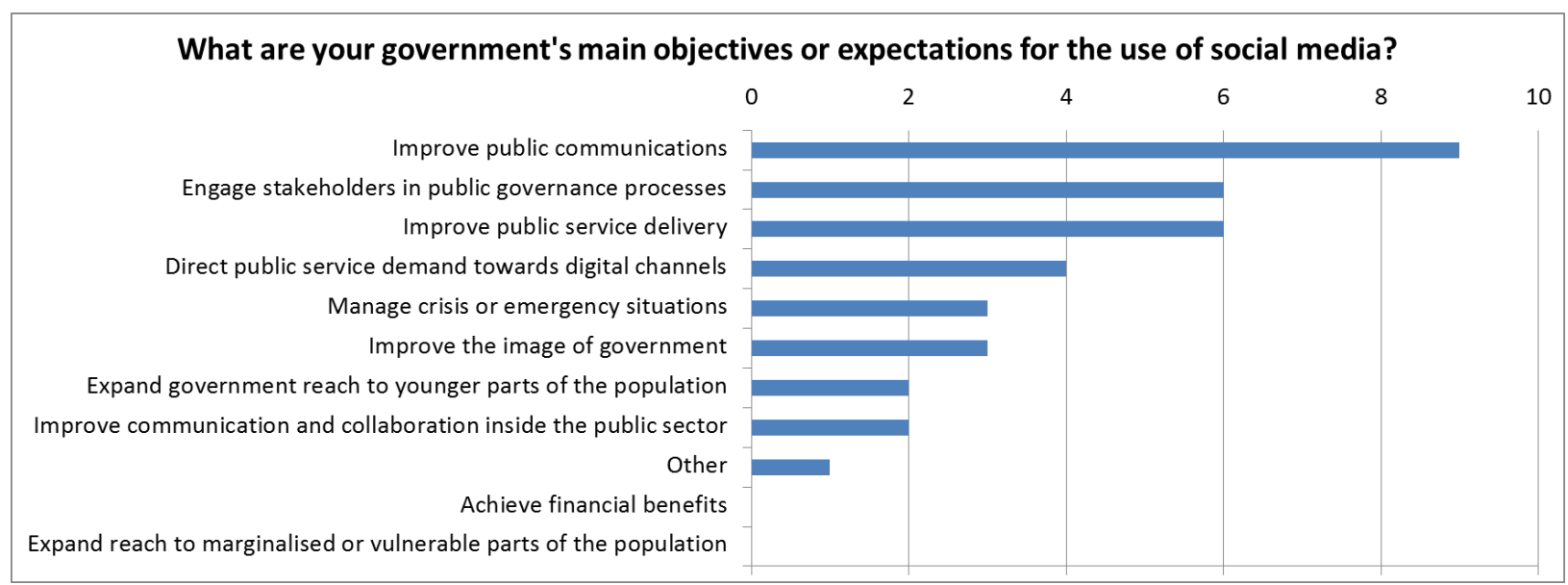

Note: Responses from 12 countries that indicated having specific objectives or expectations for government social media use; up to three answer options allowed.

Source: OECD (2013b), "Survey on government use of social media".

The primary focus of government social media use today on diffusing information is confirmed by various surveys. A survey of US public authorities at different levels of government shows that $85 \%$ of those using social media do so to "distribute information" (GovLoop, 2013). Similarly, a 2012 survey of local government authorities in the United Kingdom finds that virtually all local councils use social media for external communications (BDO, 2012). It should be noted that the information diffusion function can refer both to the dissemination of "neutral" information, e.g. statistics, that are a resources in decision-making processes. But they can also refer to purpose-oriented messaging as part of government operations, e.g. to raise awareness of an issue or to provoke specific action by recipients.

\section{Presence}

Even though only half of OECD governments have specific objectives or expectations - and even fewer have a strategy - a large majority of them have an official social media presence (Table 1). Twitter is used by 26 out of 34 OECD governments to represent the highest state institution (i.e. the office of the head of state, head of government or the government office). Facebook is slightly less popular, but still used by 18 out of 34 OECD governments as a means to present themselves on the Internet. Worldwide, at least three out of four governments have some sort of Twitter presence. ${ }^{6}$

\footnotetext{
${ }^{6}$ Information shared by Jerôme Tomassini, Twitter France, at OECD conference "The Power of Social Media", 20 February 2014, www.oecd.org/social-media/smwparis.htm.
} 
Table 1. Institutional Twitter and Facebook accounts for head of state, head of government or government as a whole, OECD countries

\begin{tabular}{|c|c|c|}
\hline Country & Twitter & Facebook \\
\hline Australia & - & - \\
\hline Austria & - & - \\
\hline Belgium & - & - \\
\hline Canada & PMwebupdates & - \\
\hline Chile & GobiernodeChile & GobiernodeChile \\
\hline Czech Republic & Strakovka & Uradvlady \\
\hline Denmark & - & - \\
\hline Estonia & $\begin{array}{l}\text { Stenbockimaja } \\
\text { Estoniangovt }\end{array}$ & Stenbockimaja \\
\hline Finland & $\begin{array}{l}\text { Valtioneuvosto } \\
\text { Fingovernment } \\
\text { Tpkanslia }\end{array}$ & - \\
\hline France & $\begin{array}{l}\text { Elysee } \\
\text { Matignon } \\
\text { Fil_gouv }\end{array}$ & $\begin{array}{l}\text { Elysee.Fr } \\
\text { Matignon.Fr }\end{array}$ \\
\hline Germany & $\begin{array}{l}\text { Regsprecher } \\
\text { Bundesreg }\end{array}$ & - \\
\hline Greece & PrimeministerGR & GovGR \\
\hline Hungary & Kormany_HU & Kormanyzat \\
\hline Iceland & - & - \\
\hline Ireland & $\begin{array}{l}\text { Govdotie } \\
\text { Merrionstreet }\end{array}$ & Merrionstreet \\
\hline Israel & $\begin{array}{l}\text { IsraeliPM } \\
\text { IsraeliPM_ar } \\
\text { IsraeliPM_heb }\end{array}$ & IsraeliPM \\
\hline Italy & $\begin{array}{l}\text { Palazzo_chigi } \\
\text { Quirinalestampa }\end{array}$ & - \\
\hline Japan & $\begin{array}{l}\text { Kantei_saigai } \\
\text { Kantei } \\
\text { Jpn_PMO }\end{array}$ & $\begin{array}{l}\text { Japan.PMO } \\
\text { Sourikantei }\end{array}$ \\
\hline Korea & $\begin{array}{l}\text { Bluehousekorea } \\
\text { PrimeministerkR } \\
\text { Govkorea }\end{array}$ & $\begin{array}{l}\text { PrimeministerKR } \\
\text { Govkorea } \\
\text { Cheongwadae }\end{array}$ \\
\hline Luxembourg & Courgrandducale & Courgrandducale \\
\hline Mexico & $\begin{array}{l}\text { PresidenciaMX } \\
\text { Gobrep }\end{array}$ & PresidenciaMX \\
\hline Netherlands & $\begin{array}{l}\text { Khtweets } \\
\text { Rijksoverheid } \\
\text { MinPres }\end{array}$ & Ministerpresident \\
\hline New Zealand & - & - \\
\hline Norway & $\begin{array}{l}\text { Kronprinsparet } \\
\text { Regjeringen }\end{array}$ & Kongehuset \\
\hline Poland & $\begin{array}{l}\text { PremierRP } \\
\text { PrezydentPL }\end{array}$ & PolandgovPL \\
\hline Portugal & Presidencia & PresidenciadaRepublicaPortuguesa \\
\hline Slovak Republic & - & - \\
\hline Slovenia & $\begin{array}{l}\text { VladaRS } \\
\text { GovSlovenia }\end{array}$ & - \\
\hline Spain & DesdelaMoncloa & $\begin{array}{l}\text { CasaReal } \\
\text { PalaciodelaMoncloa }\end{array}$ \\
\hline Sweden & - & Kungahuset \\
\hline Switzerland & BR_sprecher & - \\
\hline
\end{tabular}




\begin{tabular}{|l|l|l|}
\hline Country & Twitter & Facebook \\
\hline Turkey & $\begin{array}{l}\text { Tccankaya } \\
\text { Trpresidency }\end{array}$ & $\begin{array}{l}\text { Tccankaya } \\
\text { Trpresidency }\end{array}$ \\
\hline United Kingdom & $\begin{array}{l}\text { BritishMonarchy } \\
\text { Number1Ogov }\end{array}$ & TheBritishMonarchy 10DowningStreet \\
\hline United States & $\begin{array}{l}\text { WhiteHouse } \\
\text { LaCasaBlanca }\end{array}$ & $\begin{array}{l}\text { WhiteHouse } \\
\text { WhiteHouse.Espanol }\end{array}$ \\
\hline
\end{tabular}

Source: Author's compilation, based on publicly available data.

Note: The statistical data for Israel are supplied by and under the responsibility of the relevant Israeli authorities. The use of such data by the OECD is without prejudice to the status of the Golan Heights, East Jerusalem and Israeli settlements in the West Bank under the terms of international law.

But even those OECD countries that do not have an official account for the highest state institutions are usually in one way or the other present on either of the two major social media platforms:

- Australia has no institutional account for the centre of government as such but the government's main web portal provides links to a large list of social media presences for government departments, public service agencies and sub-national authorities. ${ }^{7}$

- Austria has a dormant institutional account for the federal Chancellery @ Teamkanzler, which has emitted no tweet since November 2011.

- Sweden has no institutional accounts for the highest government institutions. Instead it has Foreign Minister Carl Bildt who has been singled out as "the most Twitter savvy politician in Sweden, in Europe and probably worldwide". ${ }^{8}$ And the country is home to a unique experiment where the official @ Sweden account is curated by a different citizen each week.

- Several OECD countries have a social media presence for their national service portals, e.g. Belgium's www.belgium.be.

Social media use is by no means exclusive to the top executive institutions. Individual ministries, departments or programmes also have strong levels of social media presence in some countries. In the United States, a 2012 census showed that the roughly 700 federal departments, agencies and initiatives had a stock of around 3,000 Facebook pages, 1,000 Twitter accounts, 700 YouTube channels and 500 Flickr pages (Mergel, 2013). This often includes accounts for specific public service areas that are better recognised by the public. Law enforcement services, for example, typically have a presence of their own, apart from the institutions they formally belong to, e.g. ministries of interior.

Sub-national government authorities are also increasingly represented on social media. The following data provide some illustrations:

- In the United States two thirds of counties and municipalities had an official social media presence as early as 2011 . Facebook is the preferred channel with over $90 \%$, followed by Twitter with around $70 \%$ and blogs, which were used by around $20 \%$ of US local authorities (ICMA, 2011).

- In the United Kingdom a 2012 survey reported that over $90 \%$ of local councils have a Twitter account, over $80 \%$ a Facebook account, over 50\% a Flickr account to share pictures; only $3 \%$ of local councils reported having no social media presence at all (BDO, 2012).

\footnotetext{
${ }^{7}$ For more information see http://australia.gov.au/news-and-media/social-media.

${ }^{8}$ For more information see http://twiplomacy.com/info/europe/sweden.
} 
- In Sweden each of the 21 regional councils (Landstinget) has a Facebook account and 11 of them use Twitter. Local municipalities are to $80 \%$ represented on Facebook, and $43 \%$ on Twitter; half of them report using blogs. ${ }^{9}$

But these examples should not lead to a rapid conclusion that all local governments use social media. Overall uptake and the choice of particular platforms vary a lot depending on the national or local context. In 2012, a survey of 75 larger municipalities across Europe found that only $32 \%$ had a Twitter account, $30 \%$ were on YouTube, and only $16 \%$ on Facebook. At the same time, over half of these municipalities operated a blog (Bonsón et al., 2012).

\section{Popularity}

An imminent question is whether populations are interested and engage with the social media presence of their governments. Clearly, some government institutions managed to build sizeable communities around their social media presence. The United States @ WhiteHouse and United Kingdom@Number10Gov clearly stand out with several million followers on Twitter; their equivalents on Facebook also have very high numbers of fans.

But quantifying "popularity" and comparing it across different social media presences remains a matter of much discussion. Unfortunately, "fake" followers and likes can be obtained and purchased quite easily; other ways to "cheat" in terms of quantifiable social media impact are plentiful. And although services exist that supposedly "audit" social media presences against some of these practices, their methodologies still have to prove they can be applied more generally. ${ }^{10}$

In the absence of a perfect measure, social media "popularity" of government accounts will be illustrated using two proxy variables:

- A harmonised measure for the number of "followers" or "likes" on Twitter or Facebook, respectively. This measure points towards the interest of the wider population and organisations in the content provided by government institutions on social media. To enable international comparisons, the absolute numbers will be divided by the size of the respective population.

- A harmonised measure for "re-tweets", i.e. the re-diffusion of original government content by other social media users. This measure indicates the degree of relevance that social media users attribute to the content emitted by government institutions. The greater this number, the greater the potential "snowball" effect because a re-tweet is seen by all the followers of the Twitter user who does the re-tweet. To enable comparison, the number of re-tweets obtained by a government account will be divided by the number of tweets it originally emitted.

Regarding the first variable (followership), the relatively small governments of Monaco and Andorra lead the comparison (Table 2 and Figure 5). Among OECD countries, the United Kingdom's @ Number10Gov comes first (and fifth globally) with a reach of $4.2 \%$ of the population. Reaching the equivalent of 3.5\% of its domestic population, Chile's @GobiernodeChile turns out to be the second most popular government Twitter account in the OECD (cf. Mickoleit, 2013). The governments of Ecuador, Costa Rica, Turkey, Montenegro and Venezuela complete the global top 10 by Twitter popularity. The United States' @WhiteHouse has a reach of 1.6\% of the domestic population and comes eleventh globally.

\footnotetext{
${ }^{9}$ For more information see www.skl.se/press/nyheter_2/allt-fler-kommuner-anvander-facebook.

${ }^{10}$ For more details on "fake" accounts and interactions and how to detect them, see for example http://nextdevmedia.com/theinside-scoop-on-fake-followers-on-twitter/.
} 
Table 2. Most followed government institutions on Twitter, 2014

\begin{tabular}{|l|l|r|r|}
\hline Country & Government Twitter account & Followers & Followers as share of population \\
\hline Monaco & @GvtMonaco & 10,338 & $27.3 \%$ \\
\hline Monaco & @palaismonaco & 5,407 & $14.3 \%$ \\
\hline Andorra & @GovernAndorra & 7,135 & $9.0 \%$ \\
\hline Ecuador & @Presidencia_Ec & 659,099 & $4.2 \%$ \\
\hline United Kingdom & @Number10gov & $2,676,330$ & $4.2 \%$ \\
\hline Chile & @GobiernodeChile & 616,501 & $3.5 \%$ \\
\hline Costa Rica & @presidenciacr & 108,668 & $2.2 \%$ \\
\hline Turkey & @tccankaya & $1,520,747$ & $2.0 \%$ \\
\hline Montenegro & @MeGovernment & 11,209 & $1.8 \%$ \\
\hline Venezuela & @PresidencialVen & 506,889 & $1.7 \%$ \\
\hline
\end{tabular}

Source: Author's calculations based on Twiplomacy, 2014, and World Bank population data for 2013.

Figure 5. Most followed government institutions on Twitter, 2014

Number of followers divided by domestic population

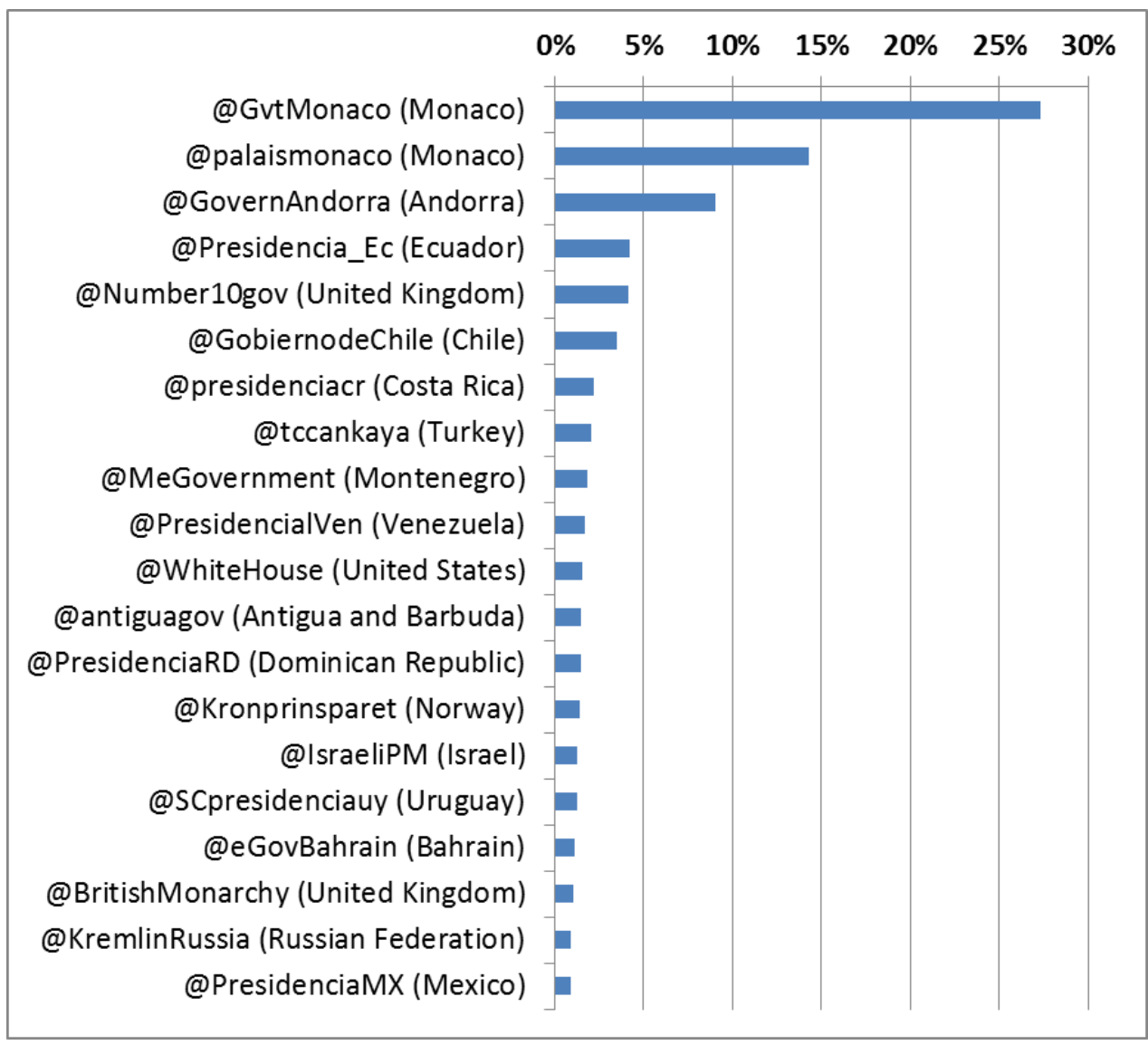

Source: Author's calculations based on Twiplomacy, 2014, and World Bank population data for 2013

Note: The statistical data for Israel are supplied by and under the responsibility of the relevant Israeli authorities. The use of such data by the OECD is without prejudice to the status of the Golan Heights, East Jerusalem and Israeli settlements in the West Bank under the terms of international law. 
Regarding the second popularity variable (re-diffusion of original content), the Spanish Monarch's@CasaReal leads the global comparison (Table 3). Each of its original Twitter messages is replicated by an average of 782 other social media users, i.e. seen by the accumulated followership of these social media users. Very high re-diffusion numbers are also achieved by the United States' @WhiteHouse and Japan's @Kantei_Saigai.

Table 3. Most re-tweeted government institutions on Twitter, 2014

Ordered by average re-tweets obtained for every tweet emitted

\begin{tabular}{|l|l|r|r|}
\hline Country & Government Twitter account & Total re-tweets & $\begin{array}{r}\text { Average re-tweets } \\
\text { per tweet }\end{array}$ \\
\hline Spain & @CasaReal & 49,254 & 782 \\
\hline United States & @WhiteHouse & 614,943 & 272 \\
\hline Japan & @Kantei_Saigai & 367,397 & 149 \\
\hline United Kingdom & @Number1Ogov & 197,216 & 87 \\
\hline Japan & @kantei & 186,917 & 61 \\
\hline Indonesia & @IstanaRakyat & 130,090 & 51 \\
\hline Mexico & @PresidenciaMX & 96,032 & 40 \\
\hline Russian Federation & @KremlinRussia & 111,143 & 35 \\
\hline Netherlands & @KHtweets & 17,270 & 32 \\
\hline Venezuela, RB & @PresidencialVen & 84,604 & 31 \\
\hline Ecuador & @Presidencia_Ec & 91,884 & 29 \\
\hline Korea, Rep. & @bluehousekorea & 86,319 & 28 \\
\hline France & @Elysee & 82,038 & 28 \\
\hline Turkey & @tccankaya & 56,816 & 27 \\
\hline Italy & @QuirinaleStampa & 9,157 & 26 \\
\hline Israel & @lsraeliPM & 69,544 & 25 \\
\hline Italy & @Palazzo_Chigi & 23,597 & 23 \\
\hline United Kingdom & @BritishMonarchy & 66,735 & 22 \\
\hline Argentina & @CasaRosadaAR & 55,496 & 48,203 \\
\hline European Union & @EU_Commission & & 23 \\
\hline
\end{tabular}

Source: Based on Twiplomacy, 2014.

Note: The statistical data for Israel are supplied by and under the responsibility of the relevant Israeli authorities. The use of such data by the OECD is without prejudice to the status of the Golan Heights, East Jerusalem and Israeli settlements in the West Bank under the terms of international law.

\section{Comparing government institutions to government leaders}

Notwithstanding impressive rates for government institutions, actual political personalities are more popular on social media. The top ten most popular political leaders on Twitter reach the equivalent of up to $50 \%$ of the domestic population (Table 4). And in terms of re-diffusion of their messages, some of these government leaders obtain up to 2,000 direct re-tweets (consider, however, their relatively high popularity outside the country they represent). 
Table 4. Most popular government and state leaders on Twitter, 2014

\begin{tabular}{|l|l|r|r|}
\hline Country & $\begin{array}{l}\text { Government leader } \\
\text { account }\end{array}$ & $\begin{array}{r}\text { Followers as share of } \\
\text { population }\end{array}$ & $\begin{array}{r}\text { Average re-tweets } \\
\text { per tweet }\end{array}$ \\
\hline Jordan & @QueenRania & $49.6 \%$ & 183 \\
\hline $\begin{array}{l}\text { United Arab } \\
\text { Emirates }\end{array}$ & @HHShkMohd & $31.1 \%$ & 557 \\
\hline United States & @BarackObama & $13.8 \%$ & 1443 \\
\hline Ecuador & @MashiRafael & $10.1 \%$ & 141 \\
\hline Argentina & @CFKArgentina & $7.0 \%$ & 238 \\
\hline Malaysia & @NajibRazak & $6.8 \%$ & 305 \\
\hline Venezuela, RB & @NicolasMaduro & $6.7 \%$ & 2066 \\
\hline Turkey & @Cbabdullahgul & $6.2 \%$ & 349 \\
\hline Colombia & @JuanManSantos & $6.0 \%$ & 210 \\
\hline Turkey & @RT_Erdogan & $5.7 \%$ & 599 \\
\hline
\end{tabular}

Source: Author's calculations based on Twiplomacy, 2014, and World Bank population data for 2013.

In comparing the numbers, political leaders are clearly more popular on social media than the institutions they represent. Take, for example, the Facebook account of US President Barack Obama, which has 17 times more fans than the White House's Facebook account; or @BarackObama on Twitter with around eight times more followers than @ WhiteHouse. This "popularity bonus" is a fact around the world: the average government leader has at least four times more followers on Twitter than the average government institution (Figure 6).

Figure 6. Followership bonus of government leaders versus government institutions on Twitter, 2014

Average followership of government leaders compared to government institutions, divided by domestic population size

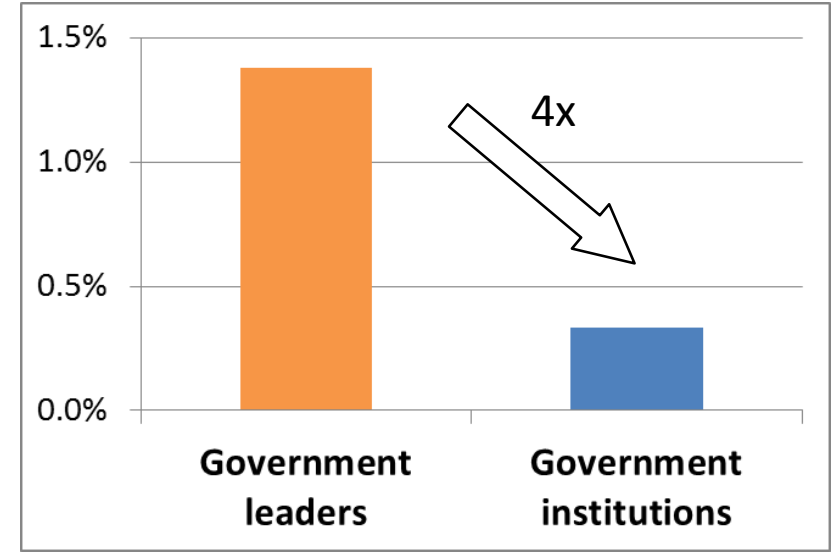

Note: The figure compares the average popularity of personal Twitter accounts operated by state and government leaders from 98 countries (i.e. presidents and prime ministers) to that of Twitter accounts operated by the highest government institutions in 109 countries (i.e. offices of president, prime minister or government). The average popularity level represented here is harmonised by using domestic population as denominator.

Source: OECD calculations, based on Twiplomacy, 2014, and World Bank population data for 2013.

It is easy to explain the greater social media popularity of political leaders. In a way they need to "sell" their messages in order to obtain votes or to raise funds. Considering that expectation of 
increased sales is one of the main drivers of social media adoption in the private sector, it is not surprising that social media are a widely-deployed and effective lever of politicians' campaigning, rallying and fund-raising too. Another factor to consider is the predominance of interpersonal relationships on social media, which makes it somewhat more difficult for institutional presences to network with individuals (see discussion of push, pull and networking strategies further below).

This raises the question whether government institutions should at all aim for higher popularity scores on social media, e.g. by turning their presence more "personal". After all, institutions are the main interface of day-to-day interactions between the state and its citizens; they deliver public information, goods and services. This, and the fact that social media uptake among many parts of the population is very high, could make the case for government institutions exploring more effective ways of using social media (see next chapter for an overview of opportunities and challenges).

\section{Activity levels}

It seems worthwhile to explore whether greater activity, i.e. more information emitted by governments, can lead to greater popularity. Activity levels of governments on social media are very heterogeneous in international comparisons. Some government institutions emit over 70 Twitter messages every day on average - like Mexico's presidency (@PresidenciaMX) and Mexico's federal government (@gobrep) (Table 5). Several other Latin American governments are high-frequency tweeters too, e.g. the Dominican Republic, Colombia, Venezuela, Bolivia, Ecuador.

Table 5. High-frequency government institution tweeters, 2014

\begin{tabular}{|l|l|l|r|}
\hline Country & Twitter account & Name & Tweets/day \\
\hline Mexico & @PresidenciaMX & Presidencia México & 78.86 \\
\hline Mexico & @gobrep & Gobierno República & 71.43 \\
\hline Dominican Republic & @PresidenciaRD & PresidenciaRD & 57.20 \\
\hline Colombia & @infopresidencia & Presidencia Colombia & 48.00 \\
\hline Venezuela, RB & @PresidencialVen & Prensa Presidencial & 39.15 \\
\hline Bolivia & @mincombolivia & Min. de Comunicacion & 35.62 \\
\hline Ukraine & @Kabmin_UA & Kaбмiн Yкpaïни & 29.09 \\
\hline Croatia & @VladaRH & Vlada R. Hrvatske & 27.84 \\
\hline Kazakhstan & @ortcomkz & ortcomkz & 20.11 \\
\hline Ecuador & @Presidencia_Ec & Presidencia Ecuador & 18.14 \\
\hline European Union & @EU_Commission & European Commission & 16.36 \\
\hline Costa Rica & @presidenciacr & Casa Presidencial CR & 15.85 \\
\hline Chile & @GobiernodeChile & Gobierno de Chile & 15.35 \\
\hline United States & @WhiteHouse & The White House & 15.10 \\
\hline El Salvador & @presidencia_sv & Casa Presidencial & 13.57 \\
\hline Indonesia & @IstanaRakyat & Istana untuk Rakyat & 13.37 \\
\hline Indonesia & @setkabgoid & Sekretariat Kabinet & 13.21 \\
\hline Russian Federation & @Pravitelstvo_RF & Пpabuteльctвo Poccuи & 13.08 \\
\hline Ukraine & @Programa_PP & Programa Poroshenka & 11.46 \\
\hline Kazakhstan & @ortcomkzE & ortcomkzE & 11.42 \\
\hline
\end{tabular}

Source: Based on Twiplomacy, 2014. 
But the vast majority of social media accounts of central government institutions and officeholders are much less active. The average number of messages emitted by the 170 government institutions in the sample is six. And only 23 of them emit more than ten messages a day. Comparable data on Facebook activity is not readily available. Given the specific characteristics of the two platforms though, average activity levels on Facebook are likely to be lower.

It is quite clear that high levels of activity do not necessarily lead to higher popularity of government institutions on social media. Figure 7 shows that there is no correlation at all between the frequency at which government institutions publicise content on Twitter and the public attention they receive in return. Half of the ten most popular governments worldwide on Twitter are actually quite modest in their communications, emitting no more than five messages on an average day: Monaco, Andorra, United Kingdom, Turkey and Montenegro.

Figure 7. Frequency of content posting compared to relative popularity on Twitter, 2014

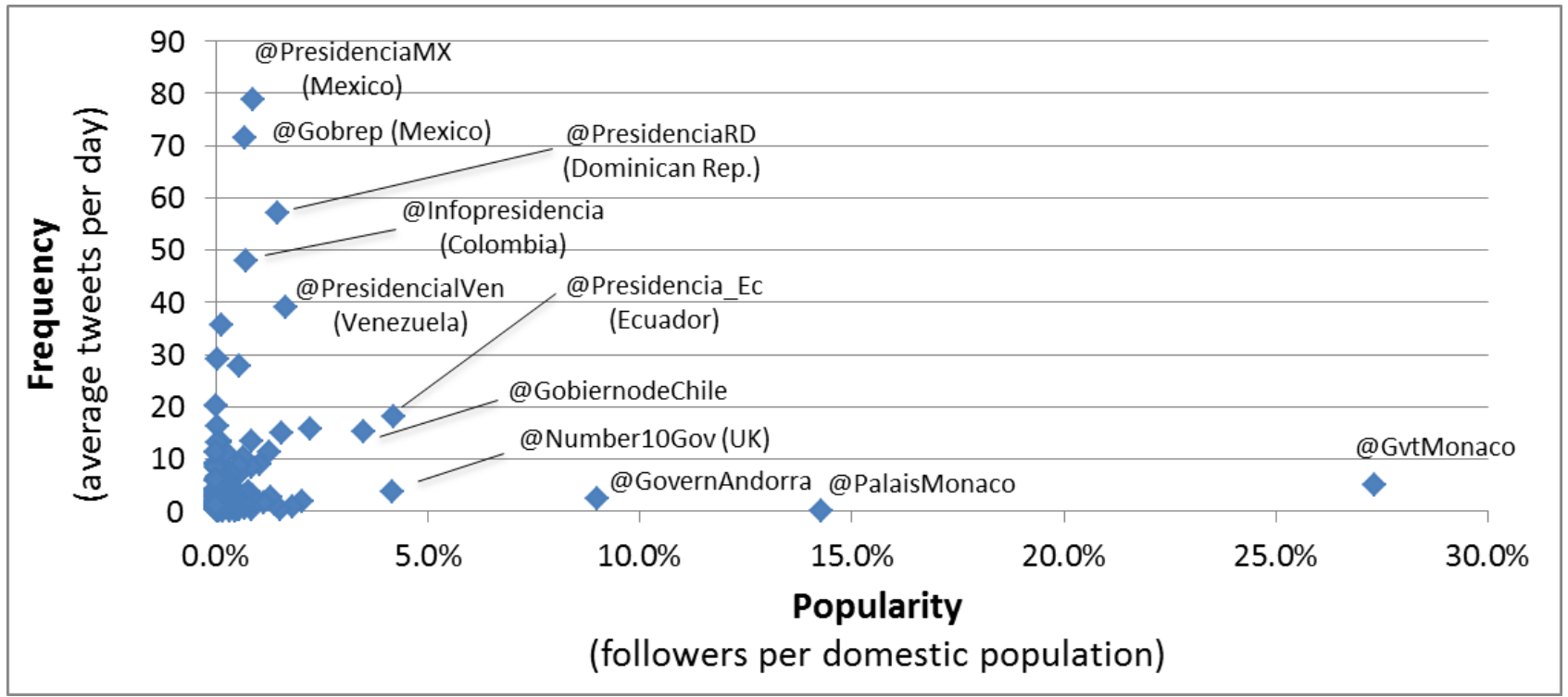

Note: The chart plots frequency of emitting tweets against the relative popularity of 168 institutional government Twitter accounts.

Source: Author's calculations based on Twiplomacy, 2014.

Additional examples confirm frequency of messaging on social media does not determine popularity. Take the official Twitter accounts of the governments of Ukraine (@Kabmin_UA and @Programa_PP), Kazakhstan(@ortcomkz and @ ortcomkzE), Indonesia (@setkabooid), or the European Commission (@EU_Commission). Each of them emits over 10 Twitter messages on an average day. Yet their reach is practically null, equivalent to $0.0 \%$ of the respective domestic population. ${ }^{11}$ For an inverse case one can cite Turkey's presidential Twitter account @ Tccankaya,

\footnotetext{
${ }^{11}$ Interestingly, the uptake rate for the Ukrainian Twitter accounts did not grow in any significant way during the dramatic events in 2014 despite heavy social media use all around.
} 
which emits less than two Twitter messages per day but reaches $2 \%$ of the domestic population, making it rank eighth in global comparison (see Table 2 earlier). ${ }^{12}$

Only in Latin America does there seems to be a strong correlation between high government activity and their popularity on social media. Several Latin American governments show very high frequencies of social media messaging; and they also reap significant returns in terms of followership. The following examples are taken from the global top 20 list of governments with the highest Twitter followership (Figure 5):

- Ecuador (@Presidencia_Ec, 18 tweets/day on average,4.2\% share of followers/population),

- Chile (@GobiernodeChile, 15,3.5\%),

- Costa Rica (@presidenciacr, 16, 2.2\%),

- Venezuela (@PresidencialVen, 39, 1.7\%),

- Dominican Republic (@PresidenciaRD, 57, 1.5\%),

- Uruguay (@SCpresidenciauy, 11,1.3\%), and

- Mexico (@PresidenciaMX,79,0.9\%).

This illustration from Latin America indicates the importance of context when determining social media strategies and comparing the potential impact government institutions can expect. Social media are hugely popular across Latin America. ${ }^{13}$ In fact, Latin Americans beat the rest of the world in terms of time spent on social media (eight hours/month versus five hours/month); and half of the global top 10 countries for time spent on social media are in the region: Argentina, Brazil, Peru, Chile, Mexico. ${ }^{14}$ These factors explain some of the social media popularity of government institutions in the region.

\section{Interaction and content}

So if quantity of messaging does not determine popularity, one needs to look closer at the quality of governments' social media use, i.e. their strategies and content. It has been argued that governments which pursue a "push" strategy, i.e. using social media to simply broadcast messages, reach much smaller audiences than those that pursue a "pull" or "networking" strategy, i.e. using social media to actively interact with stakeholders (cf. Mergel, 2010).

Empirical evidence indeed suggests that government institutions that actively invite interaction achieve higher followership rates on social media. A simple correlation analysis of the complete contents emitted by selected government Twitter accounts during six months in 2012 shows that use of interactive elements (hashtags, replies, mentions) to some degree correlates with greater popularity (correlation factor $\mathrm{R}^{2}=0.2885$ ) (Figure 8). The correlation factor $\mathrm{R}^{2}$ rises to 0.42 when the two outliers, Chile and Germany, are excluded from the analysis.

\footnotetext{
${ }^{12}$ Turkey's case is also noteworthy because in 2014 the government effectively blocked access to Twitter from within the country for around two weeks. Despite this, all the country's institutional and personal accounts included in the Twiplomacy sample remain active until this day, and some of them enjoy a remarkable followership too.

${ }^{13}$ For more information see www.emoderation.com/social-media-fast-facts-latin-america for facts on general social media uptake and use across the continent.

${ }^{14}$ For more information see www.comscore.com/Insights/Press-Releases/2012/12/Argentina-Ranks-First-in-WorldwideDesktop-Social-Networking-Engagement.
} 
Figure 8. Government use of interactive tweets compared to their followership on Twitter, 2012

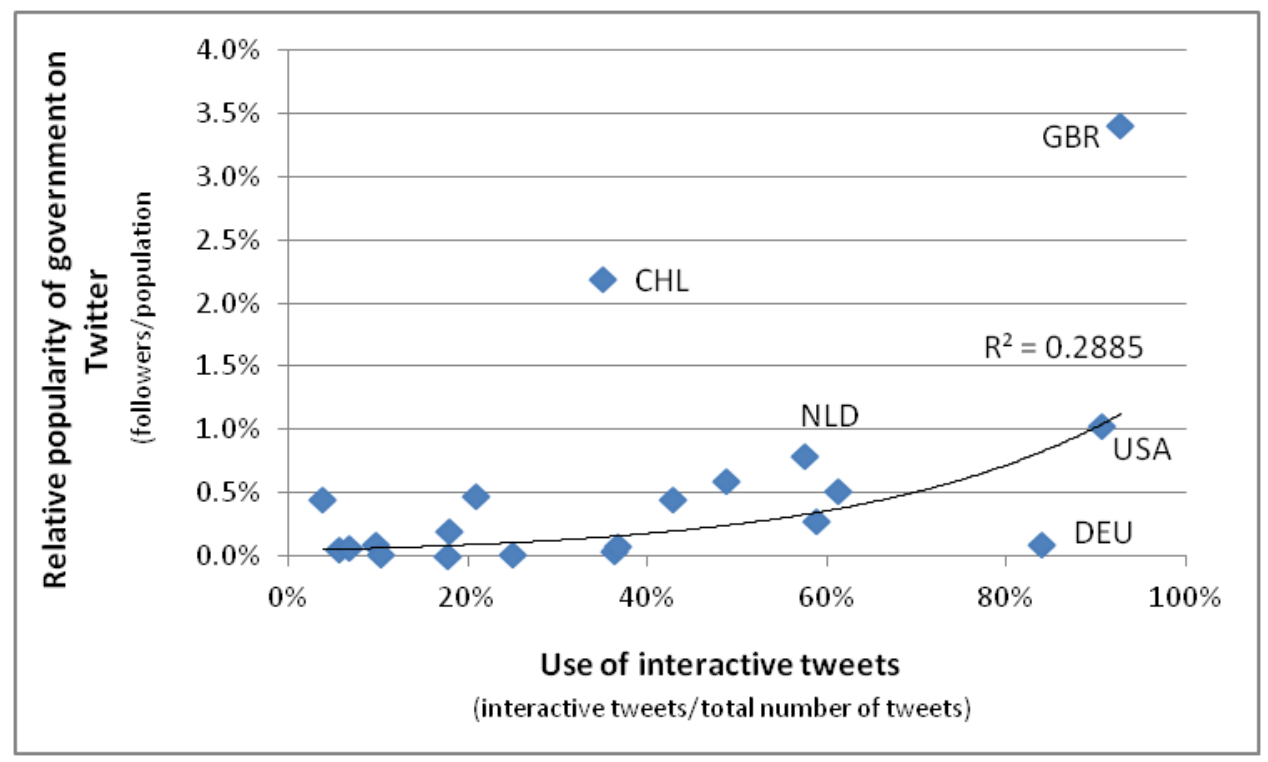

Note: Based on an analysis of all tweets emitted by each of the accounts during January to May 2012; relative popularity as of September 2012. "Interactive tweets" are defined as those having at least one of the following characteristics: hashtag, mention, reply, retweet.

Source: Author's data collection, using www.twitonomy.com.

But the use of technical means to invite interaction has its limits. Despite using technical means to incite interaction, some governments simply do not achieve high popularity rates on social media. Take the official account of Germany's federal government, @Regsprecher. In the sample used for Figure 8 above, $80 \%$ of its Twitter messages use at least one interactivity feature. Yet the account reached the equivalent of just $0.1 \%$ of Germany's population.

Content of social media messages arguably plays a major role in determining popularity of governments' social media efforts. The start of this chapter ("current strategies") clarified that governments currently focus on using social media as a lever of their communications strategies. So it is not entirely surprising that social media messages from some government institutions focus on the person holding office and his/her agenda: ${ }^{15}$

- More than half (55\%) of the Twitter messages emitted by @WhiteHouse between January and May 2014 contain the term "Obama"; one third (33\%) contain the term "President". This person-orientation of the institutional account has not changed significantly since 2012, when the term "Obama" appeared in 41\% of tweets by @WhiteHouse and the term "President" in $32 \%$.

- $\quad 40 \%$ of Twitter messages emitted by @Number10Gov between January and May 2014 contain the term "PM", i.e. refer to the Prime Minister and his agenda. The personorientation was just as strong in 2012 when the term "PM" appeared in $41 \%$ of tweets by @ Number10Gov.

\footnotetext{
15 Author's calculations based on semantic analysis of tweets emitted by @Whitehouse and @ Number10gov over the period January - May 2014 (2,223 tweets and 676 tweets, respectively) and over the period January - May 2012 (1,504 tweets and 517 tweets, respectively). Data extracted using www.twitonomy.com.
} 
However, not all government institutions have a strong focus on communicating their officeholders' agendas. The Chilean government's account @GobiernodeChile is very popular on social media, as described earlier. Yet, only $13 \%$ of its tweets contain the terms "Presidente" or "Presidenta", i.e. relate to the activities of the president. And only 15\% of tweets contain "Ministro" or "Ministra", i.e. communicate the agenda or activities of individual ministers. What is more, the account decreased its person-orientation quite significantly since 2012 when the term "Presidente" occurred in $22 \%$ of the tweets and the terms "Ministro" or "Ministra" in 26\%. A clear choice was made to use the institutional account primarily for institutional purposes.

World clouds can be used to visualise the frequency of certain terms in social media messages by government institutions. Figure 9 displays the word clouds for the aforementioned @WhiteHouse, @Number10gov and @GobiernodeChile. The strong "press release" orientation of the former two is visible because the few terms that clearly stand out relate to the person holding office. This is different in Chile where the frequencies of different terms are more balanced, which points to an approach that focuses less on individual politicians' agendas and more on specific topics of interest.

Figure 9. Recurrent terms in government institutions' social media messages

@WhiteHouse (United States)

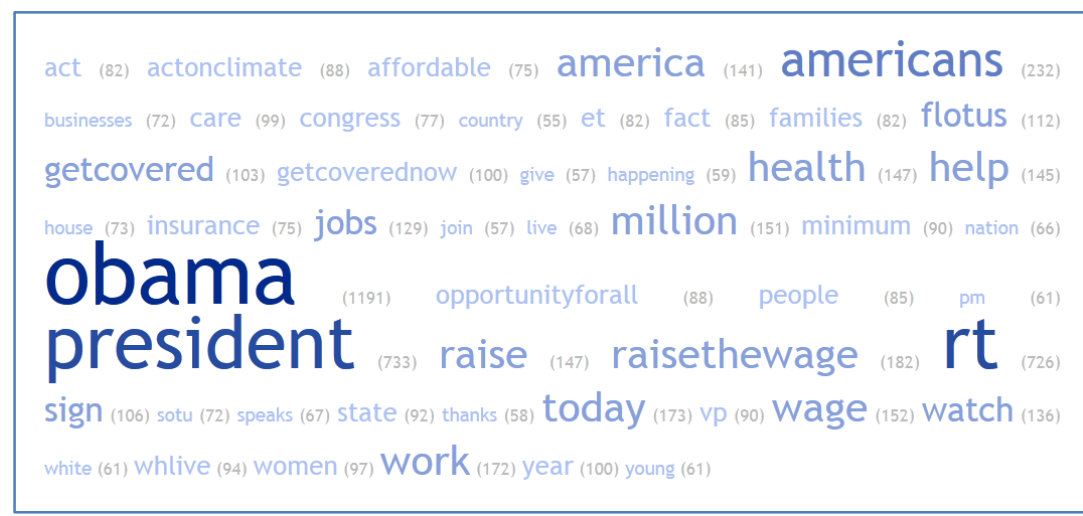

@Number10gov (United Kingdom)

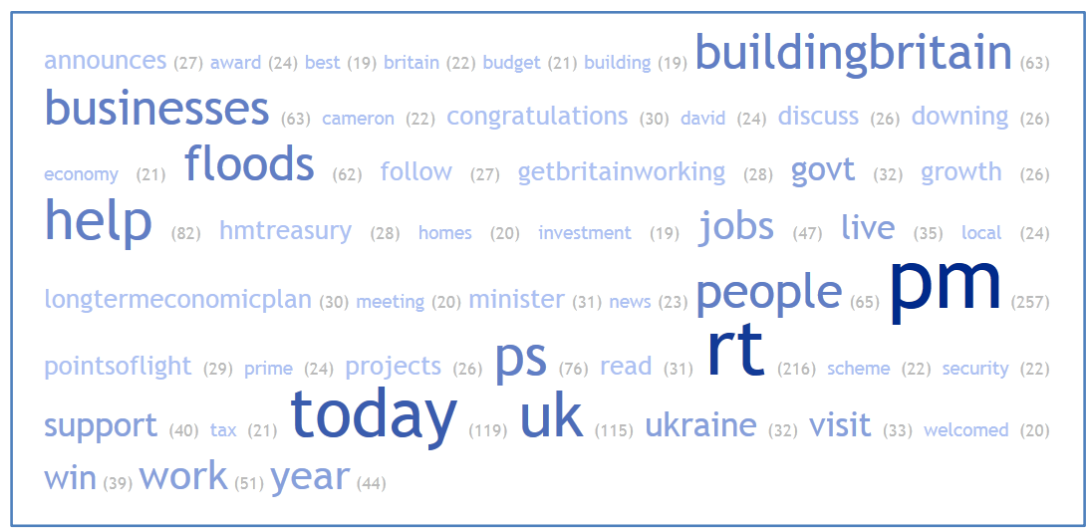


@Gobiernodechile (Chile)

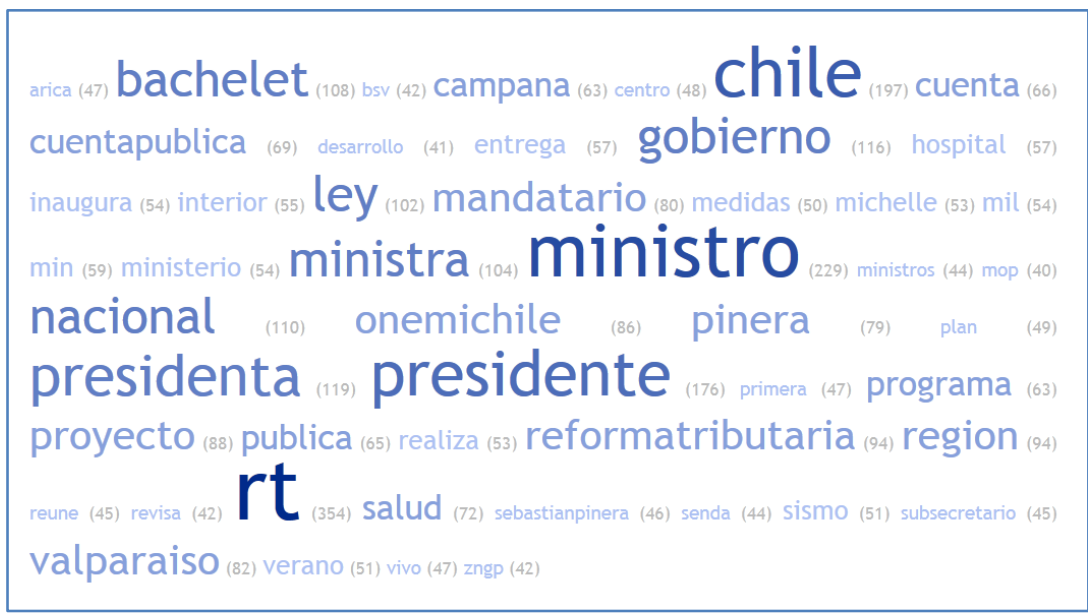

Note: Semantic analysis of all tweets emitted by the respective account between January and May 2014. The sample contains 2,223 tweets for @WhiteHouse, 676 tweets for @Number10gov, and 2,269 tweets for @GobiernodeChile. The word clouds contain the fifty most recurrent terms in each sample. The frequency of each term is indicated in parentheses.

Source: Author's data extraction using www.twitonomy.com. Word clouds created using http://tagcrowd.com.

Where the primary objective of governments is to use social media for one-way communications - akin to press releases - no specific tactics or methods are necessary. But the question is increasingly raised whether the public sector can and should leverage social media for more than just broadcasting its messages. The aim of the following sections is to understand if and how social media can become a tool to support and potentially transform the public sector's core "business", i.e. interaction with people and delivery of public services. 


\section{POTENTIAL AND CHALLENGES OF SOCIAL MEDIA USE IN GOVERNMENT}

This section outlines current directions governments take for the use of social media. While governments are still mostly experimenting with this new medium, the empirical overview in the previous chapter confirmed that many government institutions still use the channel in a rather traditional communications sense, i.e. mainly to broadcast messages that are in fact re-packaged press releases.

But social media can provide governments more value than simply improving communications. In the current global socio-economic context it seems opportune to analyse the potential of this channel to re-build mutual trust between governments and their constituents, and to improve government's responsiveness to citizens.

\section{Policy processes: more open, inclusive and participatory}

Mutual trust between governments and their constituents is being shaken the world over. Global surveys show that across OECD countries only $40 \%$ of the population have trust in their national government, down from 45\% in 2007 (Gallup World Poll, cited OECD, 2013a). And the tail of countries reporting a loss in confidence is longer than the head of countries that reported gains.

The reasons for lack and decline in confidence are multifaceted. Deteriorating economic circumstances certainly provide a starting point for explanations, but are not enough. Other political and societal factors are also at play. Over the past decade technology, in particular, has become a major facilitator to express disenchantment. Mass e-mailings were used as early as 1999 to stage massive protests against the WTO Minister's meeting in Seattle or against the meeting of G8 heads of state in Genoa in 2001. The role of technology as a catalyst of discontent has only accelerated since then - arguably faster than governments' capacities to use technology to channel discontent towards constructive transformation. Today, technology, and in particular social media, make it easier than ever for people to:

- obtain and diffuse information, including "leaking" of information not intended for public audiences;

- diffuse false information (deliberately or not);

- analyse, interpret and present complex policy materials in ways that can be understood by non-expert audiences; channel diffuse interests around common issues and place these issues on decision makers' agendas, e.g. through online petitions.

The question is though whether governments can also use those technologies reform existing processes and make them more open, inclusive and participatory. Promising applications of social media to this purpose are their use to empower people, to enable governments and to strengthen transparency and accountability of government.

Empowering people. Social media have proven to be a powerful vehicle to help diffuse opinions and desire for action achieve critical mass, which in turn attracts the attention of mainstream media and decision makers. Obviously, channelling diffuse interests and rallying for action is not new in itself; it is what established interest groups such as lobbies and unions have been doing for a long time. But the Internet and social media now empower less organised and less established groups and give them relatively inexpensive means to rally ad hoc support around common causes. With these tools in hand, formerly diffuse individuals or less resourceful groups obtain greater agenda-setting power. 
A prominent example of how social media empower people that had no effective recourse to existing intermediaries before is the Never Seconds blog in Scotland (United Kingdom). A nine-year old schoolgirl and her parents repeatedly alerted their school and local authorities to the low nutritional value of school meals. When their demands were ignored, they set up a blog in May 2012 where the family would post a photo of the day's school meal, taken with a digital camera, and rate the meal's perceived quality. ${ }^{16}$ The post immediately stroke a nerve nationally and internationally and triggered many high-profile responses, including by the UK Prime Minister. ${ }^{17}$

At the same time, more traditional resources and power distributions in policy-making processes remain of great importance and not all attempts at citizen activism lead to success. A counter-example to the Never Seconds blog is the partial privatisation of parts of the Danish company, DONG Energy, to Goldman Sachs in early 2014. The political consensus was met with fierce opposition by the general population. Using social media and attention in other media, almost 200000 signatures were collected via a dedicated online petition (equivalent to almost $4 \%$ of the population), and large protests were organised. ${ }^{18}$ Although the ad hoc interest group was extremely successful in "escalating" the issue, placing it on the national political agenda for several weeks and achieving the resignation of ministers, the actual decision was not altered and the privatisation went ahead as planned.

Enabling government. The previous two examples show that social media also enable government to be more responsive and to be quicker in responding to demands from stakeholders. But they also show that the specific political or administrative context still remains a determining factor of whether the messages, demands or pressures received through crowd-based action are actually transformed into political decisions.

It is obvious that social media enable governments to "bypass" or complement traditional means for gauging public sentiment such as opinion polls and organised interest groups. Using social media for "active listening" can help government de-escalate issues or satisfy demands before they become the issues of major discontent. As an example, the \#elephantintheroom campaign by several NGOs in the United Kingdom was quickly picked up by the UK Treasurer George Osborne who put the discussion on the impacts of tax evasion on development on the agenda of a G7 minister's meeting (see Figure 10 for the Minister's response). ${ }^{19}$

Figure 10. UK Treasurer responds to social media campaign by NGO coalition

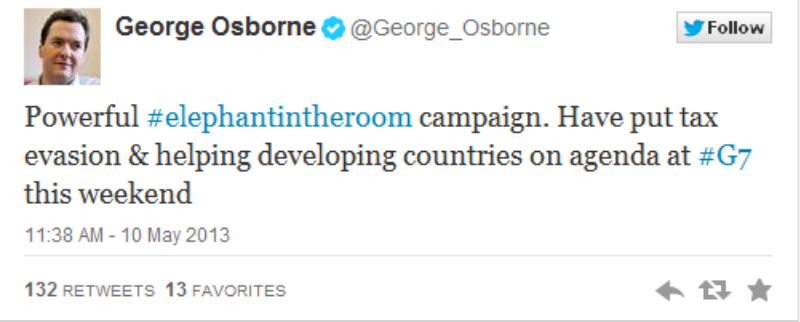

Source: https://twitter.com/George Osborne/statuses/332806826074730496.

\footnotetext{
${ }^{16}$ See first blog post at http://neverseconds.blogspot.fr/2012/05/tuesday-8th-may.html.

${ }^{17}$ For more information see www.telegraph.co.uk/education/educationnews/9334721/Neverseconds-Martha-Payne-theunsquashable-school-meal-crusader-aged-nine.html.

${ }^{18}$ The online petition is available at www.skrivunder.net/nej_tak_til_statens_salg_af_dong_til_goldman_sachs.

${ }^{19}$ More details at www.christianaid.org.uk/ActNow/blog/may-2013/IF-elephant-room-budget.aspx.
} 
But the multiplication of opportunities to place issues on the government agenda also poses capacity and selection problems to government. How can or should institutions respond to a growing number of requests? How can they understand if well-organised social media campaigns actually refer to severe and real problems? How can decision-makers know if they are facing demands formulated by legitimate representatives of diffuse opinions?

None of these questions can be fully answered yet. However, there are pointers as to how social media and crowd activism can be channelled in ways that governments can handle. Online petitions have, for example, grown to become a powerful tool. Combined with reasonable thresholds, they can help governments prioritise issues raised on the Internet.

To cite a case from the legislative arm of the state, the Latvian parliament in 2011 accepted the online petition platform www.manabalss.lv as a valid means for the public to propose new legislation. The parliament accepted a new rule of procedure whereby a threshold of 10000 valid citizen signatures (equivalent to around $0.5 \%$ of the population) obliges parliament to put the proposal on its legislative agenda. So far, twelve out of over 650 proposals have achieved that threshold and were discussed in parliament. Some made it into actual legislation, e.g. the right of judicial authorities to access information on civil servants' offshore accounts.

But petitions have also made their ways into executive decision-making. In Marseille (France), a small group of people launched an online petition via www.change.org to oppose the municipal council's decision to disburse a subsidy of EUR 400000 for an open air concert that also benefited from the provision of rent-free municipal facilities and had concert-goers buy tickets. Over 70000 signatures were collected, which put enough pressure on the municipality to revoke the subsidy. ${ }^{20}$

Supporting government transparency and accountability efforts. Governments are increasingly trying to provide easy and open access to government information, e.g. through open government data policies (cf. Ubaldi, 2013). This is an important step towards greater transparency of decision-making as the value of the information opened up by governments increases as more people use and re-use that information. A good illustration of this are government budgets. In most OECD countries, budget allocation and spending information has long been available for public consultation. But only more recently has this information become more easy and affordable to access, e.g. by removing cumbersome access provisions and working with stakeholders to find more suitable formats for diffusion. The impact of the "vernacularisation" of government budgets is huge as data visualisations and analyses such as those presented at https://openspending.org are regularly picked up by mainstream media, thus helping to better inform public opinion. ${ }^{21}$

At the same time, transparency and accountability are being challenged as governments use social media to investigate crime and enforce legislation. This is obviously a critical part of police work. But in the current context where any report of (perceived) government misconduct or surveillance receive great public attention, governments could arguably do better in communicating if and how they use social media as a means for intelligence. Otherwise there is a risk that the negative image of state authorities' handling of social media outweighs the many positive and laudable initiatives of government to use social media for greater transparency and accountability (see Box 2).

\footnotetext{
${ }^{20}$ For more information see www.change.org/fr/p\%C3\%A9titions/jcgaudin-non-\%C3\%A0-la-subvention-de-400-000-eurospour-le-concert-de-david-guetta-\%C3\%A0-marseille-mp2013.

${ }^{21}$ See for example Le Monde (2012), "PLF : des avions au bouclier fiscal, la java des amendements”, 16 October, www.lemonde.fr/politique/article/2012/10/16/plf-des-avions-au-bouclier-fiscal-la-java-desamendements_1776093_823448.html ]
} 


\section{Box 2. Government information requests to social media platforms - a risk to policy coherence?}

Government agencies, notably law enforcement agencies, have a mandate to enquire about individuals as part of their work. As the Internet and social media have become major areas of illicit and illegal activities the importance of government being able to act and re-act in this medium is of great importance to national security.

At the same time, government requests for information from social media services can have an impact on perceived openness and transparency. The numbers of individual social media users that are subject of government information requests have become the topic of public debate since major social network operators started publishing statistics on the diverse requests received (see www.nasdaq.com/article/what-google-twittermicrosoft-and-facebook-have-shared-in-transparency-reports-cm271296).

During 2013, United States government authorities issued information requests concerning over 80000 individual users of Google, Facebook and Twitter services (see Figure below). Government authorities in India, Germany, the United Kingdom, France, Italy, Brazil and other countries issued less overall requests, but they still concerned thousands of individual users in 2013.

Such requests are, in principle, in line with national legislation and typically concern criminal investigations. Nevertheless, public perception of the growing number of requests is not always favourable. Improved communications on the reasons for the rise in requests could help governments maintain the legitimacy of this intelligence tool.

Total number of users referenced in government information requests to social networks, 2013

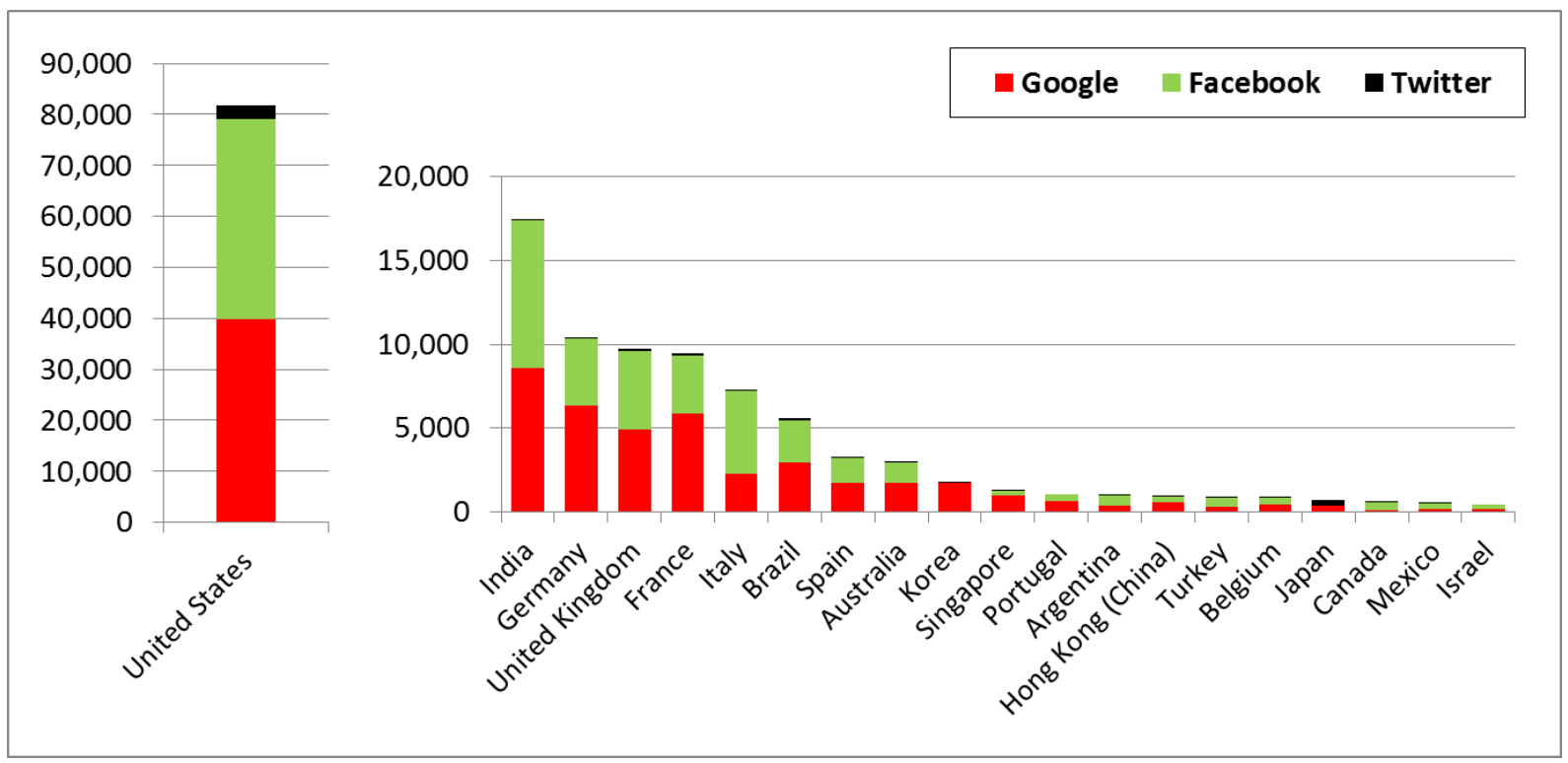

Source: Author's calculations based on publicly available corporate "transparency reports" by Google, Facebook, Twitter

Note: The statistical data for Israel are supplied by and under the responsibility of the relevant Israeli authorities. The use of such data by the OECD is without prejudice to the status of the Golan Heights, East Jerusalem and Israeli settlements in the West Bank under the terms of international law.

So if social media can spur participation, it is opportune to explore opportunities for engaging two particular groups: marginalised people in society and younger people. They certainly represent high-impact target groups for many governments in the current context. 


\section{Marginalised and hard-to-reach groups}

Social media can play a role in empowering people that face systematic risks of exclusion from political and economic processes in modern societies. In fact, social media might have the potential to alleviate some of the difficulties governments still encounter when reaching out through conventional online channels as uptake rates for digital government services remain below expectations in many countries (OECD, 2013a). Some socio-economic factors, notably education and income levels, still have a strong determining impact on online interaction rates with public authorities: more than two thirds $(68 \%)$ of Europeans with high formal education interact online with public authorities, but only one in five $(21 \%)$ with no or low formal education level does so. ${ }^{22}$

Other access and use divides exist, although some of them are less pronounced. Urban-rural divides continue are a major issue in countries with larger territories such as France or Poland. Gender differences have mostly disappeared as a determining factor for uptake of digital government services in Europe, although Croatia, Austria and Turkey continue to see e-government uptake rates among men being at least 10 percentage points higher than among women. ${ }^{23}$

Social media can help address some of those "traditional" access and use divides for digital government. Empirical evidence for the United States, for example, suggests that social media uptake is very similar across different ethnic minorities, education and income groups (cf. PewInternet, 2012). In that context, governments can consider using social media to alleviate some of the existing imbalances in supply and uptake of municipal online services, especially where the imbalances correlate with socio-economic factors such as distribution of ethnic groups, education and income levels in the municipality (Ahn, 2010; Reddick et al., 2013).

A major issue is that access and use of social media is not yet universal. While an individual's level of education makes virtually no difference in Germany, Norway, Denmark, Finland or Austria, there is a large group of European countries where education does determine a person's likeliness to use social media (Figure 11). Across the EU, 53\% of people with high levels of education use social media, but only $31 \%$ of people with a low level of education - a gap of 22 percentage points. The gap goes beyond 30 percentage points in Spain, the United Kingdom, Hungary, Portugal, Greece; and over 50 percentages points in Turkey. This confirms the continued need to address digital access and use divides on those new platforms.

\footnotetext{
222013 data for EU-27, extracted from Eurostat Information Society statistics, indicator "Individuals using the Internet for interaction with public authorities (tin00012)"

${ }^{23} 2013$ data for EU-27, extracted from Eurostat Information Society statistics, indicator "Individuals using the Internet for interaction with public authorities (tin00012)"
} 
Figure 11. Social media uptake by level of educational attainment, 2013

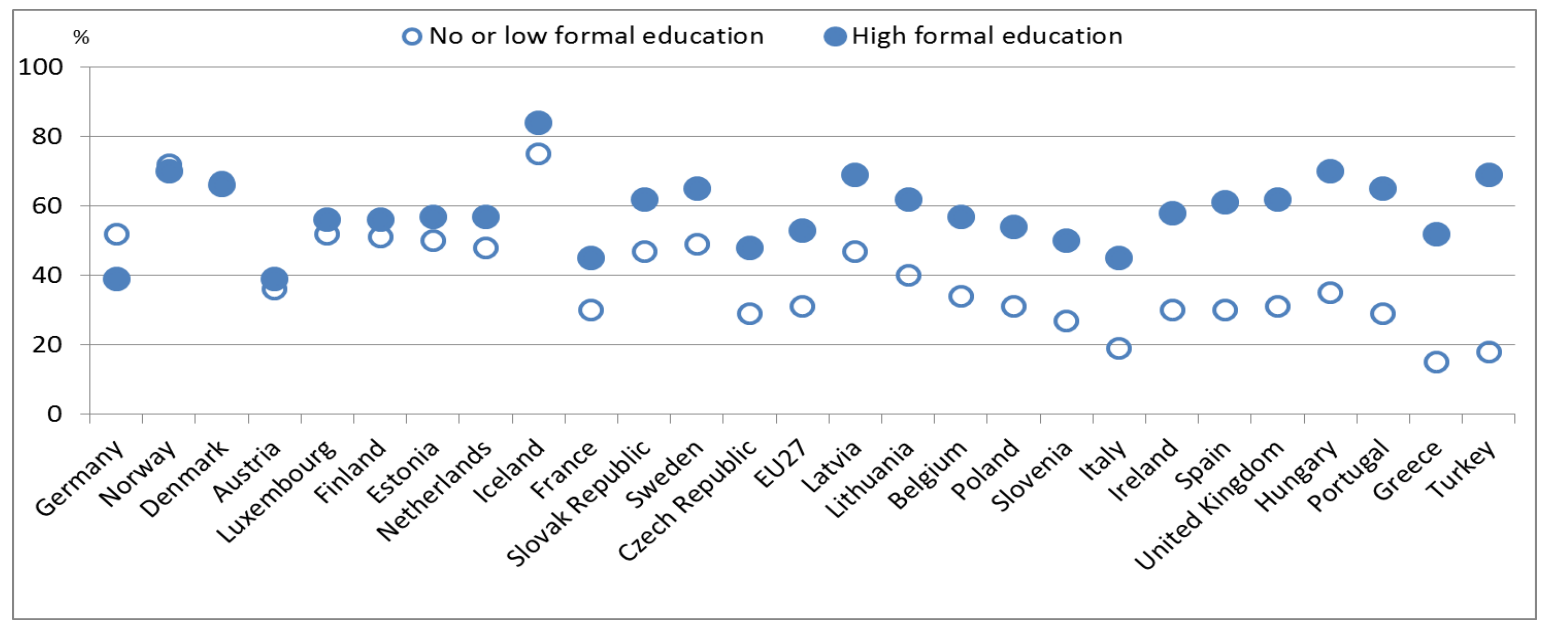

Source: Author's calculations based on Eurostat, "Internet use: participating in social networks (creating user profile, posting messages or other contributions to Facebook, Twitter, etc.)" (data for 2013).

Social media are also a tool that can empower women where they are vulnerable or marginalised. Uptake and use rates are relatively evenly distributed between women and men across most OECD countries. Interestingly, they are also relatively balanced in many non-OECD countries, which can render good practices applicable in other national contexts. An example of such transferability could be the use of social media to stimulate interest and activity among girls and women in the science, technology, engineering and mathematics (STEM) fields - a priority for many OECD countries. The initiative of the Asikana Network in Africa is one such example (Box 3) ${ }^{24}$

\section{Box 3. Social media communities of female "techies" in Africa: the Asikana Network}

Although to different degrees, OECD member countries and African countries share the challenge of encouraging girls and women to take up education and career paths in the fields commonly termed as STEM (science, technology, engineering, mathematics). The basic challenge according to experts is that "women find it particularly difficult to make their way in the IT field whether due to glass ceilings in the UK or the glass ladders in Lusaka" (http://appropriatingtechnology.org/?q=node/8). The Asikana Network is an example of using social media to actively address this issue across Africa.

The Asikana Network aims to empower young women and teach them essential information and communication technology (ICT) skills. It has three main target groups: 1) girls in high schools - members of the Asikana network create clubs where girls can meet and receive mentorship from women working in the field; 2) college students and graduates - particularly those that are either studying IT or who would like to develop in that sector; 3) women who already work in the IT sector or have related skills - here the Asikana Network provides a platform to share their knowledge and pick up skills and career development opportunities.

Social media are catalysing the success of the Asikana Network across Africa. Of course the Network actively uses Twitter (@AsikanaNetwork) and Facebook (www.facebook.com/AsikanaNetwork) to create those communities of shared interest. But another significant component is the creation of a crowd-sourced map of women tech hubs in Africa: https://womentechafrica.crowdmap.com. The map pinpoints initiatives across Africa and lets the members of the network interact with each other. At the end of 2013, 48 organisations and initiatives across 15 African countries were mapped that encourage girls and women to take up active roles in the STEM and IT fields.

Source: Adapted from Chisenga Muyoya (2014), "The Asikana Network", in Feminist Africa 18: e-spaces / e-politics, www.apc.org/en/pubs/feminist-africa-18-e-spaces-e-politics.

\footnotetext{
${ }^{24}$ See also OECD policy wiki dedicated to gender issues, www.wikigender.org.
} 
The potential for governments to use social media to reach vulnerable groups is certainly there, but is heavily dependent on local context. Governments need to avoid falling for preconceived notions that suggest social media are per se a tool to empower vulnerable groups of society. Ensuring that initiatives are targeted and purpose-oriented is just as critical as making sure that the inputs received by people through these new channels actually influence decision-making processes.

\section{Younger people}

Young people are particularly exposed to the impacts of the economic crisis. Youth unemployment and youth dropping out of education or training are a common concern among OECD member countries. In the United Kingdom, at least half of young people feel disillusioned by the state of the current jobs market (UK Prince's Trust, 2013). Other factors contributing to a lack of confidence in government have been around longer, notably declining rates of young voter turnout and party membership in many countries.

Given that young people are so familiar with technology today, it seems intuitive that governments could use social media to genuinely engage them. Unfortunately, the reality is somewhat different. If past experiences are anything to go by, governments are not very successful in linking up with young people over the Internet: only $40 \%$ on average of young Europeans interact online with the public administration; and the share can reach as low as 20\% in Italy (Figure 12). Those countries with relatively low uptake shares among the young seem like a confirmation that this statement made in 2007 still largely holds true today: "young people are often positioned by even the most well-meaning public sector sites not as citizens but as citizens-in-waiting" (Livingston, S. et al., 2007).

Figure 12. Young people's use of the Internet to interact with the public administration, 2013

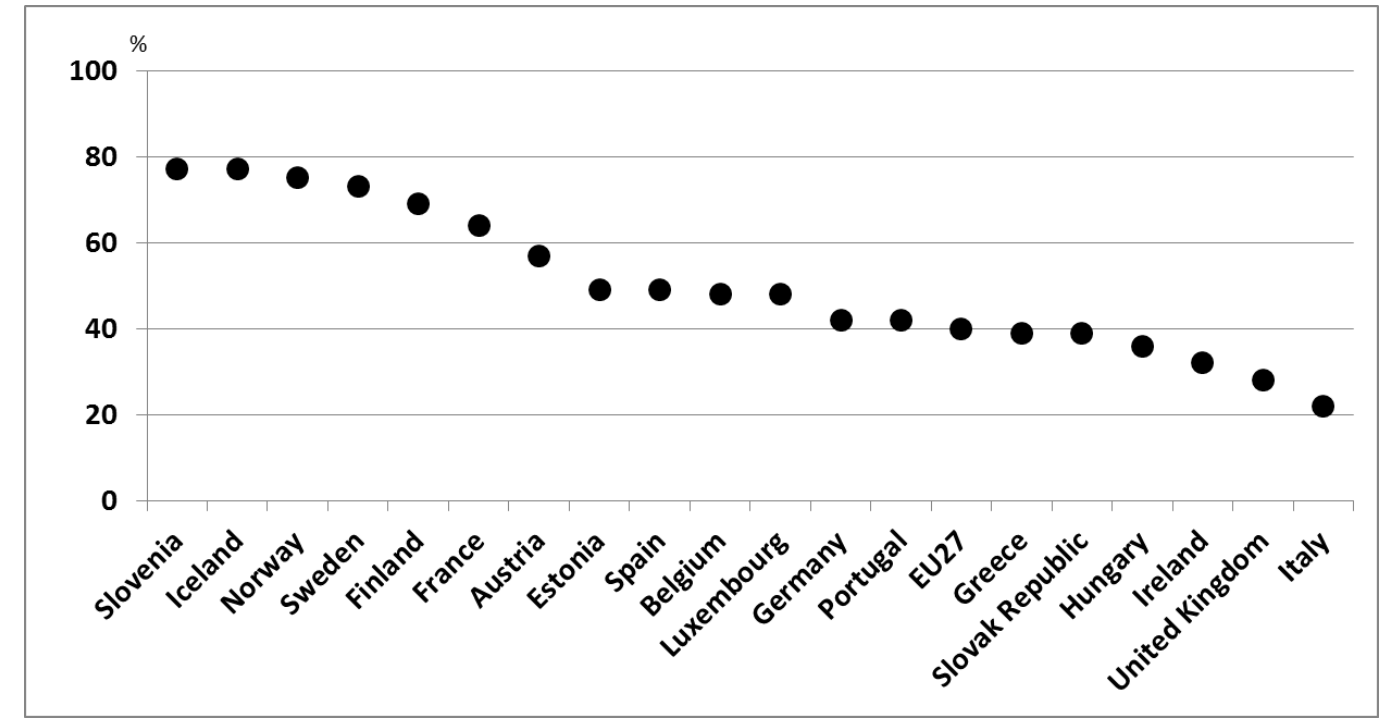

Source: Eurostat, "Internet use: posting messages to social media sites or instant messaging" and "Internet use: interaction with public authorities (last 12 months)" (2013 data).

Some analysts - and probably some decision-makers too - take the easy road by considering that low digital government uptake among 16-24 year olds is normal because this group of people has "less need or fewer obligations concerning administrative procedures". ${ }^{25}$ This assumption is of course

\footnotetext{
${ }^{25}$ See http://epp.eurostat.ec.europa.eu/statistics explained/index.php/E-government statistics, last accessed in August 2014.
} 
incorrect since young people have many needs and obligations which require contact with the public administration, e.g. issues related to education, residence, citizenship, social benefits, employment. What is correct though is that some countries are able to design online services in a way that appeals and makes sense to young people, e.g. Slovenia, Iceland, Norway and Sweden where the uptake rates are between 70 and $80 \%$ for this age group.

So the question is not whether young people need to get in touch with government, but whether they want to, i.e. whether the services and information offers appear relevant to them. There is little data to illustrate the role of social media to improve participation of young people in government processes. But one data point that is available draws a rather disillusioning picture: despite the fact that virtually all young Europeans use social media (85\% on average), only a minority of them (18\%) are interested in using social media to engage in anything of political or civic nature (Figure 13). In Austria, not even $10 \%$ of 16-24 year olds are interested in using social media for those purposes, which is a worrying finding when combined with the fact that voter abstention is very high too (see further below).

Figure 13. Young people's use of social media in general versus their use to discuss political or civic issues, 2013

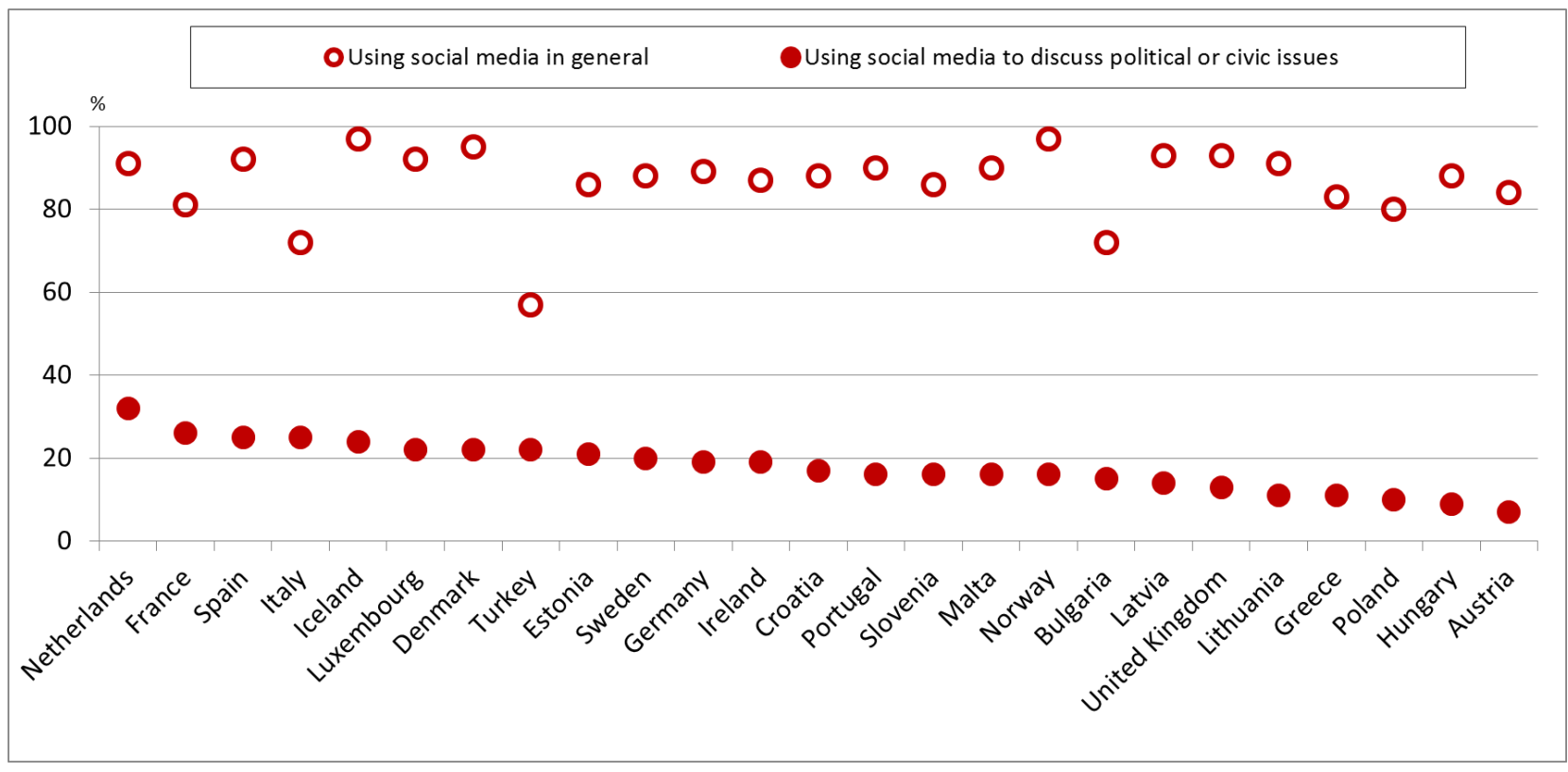

Source: Eurostat, "Internet use: posting opinions on civic or political issues via websites (e.g. blogs, social networks, etc.)" (2013 data).

Some governments might therefore wonder if it is worthy allocating resources to social media as a tool to enable participation if only a minority of young people are potentially interested. It does seem worth the effort though considering that the prospect of engaging around one in five young people could already be a success in countries like France, Spain, Italy or Iceland - which have a generation of young people frustrated about their economic situation and future opportunities, but which also have some of the highest shares of young people interested in political or civic discussions on the web (Figure 13).

Moreover, social media can be instrumental in encouraging young people to vote. Voting abstention among young people is a serious issue as surveys report that on average $21 \%$ of young 
Europeans did not participate in any election during the past three years despite being eligible (TNS, 2013). In some countries up to one third abstains, e.g. in the United Kingdom (36\%) ${ }^{26}$, in Hungary (35\%), in Austria (31\%) and in the Slovak Republic (30\%). While there is not enough evidence to establish a causal link between social media use and voter turnout, an interesting pattern emerges when cross-tabulating young voters' abstention rates with their rates of social media use to discuss civic and political issues (Figure 14).

Figure 14. Plotting young people's voting abstention rates and interest of discussing politics online, EU, $2013^{27}$
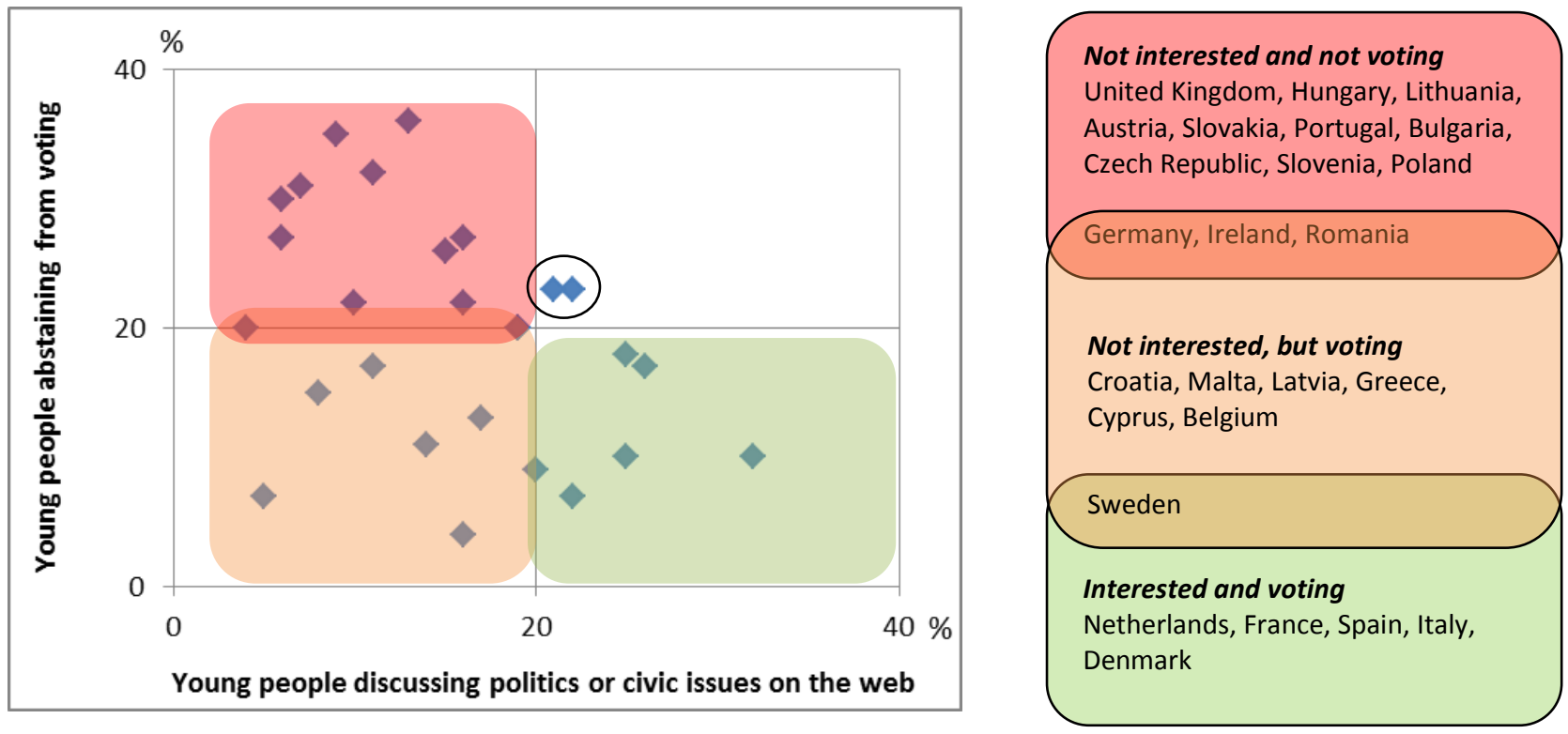

Notes:

Vertical axis: Share of 15 to 30 year olds who reported they did not vote in any elections (national or sub-national) during the last three years despite being eligible.

Horizontal axis: Share of 16 to 24 year olds who used the Internet or social media to discuss political or civic issues in 2013.

Voting is compulsory for at least some elections in Belgium, Cyprus, Luxembourg and Greece. The voting age is 18 for most of the elections in the EU Member States and in Croatia, except for Austria where the voting age is 16.

Source: Author's calculations based on data by TNS, 2012 (vertical axis) and Eurostat, 2013, "Internet use: posting opinions on civic or political issues via websites (e.g. blogs, social networks, etc.)" (horizontal axis).

Policy-relevant findings emerging from the evidence presented in Figure 14 are:

- Young Europeans who are interested in discussing politics or civic issues on the web also tend to vote - countries in the lower right quadrant, grouped as "interested and voting".

${ }^{26}$ In the United Kingdom's 2010 parliamentary elections the abstention rate of 18 to 24 year olds was reported to have reached as high as 56\% (according to http://bitetheballot.co.uk/).

27 Note by Turkey: The information in this document with reference to "Cyprus" relates to the southern part of the Island. There is no single authority representing both Turkish and Greek Cypriot people on the Island. Turkey recognizes the Turkish Republic of Northern Cyprus (TRNC). Until a lasting and equitable solution is found within the context of United Nations, Turkey shall preserve its position concerning the "Cyprus issue".

Note by all the European Union Member States of the OECD and the European Union: The Republic of Cyprus is recognized by all members of the United Nations with the exception of Turkey. The information in this document relates to the area under the effective control of the Government of the Republic of Cyprus. 
This group of countries includes Italy and Spain, where young people feel the severe impacts of the economic crisis. At the same time, at least $20 \%$ of young people there engage in political discussions online and voting abstention among the young is relatively low, less than $20 \%$. Governments in these countries have an opportunity to involve young people via social media with a view to improving their confidence in their government, their situation and surely also in themselves.

- Young Europeans who do not vote also tend to abstain from discussing politics or civic issues online - countries in the upper left quadrant, grouped as "not interested and not voting". This group includes several Central and Eastern European countries where postSoviet transition has generated "disenchantment", notably due to persistent corruption. But this group also includes countries like the United Kingdom, Austria and Portugal. Governments there face an uphill struggle when it comes to involving young people into political and policy processes. In fact, that challenge might be so high that governments might need the help of trusted intermediaries and partners to get young people involved. Some relatively successful initiatives are the "Bite the Ballot" campaign in the United Kingdom or the "Rock the Vote" campaign in the United States. ${ }^{28}$

- There are some countries where young people do not discuss politics or civic issues on the web but they nevertheless vote - countries in the lower left quadrant, grouped as "not interested but voting". Governments in this group (Croatia, Malta, Latvia, Greece, Cyprus and Belgium) might need to make greater attempts to reach out to young people, but not solely via social media, in order to anticipate and address their concerns outside of election cycles.

- Finally, the cases of Estonia and Luxembourg (circle in Figure 14) indicate that some countries do not fit either category and represent cases of their own.

The notion that governments in some countries can indeed turn towards social media to involve young people is confirmed by taking a look at the most prominent topics discussed on Facebook over the course of a year (Tables 6 and 7):

- In Argentina, political and civic issues represented seven of the ten most talked about topics on Facebook in 2013. They covered natural disasters (La Plata, Inundaciones), national elections, legislation and politicians. In 2014, Argentina is again among those countries where civic and political issues are most discussed on Facebook.

- In Australia, election themes and candidates represented half of the top 10 most discussed topics on Facebook in 2013. In 2014 there was less focus on political and civic issues.

- In Italy and Spain, half of the most talked about topics on Facebook in 2013 were of political or civic nature, which coincides with the earlier finding that young people in these two countries are relatively interested in using social media to get involved in political processes in the wider sense. This is, however, only partly confirmed in 2014 where Spanish Facebook discussions still seem to have strong political and civic orientation, but less so in Italy.

\footnotetext{
${ }^{28}$ The "Bite the Ballot" campaign in the United Kingdom made massive use of social media during the "national voter
} registration day" on 5 February 2014. The hashtag \#nvrd became a trending Twitter topic that day. 
- There is relatively low representation of civic or political issues in the United Kingdom's top ten Facebook discussions. Only two topics in 2013 and three in 2014. This coincides with the earlier finding that young people in the UK and the risk of their alienation from political processes.

- In Japan and Korea only few civic and political issues make it to the top 10 of most discussed Facebook topics. However, this finding must be relativized by a very strong penetration of alternative social networks in those countries, e.g. Mixi or Line in Japan, Me2Day, Naver Cafe or Kakao Talk in Korea. An analysis of discussions on those networks would be necessary to arrive at more solid findings.

- Facebook's popularity in Brazil was rivalled by the social network Orkut until the service was discontinued by its owner, Google, in 2014. A thorough analysis of trends until 2014 should take dynamics on that platform into account.

Despite the fact that only little comparable data is available, the findings so far clearly show that "young people" is not a homogenous category. Stereotypical approaches to social media that focus on establishing a government presence without due consideration for context factors are unlikely to address the real challenges of young people. As a matter of example, a study of young people's attitudes in the UK towards solving their problems finds that around two thirds prefer to talk to someone in person rather than online; it also reports that one quarter of unemployed young people are uncomfortable filling in job applications online (UK Prince's Trust, 2013). This is the kind of context data that decision-makers need to consider when designing social media strategies and guidelines that are supposed to address young people's concerns. 
Table 6. Most discussed topics on Facebook, individual countries, 2013

Countries ordered by total number of topics that relate to current political or civic issues (highlighted).

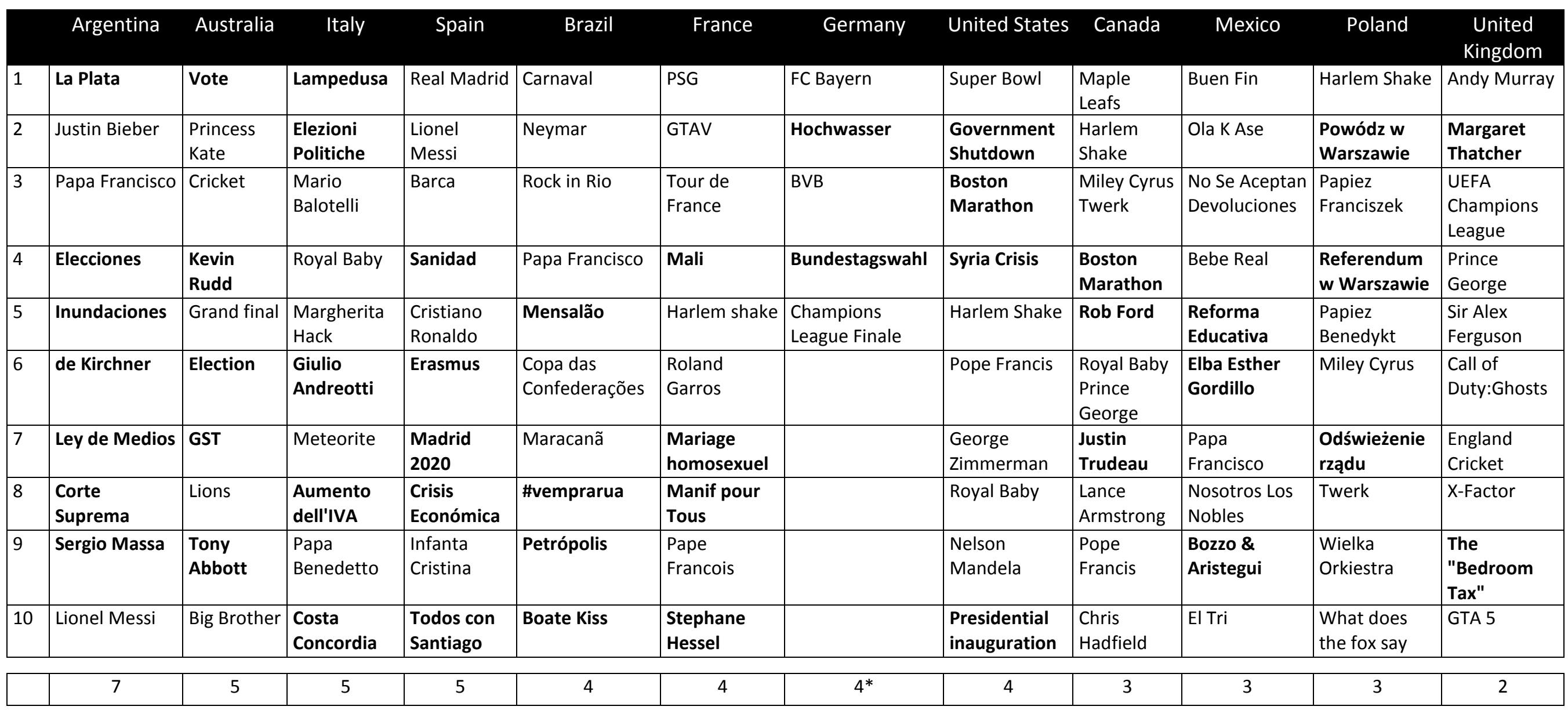

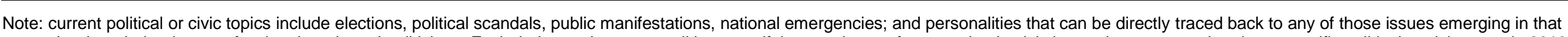

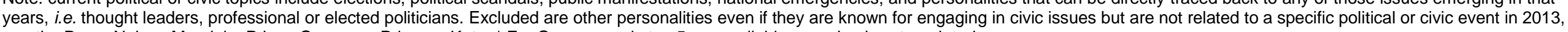
e.g. the Pope, Nelson Mandela, Prince George or Princess Kate. * For Germany only top 5 are available, so value is extrapolated.

Source: Author's compilation based on corporate information by Facebook, 2013: http://newsroom.fb.com/trends/770/2013-year-in-review. 
Table 7. Most discussed topics on Facebook, individual countries, 2014

Countries ordered by total number of topics that relate to current political or civic issues (highlighted).

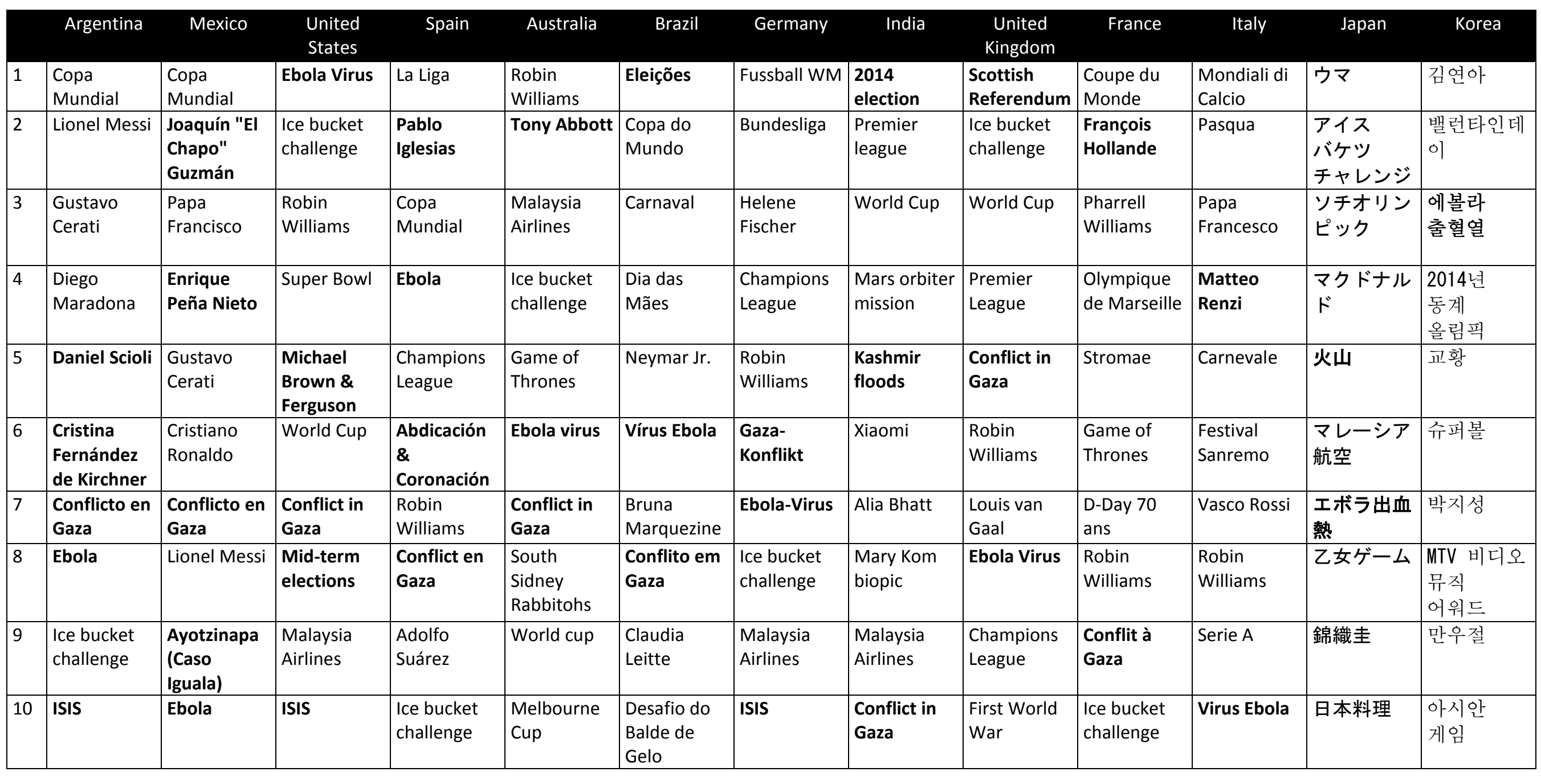

\begin{tabular}{|c|c|c|c|c|c|c|c|c|}
\hline 5 & 5 & 5 & 4 & 3 & 3 & 3 & 3 & 3 \\
\hline
\end{tabular}




\section{Public service delivery: more agile, iterative and responsive}

Social media have the potential to boost the operational capacities and responsiveness of governments in ways that traditional approaches to digital government have not been able. Although digital channels and infrastructures are now integral to public sector activities, there remain too many unanswered questions as to the returns on investments, e.g. around lower than expected uptake rates of digital public services in some countries. ${ }^{29}$ The question is therefore if and how social media can make public services more accessible and responsive, of better quality and more efficient to deliver.

By providing real-time opportunities for participation and feedback, social media are starting to blur the lines between policy development and service delivery. They give governments new tools to pilot, experiment, evaluate, and re-design services ahead of their full roll-out. This can make governments quicker to react to citizen needs, as well as more evidence-based in the design of service delivery strategies. At the same time, some social media activities raise privacy and trust concerns that governments have to address.

Some of the opportunities to transform public service delivery that are often cited and merit closer examination are: providing new - possibly more efficient - channels to deliver public information, goods and services; identifying new means and resources for collaboration in the creation and delivery of public goods and services; opening up new ways to understand and anticipate user needs at various stages in the service design and delivery process, and to re-design services in more iterative ways.

Social networks as additional service delivery channels. Social media can bridge some of the common digital divides, provided that the limitations discussed earlier are duly considered. The relative ease of reaching out to individual users helps governments segment populations, tailor service delivery to individual needs and potentially even reduce the costs of service delivery.

Chile's multi-channel strategy ChileAtiende ("Chile at your service") is an example of a national government using social media to support a wider service delivery strategy. The government uses its official Facebook and Twitter presences to respond to service users and direct them towards specific service delivery channels, notably digital channels which have the lowest delivery costs. Directing service users away from costly person-to-person transactions towards digital transactions is in fact a common objective across OECD governments. It is understandable given the different costs incurred: in the United Kingdom the average cost incurred by completing an online transaction is GBP 0.32 , compared to almost GBP 3 for phone-based transactions and over GBP 7 for face-to-face transactions with the public administration (BDO, 2012).

Many social media opportunities to support multi-channel delivery can be found at sub-national levels of government. Local authorities are often the primary interface between citizens and the state; and they are typically subject to very tight budgets. In that context social media, coupled with trends such as open government data and the advance of "smart" devices, are leading to a great amount of service delivery innovation. Applications such as FixMyStreet or SeeClickFix are now common means for people to submit reports about the state of the public space to local authorities. And indeed, most local councils in the United Kingdom expect returns on social media use in the following areas (cf. BDO, 2012): delivery of environmental services (81\% of local councils), delivery of leisure and parks services $(74 \%)$, delivery of public road maintenance services $(72 \%)$.

\footnotetext{
${ }^{29}$ Analytical work is underway at the OECD on digital government productivity; see also "Uptake of online public services" in OECD, 2013a.
} 
Social media bear many opportunities for efficiency gains in the functioning of local authorities. The Open311 system developed through "Code for America" and now in use across major US cities is at first glance a unified interface for people, regardless of whether they contact the public administration by phone, SMS, email or social media. But a significant amount of information takes place "under the hood", i.e. in the management of internal workflows. In Chicago, the "311 service tracker" lets residents check the status of service requests online. ${ }^{30}$ Since the establishment of this online ticketing system the city drastically reduced the number of phone enquiries whose only purpose is to check the status of a service request. Consequently, public administration resources are freed up. And as all service requests are centrally stored, the city administration can mine the vast amounts of data for policy-relevant patterns.

Service design and delivery collaboration via social media. Many of the knowledge-intensive occupations prevalent in public sectors today can benefit from social media to improve individual and collective productivity. Take the example of emails, arguably one of the technologies that has most dramatically changed modern workplaces and workflows. Yet, the verdict is divided on whether emails actually achieved the productivity leaps they were expected to yield. That is because some major downsides are beginning to take the upper hand as people in knowledge-intense occupations are estimated to spend up to one quarter of their time reading and writing emails (McKinsey, 2012) ${ }^{31}$ The perceived "unproductivity" is leading organisations to more effective ways of collaboration, notably social media - see Box 4 for a radical step taken by a large healthcare organisation in the Netherlands.

Box 4. "Doctor's orders: Why I quit email-and you should, too"

The following is an extract from a post written by Lucien Engelen, Director at Radboud REshape and Innovation Center at Radboud University Nijmegen Medical Center, Netherlands.

"At our Radboud University Medical Center (RUMC), we send out some 750,000 e-mails, every month. Monthly, we send these from our approximately 18,000 email addresses. Conversely, on a monthly average of 1.2 million e-mails are being sent to us. (Numbers cleared for spam and based on 2013.) ... Imagine that every incoming email read by 'someone' took 60 seconds: That would quickly add up to as much as 12.5 hours per month. Every month that's about 8 FTEs, in other words 96 people per year, mind you: one minute a mail for one person! Imagine if we could use that time instead to spend with patients and their family. ... An analysis of my incoming emails taught me that some 70 percent of the information sent to me could also be found on our intranet. It was also clear that email was increasingly used as a kind of chat, and sometimes invoked up to 10 other messages to 10 separate people. For that, I think, we have other more appropriate tools, such as our UMCN [internal network], Yammer or social media.

I therefore decided to stop e-mail. Not just BCC's or CC's, but everything. Now, you might think: "one can't just stop," and that is generally true. But not for me; it fits with my affinity for being a bit of a rebel (with a cause). ... The out-of-office assistant was set, and contained a reference to me quitting email as well as mentions of my Yammer, Twitter, Linkedln and Facebook accounts, and asked that everyone refer to my secretaries for appointments (by e-mail or Twitter @ secretarylucien).

I can firmly tell you that it already saves me a lot of time, approximately one-and-a-half to two hours per day. My colleagues are now surprised that I can find time to grab a cup of coffee, pick up the phone and respond swiftly to messages sent through other channels like social media. ... Being where your targeted audience is becoming more important than ever. For my job in healthcare, this is truer than is has ever been before. There are many great tools that are better for stimulating collaboration and co-creation than email. ..."

Source: The post was originally published on Linkedln and is now available at http://qz.com/84345/why-i-quit-e-mail-a-monthago.

${ }^{30}$ For more information see http://servicetracker.cityofchicago.org. 
Having realised that email might not be an effective tool to promote collaboration, public sector organisations increasingly trial social networks. Across the OECD, 10 out of 24 governments indicate using social media for internal communication and collaboration (Figure 15). This includes use of platforms that are based on open standards, e.g. wikis, as well as proprietary platforms, e.g. Yammer, tiddle, huddle or GovLoop.

\section{Figure 15. Government-internal use of social media, OECD, 2013}

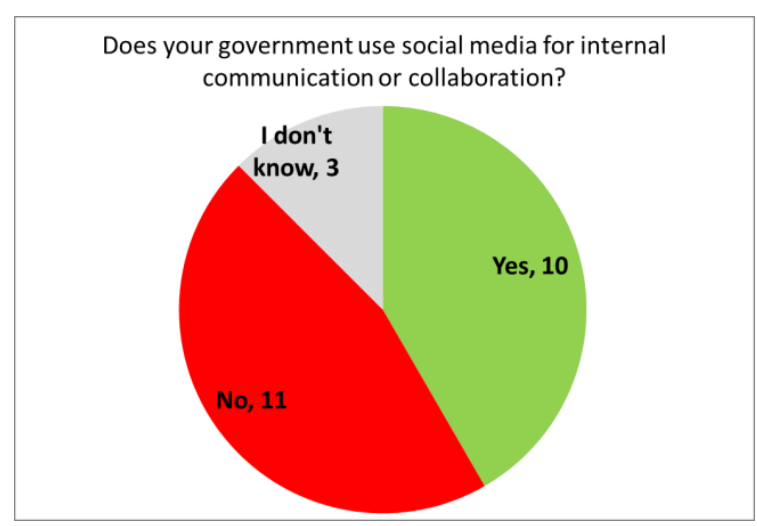

Source: OECD (2013b), "Survey on government use of social media".

Further examples of governments using social media internally are:

- Australia, where the cross-agency collaboration platform GovDex was launched in 2006 and reached around 20000 users in 2011. Civil servants use GovDex to establish communities of interest, including on the use of social media itself as is the case with the "Cross Agency Social Media Forum". ${ }^{32}$

- Canada, where the Treasury Board of Canada operates three social networking platforms since around 2009: 1.) GCpedia, a wiki-based platform to exchange and jointly develop content; 2.) GCconnex, a more interaction-oriented platform that mirrors functionalities of Twitter, blogs and Facebook for internal public administration use; 3.) GCforums, a set of discussion communities around specific topics. ${ }^{33}$

- The United Kingdom, where the Food Standards Agency (FSA) uses Yammer for internal sharing of information and for collaboration between employees and external stakeholders. ${ }^{34}$

Collaboration via social media can also unleash productivity gains in public procurement, particularly in the area of IT services and solutions. There are many examples of IT project failures, both in the public and the private sectors. A common risk factor is the length of IT projects because empirical evidence suggests that $25 \%$ of a project's initial requirements are outdated after just one

\footnotetext{
${ }^{32}$ Information from Australia's response to OECD survey, 2013; additional information: https://twitter.com/piawaugh/status/48894249479053312.

${ }^{33}$ Information from Canada's response to OECD survey, 2013.

${ }^{34}$ For more information see www.eufic.org/page/en/show/latest-sciencenews/page/LS/fftid/Proactive_social_media_strategies_can_enable_positive_engagement_with_target_audiences and_impact_government_policy.
} 
year. ${ }^{35}$ Such collaborative approaches to IT procurement are fully in line with the $O E C D$ Recommendation on Digital Government Strategies (OECD, 2014; Principle 11).

Several governments therefore turn to collaborative platforms for the procurement, design and development of (online) services. The growing popularity is illustrated by the rapid growth of the "government" category on GitHub, a major open source collaboration platform (Figure 16). In fact, the source codes of the government portals www.gov.uk (United Kingdom) and www.data.gov (United States) are freely available for re-use and adaptation. The governments of Australia and New Zealand have started re-using that source code to re-design their national government portals, thereby taking a drastically different approach to designing and implementing large-scale IT projects. ${ }^{36}$

Figure 16. Growth of the "government" category on GitHub, 2009-2012

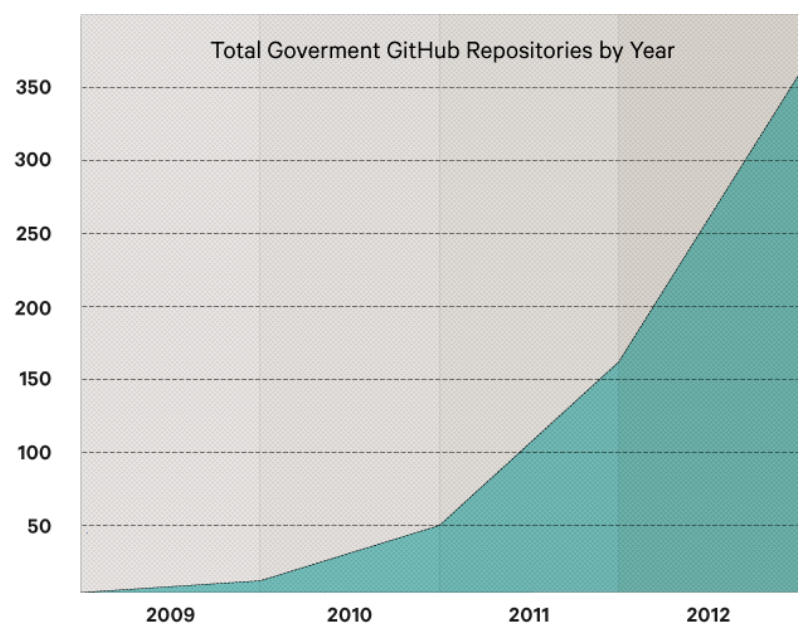

Source: www.wired.com/wiredenterprise/2013/01/hack-the-government.

Social media augment the collaboration and participation opportunities in the actual design and delivery of public services. Obviously, partnerships between the public sector and other stakeholders are nothing new per se and pre-date the technology trends discussed here (cf. OECD, 2008, 2011). But social media significantly lower the barriers to experimentation and organic development of collaboration. They stimulate the creation of platforms where government is no longer the exclusive authority for delivery of goods, services or information (cf. O'Reilly, 2010). An example of successful "platform thinking" is the city of Chicago, which set up the online platform www.ChicagoShovels.org as a volunteer-matching service that caters to residents such as the elderly or the disabled that live in areas the municipal services do not easily or quickly reach after heavy snowfalls.

Social media also have great potential in areas where co-delivery has a long tradition. In the wider sense this is the case with police work which always depended on the confidence and cooperation of citizens. The Spanish national police illustrates how genuine and continued social media engagement can be utilised for mission-critical success in the delivery of public services (see Box 5).

\footnotetext{
${ }^{35}$ From a presentation by Alexander Budzier, Senior Researcher at Said Business School, during the OECD E-Leaders 2013 meeting on 29-30 October, Bern, Switzerland, www.oecd.org/governance/eleaders.

${ }^{36}$ More information at http://australia.gov.au/about/beta-site (Australia) and www.govt.nz/about/govtnz/ (New Zealand).
} 


\section{Box 5. @Policia - Purpose-oriented social media use at the Spanish national police}

Policing heavily depends on people's confidence and co-operation to deliver an effective public service. The Spanish national police force (Cuerpo Nacional de Policía de España) early on identified the potential of social media. In 2009 it committed to using social media as an additional lever to improve their services. The commitment was backed up with financial and human resources, notably the recruitment of a social media expert, Carlos Fernandez, to lead the effort. Today, a dedicated team of ten people interacts on various social media platforms to prevent, dissuade and combat crime.

The Spanish police's constant and genuine engagement is catching on with the public. At the time of writing, the @Policia Twitter account has over 1.25 million followers (@Policia), its Facebook page has over 220000 fans (PoliciaNacional) and the videos on its YouTube channel were viewed over 5.6 million times (Policia).

A large part of this social media success is due to a deliberate choice of topics and style. Unlike many other government institutions, the Spanish police does not use social media for "corporate" communications such as relaying the agendas of its leadership or to issue traditional press releases. It rather uses social networks to support the police's primary mission by sending content-rich messages that use "plain" language, often humorous or provocative in order to attract a large audience (see the figure below for a "word cloud" of the fifty most recurrent terms in the police's social media messages).

Such genuine community interaction has led to several mission-critical successes. One of those was the recent arrest of a murderer who had been on the loose for months after his conviction in 2013. On 14 January 2014 the Spanish national police launched a co-ordinated media campaign with heavy use of social media to diffuse photos and information about the wanted individual. The posts went viral, i.e. they were replicated and diffused by a very large number of social media users, and triggered several citizen reports leading to the arrest of the convict - later the same day!

\section{Recurrent terms in the Spanish national police's social media messages}

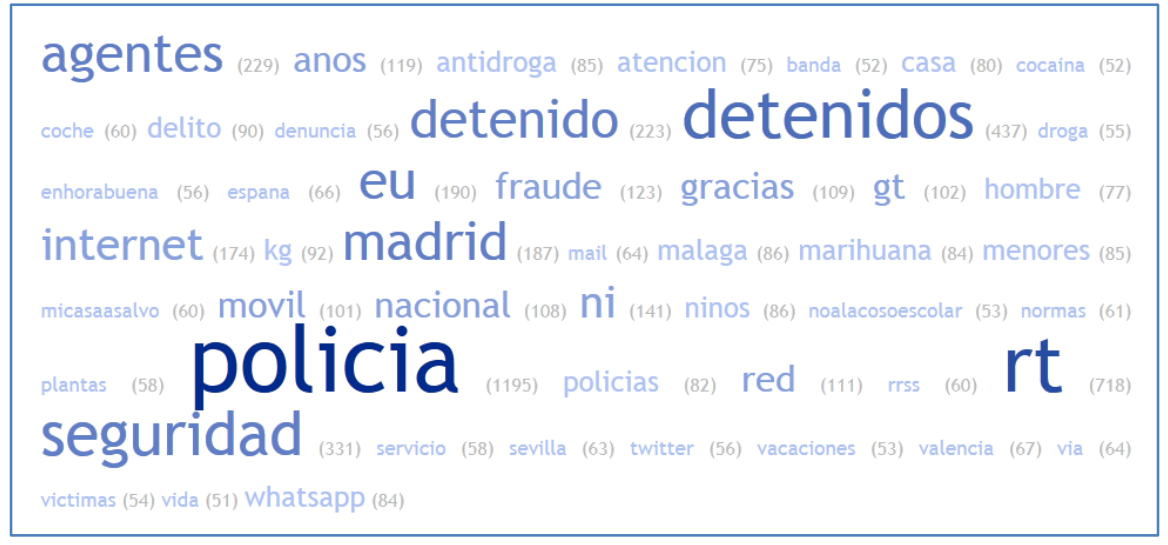

Note: Semantic analysis of 3,186 tweets emitted by @Policia between August 2013 and August 2014. The word cloud contains the fifty most recurrent terms. The frequency of each term is indicated in parentheses.

Source: Author's data extraction using www.twitonomy.com. Word cloud created using http://tagcrowd.com.

Source: Mickoleit, A. (2014); Fernández Guerra, C. (2014).

The risk of governments not embracing such "platform" thinking is simple: the barriers are coming down for individuals and non-government organisations to build their own communities of interest, which means they can increasingly bypass traditional processes and channels. The above examples, as well as the examples cited earlier in this chapter (the Latvian online petition platform to propose new legislation, the Marseille online petition that resulted in the revoking of a local authority decision), clearly show that people and organisations are going in that direction. Initiatives such as 
GovCamp in the United Kingdom illustrate how such action is also realised by civil servants that are unsatisfied with the status quo.

And there seem to be no boundaries to citizen-driven collaboration - it has even proven effective in the development of physical infrastructures. In the Dutch city of Rotterdam a community of citizens created strong social media buzz to rally for a pedestrian bridge over a route and train tracks. Unsatisfied with the initial local authorities' reactions, the community set up a crowd-funding initiative and garnered support from various public and commercial actors. As a result, construction of the "Luchtsingel" bridge started in 2012 and is planned to finish in 2014; the project today includes funding from the local authorities of Rotterdam. ${ }^{37}$

Understanding and anticipating user needs in service design and delivery. Social media open up channels to explicitly involve users in service design and delivery, as outlined above. But social media sometimes also make people implicitly participate in policy design and evaluation processes in the sense that governments mine and analyse social media interactions for analytical insights. Dutch government ministries have trialled monitoring activities in public online forums and social networks. The education and environmental ministries, as well as the national tax agency and the national employees' insurance agency were able to (cf. Bekkers et al., 2013):

- complement, and sometimes contrast, traditional methods of perception gauging such as surveys or user panels;

- anticipate emerging issues and conceive actions to avoid escalation;

- create a better image of agencies, notably in the case of the tax and customs agency;

- achieve perceived efficiency gains, although none of the departments was able to measure those.

Similar trials exist in other countries and other areas, including in the healthcare sector (see next sub-section). However, a common risk to monitoring and mining social media data for policy intelligence is that of perceived privacy breaches. As outlined earlier, public sensitivities to government investigation and "surveillance" are high in many countries. ${ }^{38}$ Government mining of personal data can even be resented when that data is supposedly in the public domain, e.g. interactions in online forums or publication of information on social networks.

To counter some of these resentments governments should be transparent about their social media monitoring and mining policies (including also use of social media data as part of law enforcement, see Box 5 earlier). Disclaimers that outline what data is being monitored and to what purpose can greatly improve comprehension by users. Moreover, governments can make the effort to distinguish and categorise different types of personal information and the degree of sensitivity people attach to those categories of information (cf. Bekkers et al., 2013).

The healthcare and public employment service sectors are further explored here because of their importance in national reform and economic stimulus plans across OECD countries. Crisis and

\footnotetext{
${ }^{37}$ For more information see www.luchtsingel.org.

38 In fact, public sensitivities to mining social media activities concern not only government but also companies as illustrated by ongoing debates around "experiments" by Facebook and OKCupid. See www.huffingtonpost.com/josephfarrell/why-okcupids-experiments-_b_5655217.html.
} 
emergency communications also hold high potential for social media use and are treated in detail in a separate report (cf. Wendling et al., 2013).

\section{Healthcare service delivery}

Healthcare provision is changing dramatically under the influence of the Internet and related technologies: ${ }^{39}$ looking for healthcare information on the Internet has become a standard activity (44\% of Europeans do so) $;^{40}$ online forums are popular places for exchanges around healthcare; new treatment opportunities such as remote medicine applications benefit from the rapid diffusion of broadband Internet, mobile and "smart" devices.

However, digital opportunities are not equally realised across countries. There is surely a link between the satisfaction of people with the national healthcare quality and their use of the Internet to look for healthcare-related information (Figure 17). But still, even in countries where satisfaction levels are very high, i.e. they surpass $80 \%$, no more than 50 to $60 \%$ of people use the Internet as a source for healthcare information. The reservation is partly due to lack of confidence in the Internet as a reliable source for healthcare information, as well as the very important patient-practitioner relationship. Considering, however, the strong cost reduction pressures to which national healthcare sectors are submitted, there is arguably still a lot of space for public healthcare actors to leverage the Internet as part of their service delivery strategies.

Figure 17. Plotting healthcare satisfaction with Internet use to obtain healthcare information, Europe, 2013

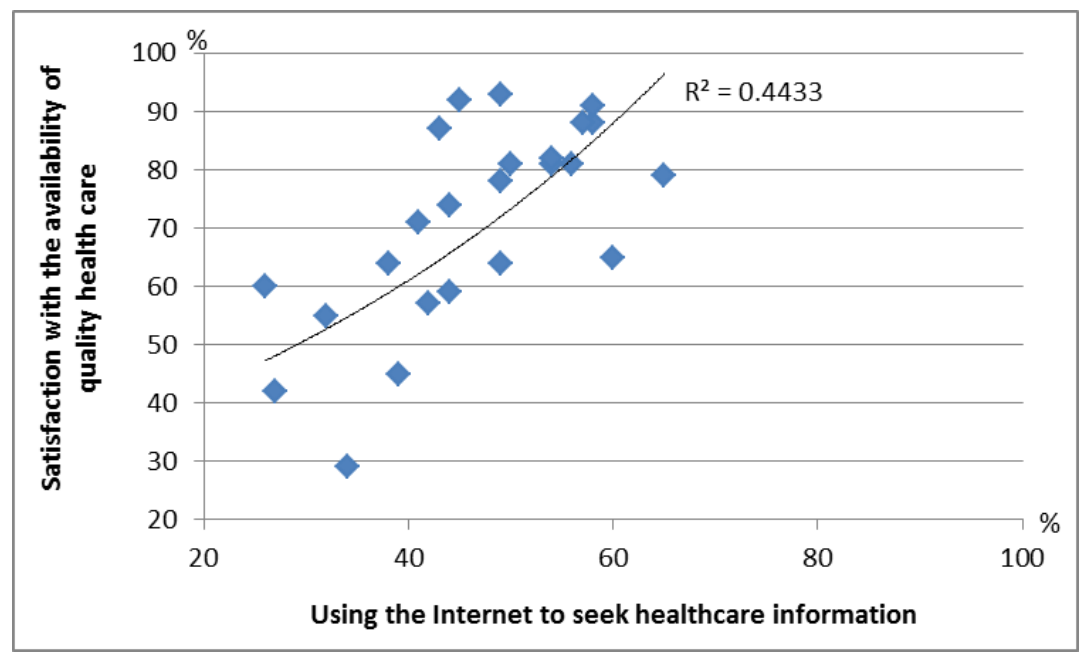

Source: Gallup WorldPoll, cited in OECD, 2013a (vertical axis); Eurostat, 2013 ("Individuals using the Internet for seeking health information (Tin 00130)" (horizontal axis).

Social media have also entered the area of healthcare, although this is today primarily a channel for exchange between practitioners, experts and corporations. Commercial social networks such as www.doctors.net.uk or www.sermo.com count hundreds of thousands of active members. Connecting

\footnotetext{
${ }^{39}$ For a more comprehensive overview of current trends in ICT and healthcare, see OECD (2013), ICTs and the Health Sector: Towards Smarter Health and Wellness Models, OECD, Paris.

402013 data for EU-27, extracted from Eurostat Information Society statistics, indicator "Individuals using the Internet for seeking health information (Tin00130)"
} 
doctors and patients, however, meets a lot of hesitation. Trials exist, e.g. in the United States where doctors use social media to provide patients explanations, educate them or improve individual care (Saleh et al., 2014); or in Denmark, where researchers identified several potential impact domains for social media at both the individual and the collective level of healthcare (Table 8).

Table 8. Potential social media impacts in healthcare at the individual and the collective level

\begin{tabular}{|c|c|}
\hline Individual level & Collective level \\
\hline $\begin{array}{l}\text { - } \quad \text { More effective health information retrieval } \\
\text { - } \quad \text { Empowered and well-informed patients } \\
\text { - } \quad \text { Increased transparency } \\
\text { - } \quad \text { Practitioners' reluctance to post on social media due to } \\
\text { - } \quad \text { Verceived un-professionalism or fear of lawsuit } \\
\text { - } \quad \text { Unintended consequences of exposure to health- } \\
\quad \text { related information through social media }\end{array}$ & $\begin{array}{l}\text { - } \quad \text { Gains on overall reduction in cost due to } \\
\text { crowdsourcing } \\
\text { - } \quad \text { Channel cost savings } \\
\text { - } \quad \text { Connecting peers, families and patients in new } \\
\text { - } \quad \text { Use of the stored data for research } \\
\text { - } \quad \text { Overall well-being improvement }\end{array}$ \\
\hline
\end{tabular}

Source: Andersen et al., 2012.

A sometimes overlooked target group in this field are seniors. Given the pressures of ageing society though, more and more digital initiatives focus on healthcare service delivery to the elderly. And it does indeed make sense, for example in Japan or the United States where more than half of over 65 year olds use the Internet (MIC, 2013; PewInternet, 2012). And the elderly are catching up in social media use too. Although uptake rates are still relatively low, they are growing fast and reach $20 \%$ and more for people over 65 in Korea, Iceland, Norway and the United Kingdom (Figure 18). Numbers are even higher for 55 to 64 year olds, an age bracket that includes many soon-to-be retired people.

Figure 18. Uptake of social media by senior age groups, 2013

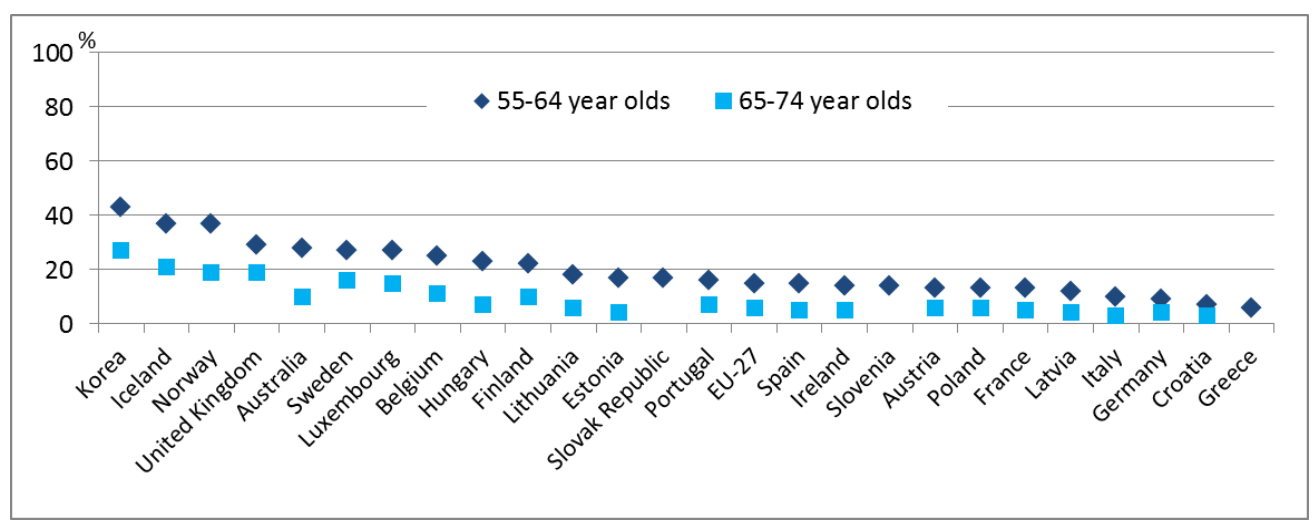

Note: Age brackets are different for Australia (50-64 year olds, over 65 year olds) and Korea (50 to 59 year olds, over 60 year olds).

Source: Eurostat, 2013, "Internet use: posting messages to social media sites or instant messaging". Except for Australia: AIMIA, 2013, "Yellow social media report"; and Korea: KISA, 2013, Survey of Internet usage.

Overall, however, acceptance of social media use is still low with both practitioners and patients. On the side of practitioners, reservation results from the uncertainties on ethical and legal consequences that social media interactions with patients can have (cf. Andersen et al., 2012). On the side of patients, reservation is mainly due to protection of privacy and the control over personal data. Especially initiatives to mine individuals' healthcare data - even in aggregated and anonymised forms - are met with strong opposition as recently experienced by the care.data project in the United 
Kingdom (see also Volpe et al., 2013). ${ }^{41}$ Initiatives to improve patients' control over data re-use are underway, e.g. the "Blue Button" project in the United States. Success of such initiatives will to a large degree determine patients' confidence in social media and Internet-based healthcare services.

\section{Public employment services}

Employment services too are undergoing major transformations due to the Internet. Half of Europe's unemployed use the Internet to support their return to employment (Figure 19). In fact, the quasitotality of job seekers use the Internet to look for jobs or send applications in Sweden (90\%); rates are also very high in the Netherlands, Iceland, Norway, Estonia, Austria and Finland (between 70 and $80 \%)$.

Figure 19. Share of unemployed who use the Internet to look for jobs or send an application, Europe, 2013

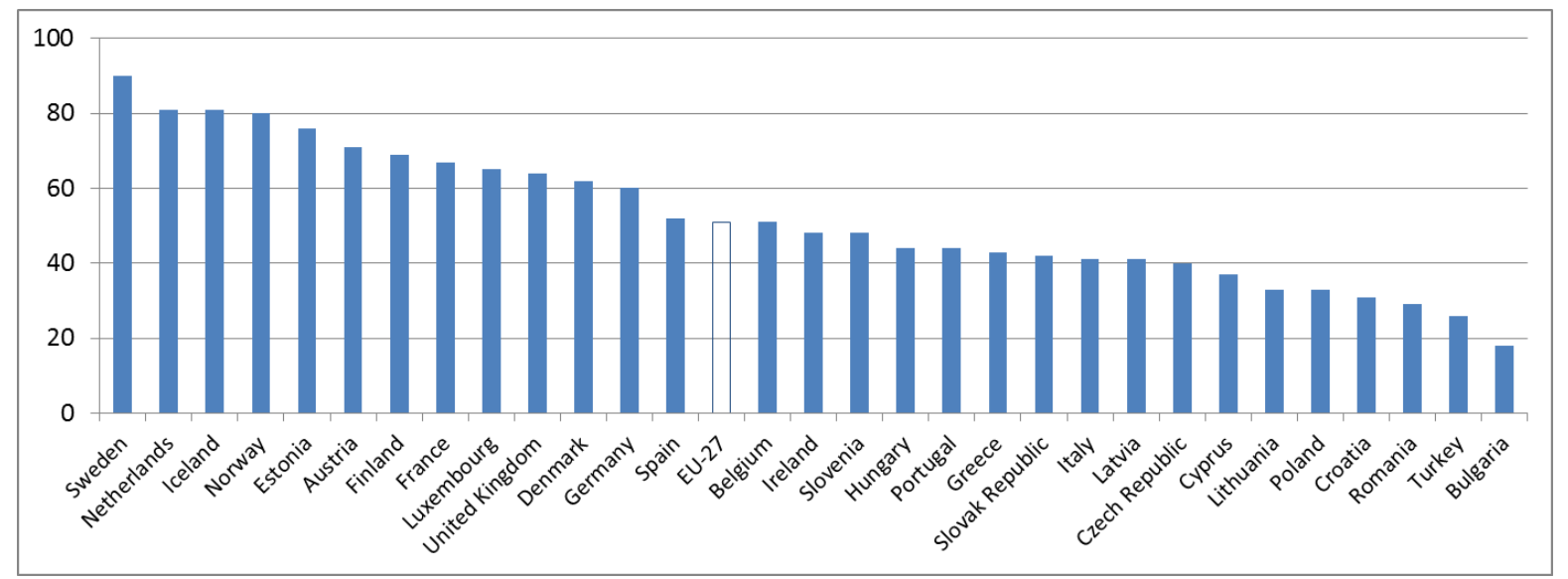

Source: Eurostat, 2013, "Individuals using the Internet for looking for a job or sending a job application".

Social media are further accelerating the transformation of digital strategies that job seekers and employers devise. Sure enough, websites like Indeed.com, Monster and CareerBuilder remain the world's most popular online job platforms. But their dominance is being challenged by career-oriented social networks such as LinkedIn, Xing and viadeo, as well as generalist social media such as Facebook and its "Social Jobs Partnership". A survey for the United States reports that most job seekers (40\%) still their find jobs through personal connections, e.g. referrals; but the second-best sources for finding jobs are to equal degrees online social networks $(21 \%)$, online job sites $(20 \%)$ and classified ads (19\%) (Jobvite, 2014).

This changing reality creates both opportunities and challenges for providers of public employment services (PES), e.g. government job centres. PES providers can leverage the Internet and social media to better activate job seekers and to provide employers with more targeted services.

But many national PES providers have been slow to adapt to the emergence of today's digital and multi-actor environment. As a result, the perceived relevance of public employment agencies varies strongly across countries: it is very high in Croatia, Lithuania, the Czech Republic, the Slovak Republic and Germany where at least $80 \%$ of job seekers consult their national public employment

${ }^{41}$ For more information on the "care.data" project, see www.wired.co.uk/news/archive/2014-02/26/demand-transparencyfrom-nhs. 
agency; but it is very low in Italy, Spain and Turkey where less than one third of job seekers do so (Figure 20). ${ }^{42}$

Figure 20. Share of unemployed who contacted national public employment services, Europe, Q3 2013

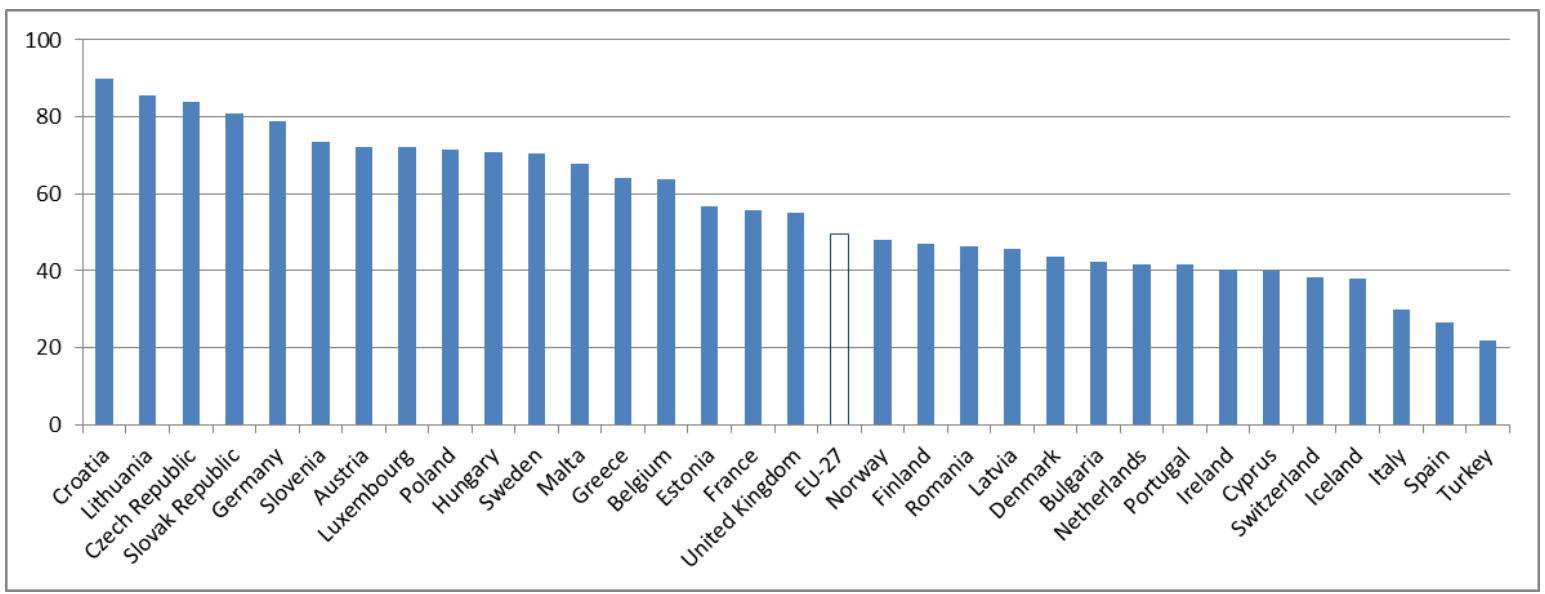

Source: Eurostat, 2013, "Methods used for seeking work: Percentage of unemployed who declared having used a given method: [contacted national public employment services]".

So the context is one where the Internet is integral to job seekers' and job advertisers' strategies, and where some national public service providers have lost their exclusive position in the market. A crosstabulation of these two factors (use of the Internet by job seekers; perceived relevance of national PES) makes patterns emerge that point towards different ways in which national PES can leverage the Internet and social media to support their core mission (Figure 21; specific actions, however, require careful consideration for other context factors that are not covered here).

\footnotetext{
${ }^{42}$ For more information on the perceived relevance of employers and job seekers of a specific national PES provider, Pôle Emploi, and on its digital initiatives see chapter on "The RGPP and the quality of service" in OECD, 2012, Public Governance Reviews: France, OECD, Paris.
} 
Figure 21. Plotting different strategies of the unemployed - contacting public employment services and using the Internet to look for a job, Europe, 2013

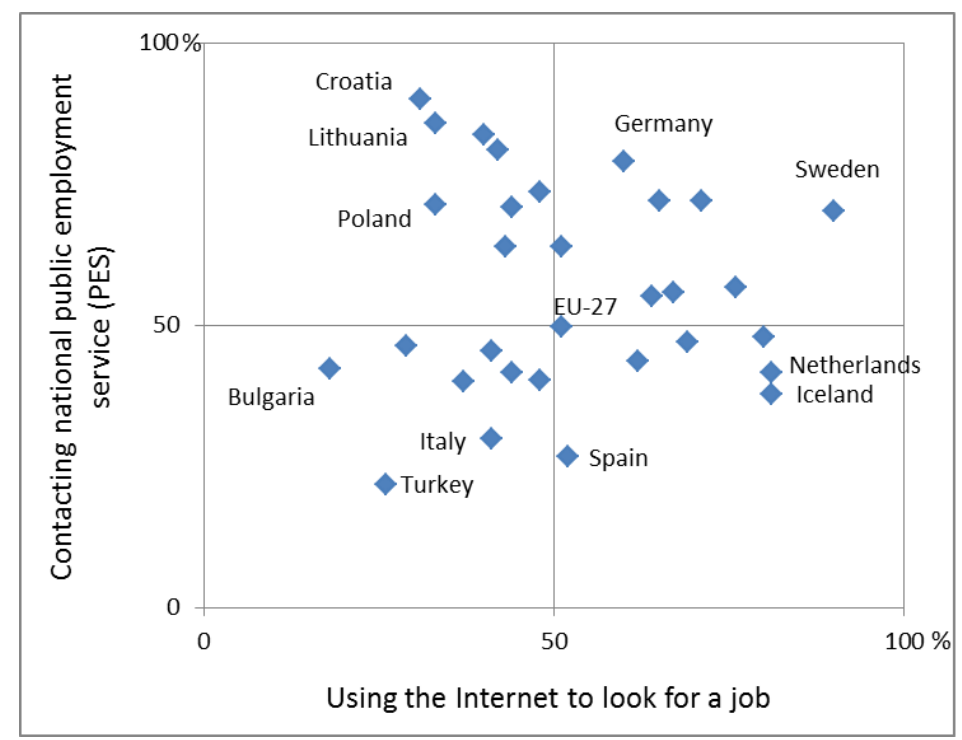

Source: Eurostat, 2013, "Methods used for seeking work: Percentage of unemployed who declared having used a given method" (vertical axis) and "Individuals using the Internet for looking for a job or sending a job application" (horizontal axis).

- Countries in the lower left quadrant (e.g. Bulgaria, Italy, Turkey) face challenges that social media are unlikely to alleviate in the short term: low levels of consultation of the national PES by job seekers and low shares of job seekers who use the Internet for job searches. Activating job seekers and increasing the perceived relevance of the PES in this group of countries requires choices that go beyond the scope of this paper.

- Countries in the upper left quadrant (e.g. Croatia, Lithuania, Poland) have high levels of domestic PES consultation by the unemployed. But only few job seekers use the Internet as part of their job searches. This indicates potential for the domestic PES providers to develop targeted programmes that enable and encourage the unemployed to integrate the Internet and social media into their job searches and skills development.

- Countries in the lower right quadrant (e.g. Spain, Netherlands, Iceland) show belowaverage levels of PES consultation by job seekers (as low as $27 \%$ in Spain). At the same time, more than half of the unemployed in those countries use the Internet to look for jobs (as many as $81 \%$ in Netherlands and Iceland). In these countries there seems to be quite some potential for domestic PES to use social media to more effectively support job seekers.

- Finally, countries in the upper right quadrant (e.g. Germany, Sweden) have relatively high consultation rates of the domestic PES by job seekers, as well as high numbers of unemployed who use the Internet use to look for jobs. These countries can be sources for good practices on how PES can leverage social media to support their main mission, i.e. bringing people into employment (see an example from Germany in Box 6). 


\section{Box 6. Public employment services 2.0 in Germany: Bundesagentur für Arbeit}

The German public employment service (PES) provider, Bundesagentur für Arbeit (BA), has shown good context awareness and purpose orientation in its choices of social media use. Instead of allocating many resources towards a social media presence that mainly communicates press releases - the BA does not have an organisation-specific Facebook page and only operates a low-key Twitter account to broadcast news items - the German PES found ways to more effectively use social media to serve its main clients: job seekers overall, young people specifically, and job advertisers.

The BA displayed particularly good "out of the box" thinking when entering a co-operation agreement with the online professional and careers network Xing in 2012. The choice was based on analysis of the local context: Xing is conceptually similar to Linkedln but counts on a larger user base in German-speaking countries than its US-based competitor (around half of Xing's 13 million global users reside in Germany, Austria and Switzerland). In practical terms the co-operation between BA and Xing means that employers who post a vacancy on Xing can opt in to also publish their vacancy at the BA's online jobs database "Jobbörse" - just by ticking a checkbox. Job seekers that consult these vacancies on the Jobbörse are in turn routed to Xing where they can use the platform's social networking services to engage with other users, e.g. to enquire about the vacancy or the employer.

Sources: http://personalmarketing2null.de/2012/12/12/bundesagentur-arbeit-2-0-unternehmen-arbeitsagentur-xing-twitterfacebook/; http://bildungsklick.de/pm/86231/bundesagentur-fuer-arbeit-und-xing-ag-starten-kooperation; http://www.socialmediastatistik.de/xing-mit-guten-quartalszahlen-wieder-mehr-zahlende-mitglieder/) 


\section{MANAGING THE NECESSARY CHANGE IN GOVERNMENT TO CREATE IMPACT}

The previous sections provided empirical baselines and an exploration of major opportunities and challenges in using social media to support the core mission of public sector organisations. This final section before the conclusion pinpoints the main practical issues governments need to consider when managing the change towards public administrations that use social media part of their mission.

\section{Formulating objectives and expectations}

Government institutions should not shy away from setting objectives or at least formulating expectations they have regarding the impact of their social media use. This can include exploring what similar institutions have done. Objectives can be adapted along the way, including through iterations of feedback gathered from employees and service users (see Box 1 for Chile's experience in building a social media strategy through various iterations).

A fundamental question that will arise at some point is whether the main objective is to use social media for simple communications, i.e. a "push" strategy, or whether to use them to support the core mission of the institution, which will typically require other types of resources and commitment to engagement, i.e. a "pull" or "networking" strategy (cf. Mergel, 2010).

In either case, government institutions should not feel pressured to be present or active in every aspect and on every platform. Aggressive branding of an institution is not always the best way forward. Social media can add value by simply encouraging and using community dynamics, e.g. in the way the German public employment agency does through its partnership with the social network Xing (see Box 6). Even in the private sector, corporate social media efforts are not always primarily geared towards communicating a brand or corporation. They sometimes focus on specific services and leverage community dynamics instead (See Box 7 on Apple's social media tactics). 


\section{Box 7. Social media @ Apple - focus on promoting services, not the corporation}

Apple is one of the most valued brands and companies in the world. It might therefore come as a surprise that Apple as a company keeps a low profile on social media. There is no official corporate Facebook page, just an automatically generate presence with over 25 million "likes" but no activity at all by the company (https://www.facebook.com/pages/Apple-Inc/105596369475033). No visible corporate account exists on Twitter either. Apple only has a more active presence on Linkedln to diffuse job adverts.

However, this should not lead to the conclusion that Apple does not use social media to support its business. Some of the company's atypical use of social media can be an inspiration to governments given that just like many governments, Apple is a relatively large and heterogeneous organisation, offers a wide and diverse range of goods and services, and is part of a complex eco-system of clients, suppliers and partners.

So, instead of creating a social media presence around the corporation, what Apple has done is to establish social media presences of specific services that add value to its business operations, for example:

- AppStore, the company's content platform for the iPhone, iPad and other devices.

- $\quad$ iTunes, the company's entertainment platform for digital music, films and other content.

- Country-specific satellites such as, e.g. iTunesJapan.

- $\quad$ iBooks, a dedicated service for e-books.

- $\quad i T u n e s U$, a platform for education-oriented services.

Another noteworthy element is that Apple operates no dedicated social media presence for either the iPhone or the iPad, two of its flagship products. Instead, Apple uses the marketing of its content services to also drive sales of its hardware products. Moreover, Apple's main vehicle for commercial messages are individual users and the media, but not really the corporation itself. The company creates marketing campaigns that aim for messages to become viral, i.e. be replicated by a large number of people and media outlets online and offline. That way, Apple utilises community dynamics to promote demand for its products and services.

\section{Governance and guidelines}

It is important to define responsibilities for social media use across government. Particularly when it comes to conflicts that need a clear answer or flows of information during a crisis situation, it needs to be clear if individual ministries or agencies resolve this within their authority or whether there is an overarching governance mechanism.

The majority of responding governments exercise little central control and steering of social media use. 14 out of 25 governments indicate having "very dispersed" or "rather dispersed" approaches, which means responsibilities for setting and implementing policies lie with individual government ministries, agencies and departments (Figure 22 and Table 9). 
Figure 22. Central government approaches to control and steering of social media use

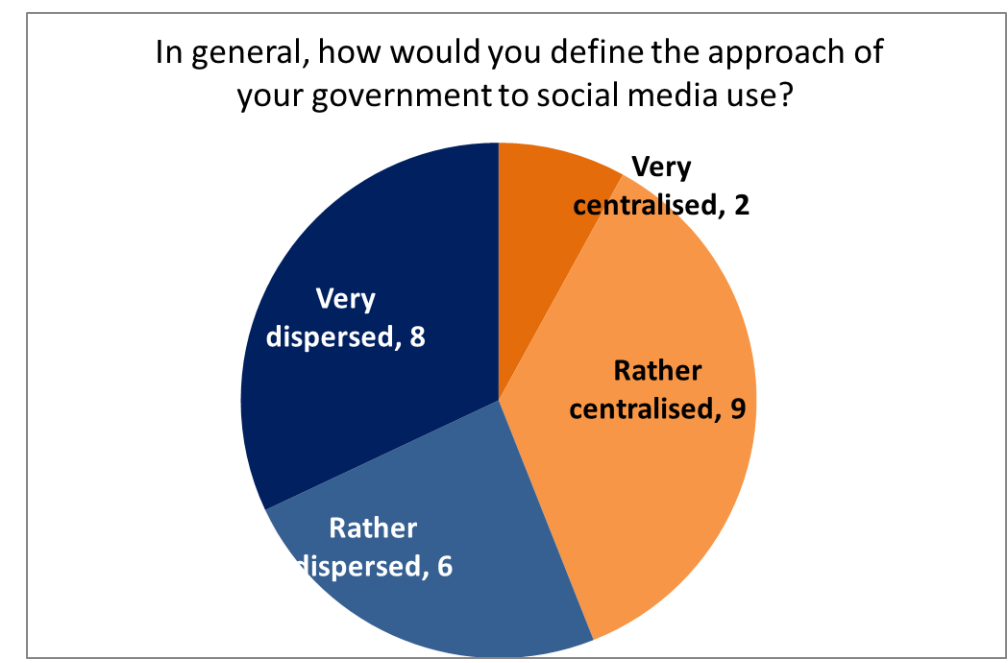

Source: OECD (2013b), "Survey on government use of social media".

Table 9. Central government approaches to control and steering of social media use

\begin{tabular}{|l|l|l|l|}
\hline Very dispersed & Rather dispersed & Rather centralised & Very centralised \\
\hline Belgium & Poland & Austria & Canada \\
\hline Spain & Turkey & Estonia & Colombia \\
\hline Switzerland & New Zealand & Australia & \\
\hline Czech Republic & Finland & Sweden & \\
\hline Japan & Iceland & Chile & \\
\hline Denmark & Ireland & Korea & \\
\hline Portugal & & Netherlands & \\
\hline Slovenia & & France & \\
\hline & Norway & \\
\hline
\end{tabular}

Source: OECD (2013b), "Survey on government use of social media".

But even in countries that consider their approaches as being centralised ("rather" or "very"), individual ministries have a great degree of autonomy in designing and implementing social media policies. In most of these cases an over-arching policy is developed by an institution situated at the centre of government and contains a mix of the following (see also Box 8):

- codes of conduct for institutions and/or individuals (i.e. what to do or not to do when using social media as an institution or as an official);

- hands-on guidance, manuals, checklists and similar resources to support social media plans of individual institutions;

- guidance for skills development and community-based exchanges of good practices. 


\section{Box 8. Institutional responsibilities for social media use in OECD countries}

The following sub-set of countries indicates having a "rather" or "very centralised" approach to social media use in government. Responsibilities are typically shared between an institution at the centre of government and individual government ministries or departments.

Australia: The Australian Public Service Commission (APS) issues a code of conduct for all government officials (www.apsc.gov.au/publications-and-media/current-circulars-and-advices/2012/circular-20121). Beyond that individual departments and agencies tailor social media policies to their specific functions and requirements.

Austria: Led by the Federal Chancellery, an inter-ministerial working group develops the strategy in cooperation with external social media experts. Each government institution remains autonomous as to the implementation of the strategy.

Canada: The Treasury Board of Canada is responsible for issuing policies and guidelines for official institutional or personal accounts. This includes a government-wide standard on social media account management (www.tbs-sct.gc.ca/pol/doc-eng.aspx?id=27033\&section=text) and a YouTube video providing guidance about social media at work (www.youtube.com/watch?v=JRvY1SzWhl0).

Chile: Central guidelines are issued by the Ministry Secretariat of the Presidency (www.guiadigital.gob.cl/plataformas-sociales). They include various documents, including a code of conduct and checklists to guide incorporation of social media into agencies' communication strategies.

Colombia: A "digital task force" at the Ministry of ICT is responsible for developing and overseeing the government's social media strategy and guidelines, which are available at www.gobiernoenredes.co.

Estonia: The Government Office under the Prime Minister coordinates all social media policy and communication across the government, e.g. the code of conduct for government officials.

France: The Government Information Service (Service d'information du Gouvernement, SIG) under the Prime Minister issues guidelines for social media use by central government institutions.

Korea: The Ministry of Security and Public Administration (MOPAS) is responsible for the "Government 3.0 Action Plan", which also contains the strategy for social media use in the public sector (https://www.gov30.go.kr/gov30/index.do). Further to that, individual public agencies and local governments develop custom guidelines for social media use.

Netherlands: The Minister of General Affairs issues a general set of guidelines for social media use that is then adapted by individual ministries.

Norway: Government-wide guidelines are issued by the Norwegian Agency for Public Management and eGovernance (Difi) under the Ministry of Government Administration, Reform and Church Affairs (FAD) (www.difi.no/sosiale-medier/veileder-i-sosiale-medier).

Sweden: The eGovernment Delegation issues guidelines that can be further tailored by individual government agencies.

Source: Adapted from OECD (2013b), "Survey on government use of social media".

Several governments have established central guidelines for the use of social media, but to different degrees for different target groups (Figure 23). A majority (16 out of 25) have governmentwide guidelines in place for official institutional accounts, e.g. a Facebook accounts of a specific ministry or department. Fewer (12 out of 25 ) have guidelines that determine what individual civil servants are expected to do and not do when they use social media in their personal capacity, e.g. how to make reference to their situation as civil servant or how to treat information obtained as a civil servant. Only a small number of governments have guidelines in place for politicians, i.e. elected leaders or political appointees. 
Figure 23. Social media guidelines in OECD governments

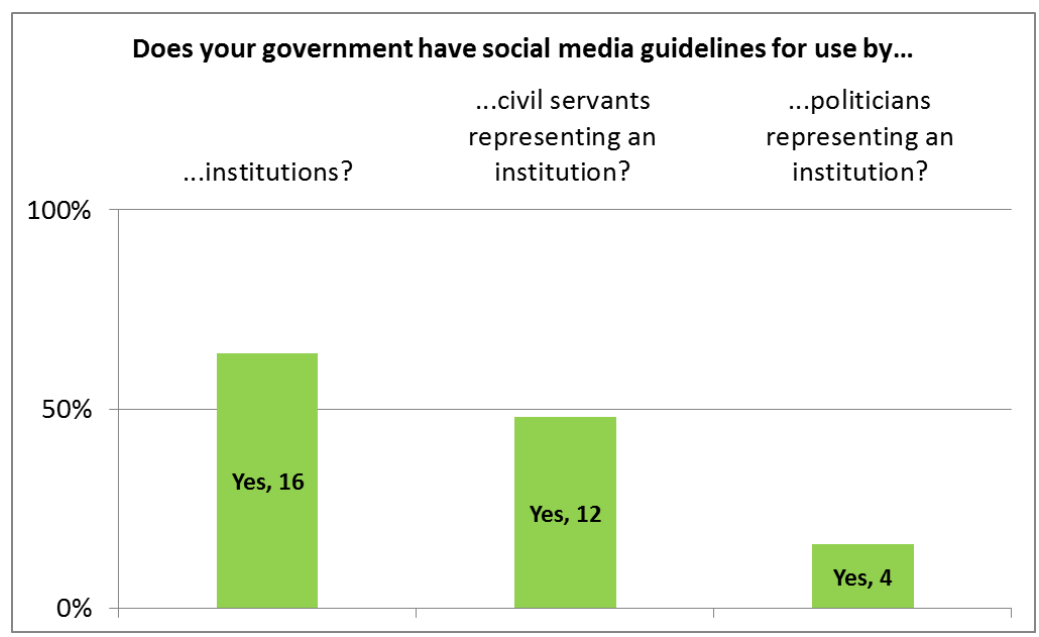

Source: OECD (2013b), "Survey on government use of social media"; multiple answers allowed.

The content of these government social media guidelines differs from country to country but a common trait is the focus on risks and benefits (Figure 24). Avoiding and managing potential risks e.g. to reputation or to security - is a concern for most governments today (13 out of 16 respondents). Also of importance are: outlining benefits (10), stating objectives (8) and indicating tactics on how to attain those objectives (8). Information on how to actually measure the impacts or assess the financial implications is hardly included in central government guidelines (more on this further below).

Figure 24. Content of government social media strategies and guidelines

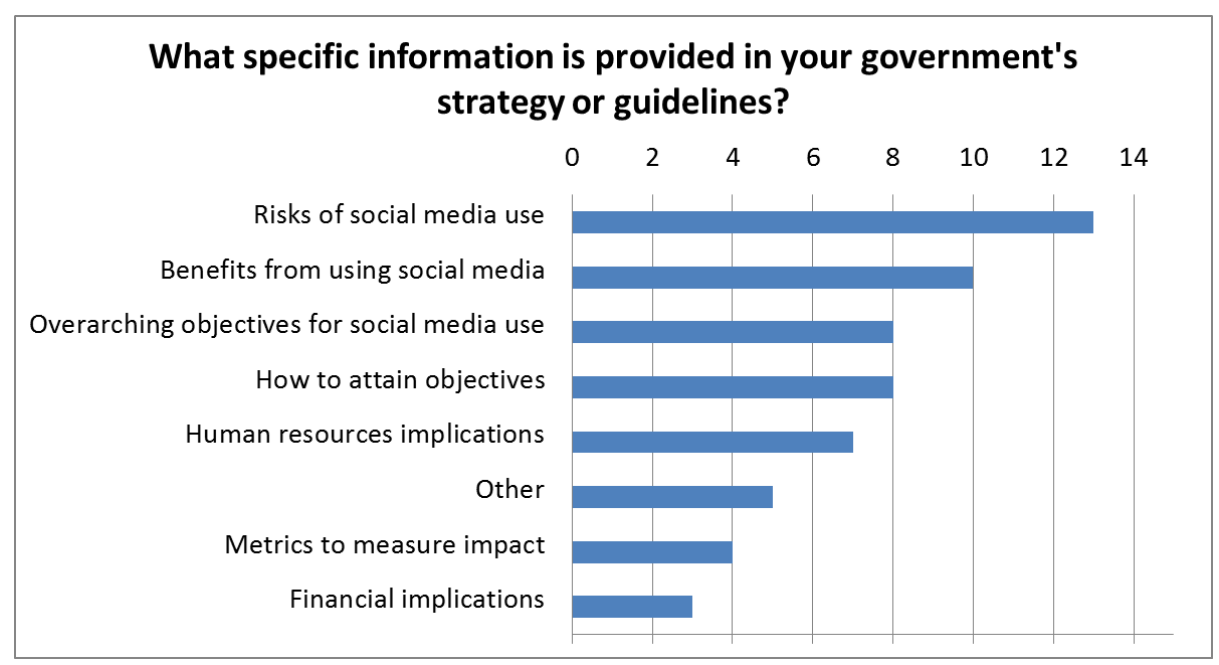

Note: Out of 16 countries that have an explicit strategy or guidelines in place; multiple answers allowed.

Source: OECD (2013b), "Survey on government use of social media".

The way responsibilities are distributed within individual government ministries or departments can have implications on the social media tactics. Comparing individual US government departments, Mergel identifies three archetypes for the location of main social media responsibility: 1) IT department, 2) public affairs office, 3) policy office. The resulting tactics, use and resources are quite different and provide some guidance for decisions on the assignment of social media responsibilities (Table 10). 
Table 10. Social media adoption tactics across the US federal government

\begin{tabular}{|c|c|c|c|c|c|c|c|}
\hline Location & Strategy & $\begin{array}{l}\text { Business } \\
\text { value }\end{array}$ & Tactic & Policy & \# of accounts & Resources & Information vetting \\
\hline IT ${ }_{\text {department }}$ & Representation & $\begin{array}{l}\text { Informational } \\
\text { broadcasting }\end{array}$ & Push & $\begin{array}{l}\text { No interactions allowed, } \\
\text { commenting disabled }\end{array}$ & $\begin{array}{l}\text { One account for } \\
\text { the whole agency }\end{array}$ & None & $\begin{array}{l}\text { Typical information clearing } \\
\text { process as for any public } \\
\text { statement }\end{array}$ \\
\hline $\begin{array}{l}\text { Public affairs } \\
\text { office }\end{array}$ & Engagement & Educational & Pull & $\begin{array}{l}\text { Dedicated social media } \\
\text { policy (i.e., commenting } \\
\text { policy) }\end{array}$ & $\begin{array}{l}\text { Official public } \\
\text { affairs } \\
\text { account plus } \\
\text { agency accounts }\end{array}$ & $\begin{array}{l}\text { Dedicated social media } \\
\text { department, incl. staff and } \\
\text { budget }\end{array}$ & $\begin{array}{l}\text { Information vetting for } \\
\text { repurposed statements; } \\
\text { ad hoc interactions }\end{array}$ \\
\hline $\begin{array}{l}\text { Knowledge } \\
\text { experts }\end{array}$ & Mingling & $\begin{array}{l}\text { Transactional \& } \\
\text { empowering }\end{array}$ & Networking & $\begin{array}{l}\text { Open exchanges with } \\
\text { social media guidelines }\end{array}$ & Unrestricted & $\begin{array}{l}\text { Dedicated social media } \\
\text { department, incl. staff and } \\
\text { budget } \\
\text { Plus expert accounts }\end{array}$ & $\begin{array}{l}\text { Information vetting for } \\
\text { repurposed statements; } \\
\text { ad hoc interactions; } \\
\text { "responsible" exchanges }\end{array}$ \\
\hline
\end{tabular}

Source: Mergel, 2013b.

\section{Legal compliance}

An important issue to consider are legal requirements for government institutions to comply with when using social media. Particular issues that frequently arise are:

- Official record keeping. In some countries public sector institutions are required to keep a record of all official or external communications. Australian state governments have such obligations and needed to review whether and how they apply to authorities' activities on social media. ${ }^{43}$ Sometimes more general agreements can provide a shortcut, e.g. the United States' Library of Congress commitment to archive all tweets ever emitted since 2006, which in fact creates an official keeper of record.

- Disclaimers. Governments should clarify what the social media presence is and is not about in order to address issues of liability ex ante. Especially in sensitive areas such as policing, healthcare or emergency responses it is important to indicate, e.g. whether accounts are monitored 24/7 and whether alerts are treated equal to other established emergency channels such as phone hotlines.

- Privacy. Personal data is typically subject to legal and regulatory requirements at domestic and international levels. It is therefore important to understand the remits within which feedback received via social media constitute such personal data and what the domestic requirements are for processing and storing such data.

- Accessibility. Government departments are usually bound to specific accessibility requirements for services or information. In some instances social media communications will need to be adapted to comply with provisions for users with special needs.

- Intellectual property. Use and re-use of third-party content needs to be in line with existing legal provisions for intellectual property protection. This requires understanding possible implications for the re-use of pictures, data or text passages in social media messaging.

\footnotetext{
${ }^{43}$ For more information see http://blog.delib.net/social-media-record-keeping-for-government-\%E2\%80\%93-is-it-necessary.
} 


\section{Skills and resources}

Entry costs to social media use are relatively low, but sustained activity does require dedication of human, organisational and financial resources. A 2013 survey of municipalities in the United Kingdom indicates that $40 \%$ of them devote one full-time equivalent or more per week to maintain their social media presence (BDO, 2013).

Greater use of social media also raises questions about the resource implications and yielded returns. An audit of the United States State Department found that the institution spent over USD 600 000 for two social media campaigns whose primary purpose was to increase the institution's "fan base" on Facebook and Twitter. The audit considered that the efforts had no direct relevance for the core mission of the institution and thus recommended re-directing resources towards the support of more specific institutional objectives. ${ }^{44}$

Identifying and developing the necessary human and financial resources to support a social media strategy is no easy task. The OECD survey shows that only 8 out of 25 responding governments have specific strategies or plans to develop civil servants' skills in this area (Figure 25). As for financial benefits, a survey in the United Kingdom reports that two thirds of municipalities believe they achieve financial benefits from social media use - although none of them has been able to demonstrate those benefits yet (BDO, 2013).

\section{Figure 25. Skills strategies for government social media use}

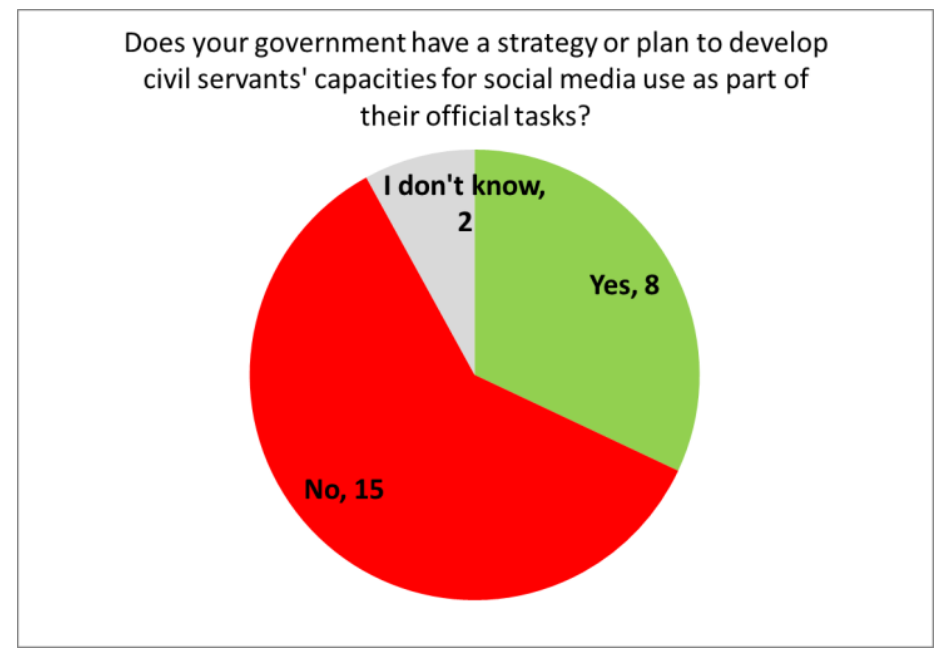

Source: OECD (2013b), "Survey on government use of social media".

Developing the right skills sets for social media use in the public sector resonates with wider public sector challenges around digital government and human resources management. Many governments face the challenge of developing the right skills and capacities to reap returns on public sector digitisation efforts. The account of a job advert by the United Kingdom Department for Business, Innovation and Skills (BIS) serves to illustrate the general trend (see Box 9).

\footnotetext{
${ }^{44}$ The audit report is available at http://washingtonexaminer.com/state-department-bureau-spent-630000-on-facebooklikes/article/2532629.
} 


\section{Box 9. The challenge of acquiring the right social media skills, an example from the UK Government.}

The following is an extract from a blog post published by a recruiting manager at the UK Department for Business, Innovation and Skills (BIS) in January 2013. It accompanies the official vacancy description and illustrates the challenge many governments are facing in recruiting, developing and retaining the right skills to make digital government and social media initiatives support core government purposes:

"I'm lucky to work with a well-rounded team: information publishing, planning, writing, editing, audio, visual, engagement. It's all in there. We have some useful official channels and the ability to create lots of different types of digital content in-house.

We often work with external partners or networks, to help facilitate the conversations we need to have with our audiences. Twitter Q\&As with professional associations, original content on news websites and discussions on Linkedln are all good examples.

These examples are, however, the exception rather than the rule. More often than not we're battling deadlines and a limited capacity within the team, which means we come to rely on our corporate channels. We put a lot of effort into driving people to BIS's official online presence, when in fact, if my online behaviour is anything to go by, very few people want to follow, like, comment on, or share an official corporate channel.

What we need is someone who can deliver opportunities to work with the communities and types of content that our audiences are really interested in. We want to work with forums, bloggers, hashtags, influencers and communities, to help get more people interested in the policies that affect them and raise awareness of the information that Government provides."

Source: Extracted from http://clearmessage.wordpress.com/2013/01/21/digital-engagement-where-it-really-matters/.

Some governments actively develop the digital and social media skills of civil servants. In Australia, the APS Code of Conduct encourages agencies to do so and the Department of Finance runs social media courses. ${ }^{45}$ These efforts are part of a larger strategy by the Australian Public Service to attract, retain and develop the right people to drive digital public services reforms. ${ }^{46}$

\section{Collaboration and communities}

The newness of the medium results in a lot of uncertainty about the conditions required to meet objectives. To deal with these uncertainties, governments establish communities of practice that foster exchange and collaboration across institutions. The majority of governments (15 out of 25 observed) established some formal co-ordination mechanism for government institutions and their social media practitioners (Figure 26). Box 10 provides some examples.

\footnotetext{
${ }^{45}$ For more information see www.apsc.gov.au/publications-and-media/current-circulars-and-advices/2012/circular-20121 and http://agict.gov.au/blog/2013/07/10/online-engagement-courses-\%E2\%80\%93-final-report.

${ }^{46}$ For more information see www.finance.gov.au/collaboration-services-skills/ict-skills.
} 
Figure 26. Government co-ordination mechanisms for exchange of social media experiences

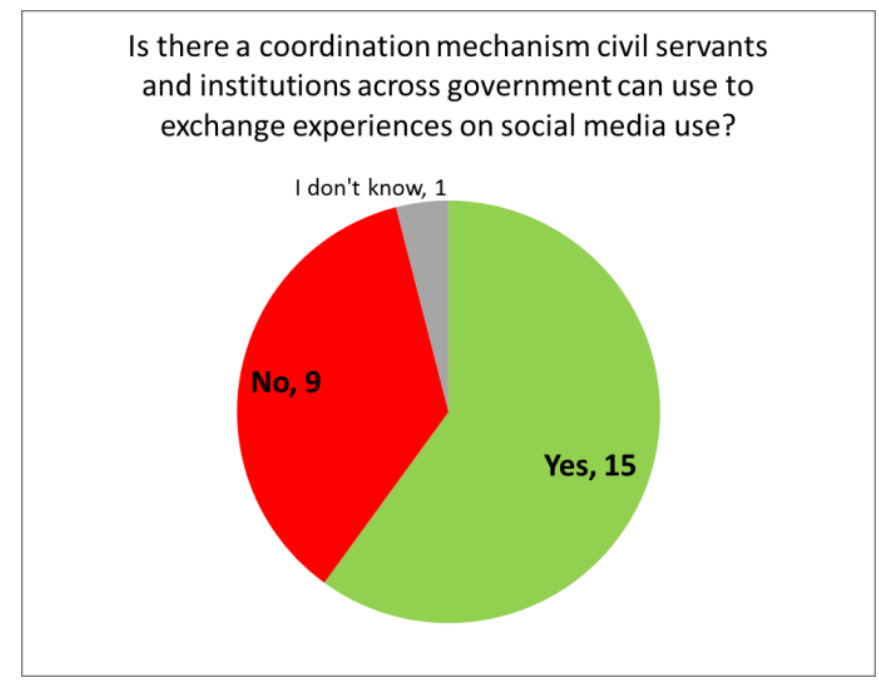

Source: OECD (2013b), "Survey on government use of social media".

\section{Box 10. Examples of co-ordination mechanisms for social media use across government}

Australia: The Cross Agency Social Media (CASM) Forum lets civil servants share experiences, documentation, advice, and lessons learned.

Denmark: Co-ordination for social media use is part of Denmark's participation in the Open Government Partnership. A yearly Open Government Camp is organised for and by stakeholders in the public sector to meet civil society including individual citizens, businesses and NGOs. The responsibility for setting up the physical environment for the event is the Ministry of Finance, Agency for Digitisation.

France: Regular meetings, exchanges and seminars are organised by the Service d'information du Gouvernement (SIG) located at the Prime Minister's office.

Korea: The "online spokesperson" system is in place since 2010. In regular meetings organised by the Ministry of Culture, Sports and Tourism individual ministries and departments share their experiences in using social media and blogging platforms.

Netherlands: A Dutch network of social media practitioners exists that is not actually operated by government. The "Civil Servant 2.0" platform is a wiki where government employees can gather and exchange information on good practices (http://ambtenaar20.pbworks.com).

United States: The US General Services Administration (GSA) facilitated the launch of the "Social Media Community of Practice" (CoP) in June 2012. The community unites more than 200 federal government social media managers and aims to spread good practices for improving citizen services and cutting service delivery costs.

Source: Responses to OECD survey on social media; official GSA information (United States).

\section{Managing social media risks}

A major challenge for governments is to understand how to navigate the risks of social media. Avoiding and managing potential risks - e.g. to reputation or to security - is a primary concern for 
governments (see Figure 24 earlier). In fact, 9 out of 25 governments report they tackle these risks by blocking selected social media on government IT equipment (Figure 27).

\section{Figure 27. Blocking of social media on government IT equipment}

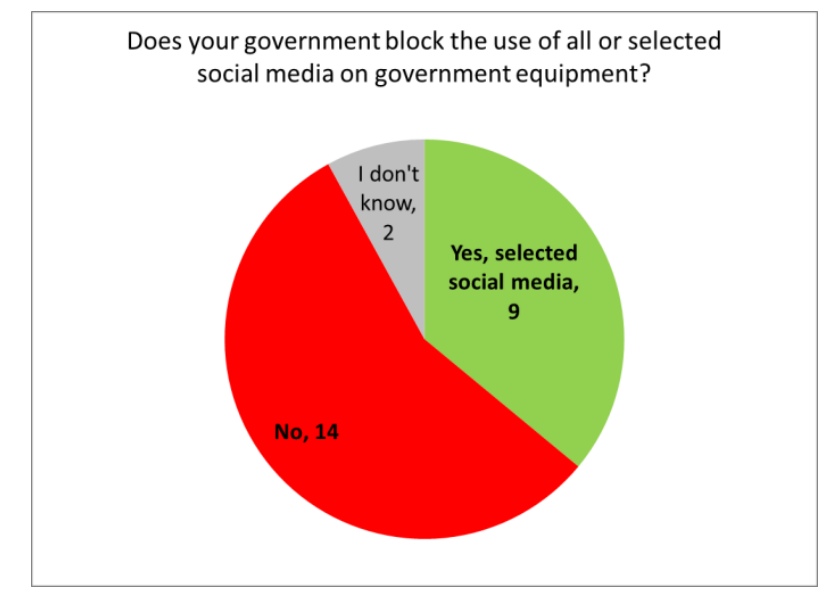

Source: OECD (2013b), "Survey on government use of social media".

But shutting out social media is going to be less and less effective for managing security and related risks. Technology use in and by governments is increasingly out of the direct control of institutions, e.g. because civil servants use social media in their personal lives and are active on their own devices in parallel to government-owned equipment. Today institutional affiliations can be easily identified on the Internet, which means that every civil servant that uses Twitter, Facebook, a blog or similar can also be traced back to the institution he or she serves. That renders initiatives such as blocking social media use quite ineffective in the wider context of risk management. This is probably one reason why only $30 \%$ of municipalities in the United Kingdom reported doing so in 2013, down from 50\% in 2012 (BDO, 2013).

So governments need to acknowledge and maybe manage the fact that social media turns individual civil servants into perceived online "ambassadors" of their institution. They also need to realise that the increasing amount of information posted online by organisations and individuals facilitates the emergence of "social engineering" practices that have already affected private and public sector organisations. ${ }^{47}$ It is therefore important to integrate social media use into wider considerations about risks to the security and resilience of government services.

\section{Monitoring and measuring impact}

A pivotal component of successful social media strategies is to measure the impacts. But this is also where the greatest challenges lie as the vast majority of governments in the OECD have no effective way of measuring, let alone assessing, the returns on their social media efforts: only 5 out of 25 governments say they use specific metrics or indicators (Figure 28).

\footnotetext{
47 For an impressive article of an individual's data being hacked through "social engineering" techniques, see www.wired.com/gadgetlab/2012/08/apple-amazon-mat-honan-hacking; for an example of a public sector organisation becoming victim of "social engineering", see www.infosecurity-magazine.com/view/35399/usgovernment-agency-compromised-by-social-engineering.
} 
Figure 28. Use of metrics or indicators to monitor impacts of government social media use

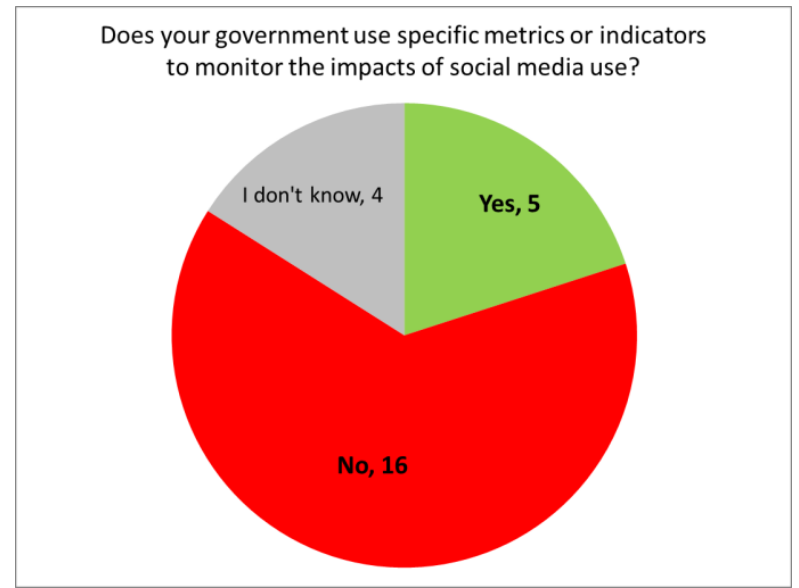

Source: OECD (2013b), "Survey on government use of social media".

Part of the problem is that metrics that are popular in commercial use of social media do not easily transfer to the public sector. Support of social media to drive product sales or to reduce marketing costs has no equivalent objective in most parts of government. Popularity metrics $-e . g$. the size of the "fan base" - are usually of little relevance to an institution's core mission. The current situation around measuring impact therefore resembles what an interlocutor at the United States government called "'Return on Ignorance' rather than 'Return on Investment" (cited in Mergel, 2013a).

Going forward, a hierarchical categorisation of objectives provides a preliminary yardstick to the maturity of social media measurement (Table 11). These include some of the simple metrics used in previous chapters, e.g. on presence and popularity. But they also include indicators that require further investigation to test their feasibility and relevance for comparisons, e.g. on penetration, perception and purpose of social media use in government.

Table 11. A categorisation of government social media objectives and potential indicators

\begin{tabular}{|c|c|c|}
\hline Objective & Indicator & Potential metrics \\
\hline Presence & $\begin{array}{l}\text { - } \quad \text { My institution is present on social media. } \\
\text { - } \quad \text { My institution is active on social media }\end{array}$ & $\begin{array}{ll}\text { - } & \text { Presence } \\
\text { - } & \text { Number of posts } \\
\end{array}$ \\
\hline Popularity & $\begin{array}{l}\text { My institution is popular on the main } \\
\text { social media channels. }\end{array}$ & $\begin{array}{l}\text { - Uptake measures, e.g. count of } \\
\text { followers, relative share of followers in } \\
\text { domestic population }\end{array}$ \\
\hline Penetration & $\begin{array}{l}\text { - My institution has reciprocal interactions } \\
\text { with social media users }\end{array}$ & $\begin{array}{l}\text { Measures of two-way interaction with } \\
\text { users, e.g. number of re-tweets, replies, } \\
\text { comments on blog posts }\end{array}$ \\
\hline Perception & $\begin{array}{l}\text { - My institution has a positive image on } \\
\text { social media. }\end{array}$ & $\begin{array}{l}\text { - Interactions with positive sentiment, } \\
\text { e.g. "favourite" or "like" } \\
\text { - Semantic analysis of interactions to } \\
\text { identify expression of sentiment } \\
\text { - Klout score }\end{array}$ \\
\hline Purpose & $\begin{array}{l}\text { - } \quad \text { My institution is a trusted source of } \\
\text { information and services } \\
\text { - } \quad \text { My institution uses social media to reach } \\
\text { users it cannot otherwise reach } \\
\text { - My institution uses social media to direct } \\
\text { public service users to specific channels }\end{array}$ & $\begin{array}{l}\text { - Interactions with "influential" users that } \\
\text { can act as multipliers. } \\
\text { - User monitoring or surveys to identify } \\
\text { interaction with specific user groups } \\
\text { - Click-through rates to digital information } \\
\text { and services offers }\end{array}$ \\
\hline
\end{tabular}


To be meaningful, those metrics need to be complemented by relevant context information. The OECD survey can, for example, be used to provide information on government strategies and policies in this area (see Table 12). Further context include statistics on use and uptake of social media, data on digital access or use divides, etc. Using such a diverse set of sources helps to piece together a solid framework for measuring the impact of social media use by governments.

Table 12. Context information about government social media strategies and policies

\begin{tabular}{|c|c|c|c|c|c|c|c|}
\hline $\begin{array}{l}\text { National } \\
\text { government }\end{array}$ & $\begin{array}{l}\text { Has a } \\
\text { strategy or } \\
\text { objectives? }\end{array}$ & $\begin{array}{l}\text { Has capacity } \\
\text { development } \\
\text { plan? }\end{array}$ & $\begin{array}{l}\text { Has } \\
\text { guidelines for } \\
\text { institutions? }\end{array}$ & $\begin{array}{l}\text { Has } \\
\text { guidelines } \\
\text { for civil } \\
\text { servants? }\end{array}$ & $\begin{array}{l}\text { Uses social } \\
\text { media } \\
\text { internally? }\end{array}$ & $\begin{array}{l}\text { Has a formal } \\
\text { co-ordination } \\
\text { mechanism? }\end{array}$ & $\begin{array}{l}\text { Uses } \\
\text { metrics or } \\
\text { indicators? }\end{array}$ \\
\hline Australia & + & + & + & + & + & + & + \\
\hline Austria & + & + & + & + & + & + & \\
\hline Belgium & + & & + & + & & + & \\
\hline Canada & + & + & + & + & + & + & + \\
\hline Chile & + & & + & & & & + \\
\hline Colombia & + & + & + & + & + & + & + \\
\hline $\begin{array}{l}\text { Czech } \\
\text { Republic }\end{array}$ & & + & & & & & \\
\hline Denmark & & & & & & + & \\
\hline Estonia & & & + & + & + & + & \\
\hline Finland & + & & + & + & + & & \\
\hline France & + & + & + & + & & + & + \\
\hline Iceland & & & & & & + & \\
\hline Ireland & + & & + & + & & + & \\
\hline Japan & & & + & & & & \\
\hline Korea & + & + & + & + & + & + & \\
\hline Netherlands & + & + & + & + & + & + & \\
\hline $\begin{array}{l}\text { New } \\
\text { Zealand }\end{array}$ & & & & & + & & \\
\hline Norway & & & + & + & & & \\
\hline Poland & & & & & + & & \\
\hline Portugal & & & & & & & \\
\hline Slovenia & & & & & + & + & \\
\hline Spain & & & + & & & + & \\
\hline Sweden & & & + & & & & \\
\hline Switzerland & & & & & & + & \\
\hline Turkey & + & & & & & & \\
\hline
\end{tabular}

Note: “+” means "Yes”, blank cells mean either "No" or "I don't know".

Source: OECD (2013b), "Survey on government use of social media". 


\section{CONCLUSION}

This paper analysed if and how national governments use social media today. It provides empirical baselines, discusses opportunities and challenges for more open policy processes and better public service delivery, and it outlines the main issues governments need to consider when managing the transition towards operations in a social media-rich environment.

This is clearly a new phenomenon for governments. At the same time there are institutions that have been experimenting with social media for quite a while. Early adopters such as government institutions in the United States and the United Kingdom as well as in several Latin American countries seem to be yielding some returns on their proactive approaches to this technology trend. They figure among the most "popular" governments on social media, expressed by a large followership and high levels of interaction.

Yet empirical evidence proves that social media popularity is much easier achieved by political leaders, i.e. individuals. The relative success of presidents and prime ministers, compared to the institutions they represent, is understandable given their need to actively "market" themselves and their messages to rally for support, funds and votes. But this also raises the question whether institutions - as the constant main interface between citizens and the state - should aim to do better in using social media.

There are many good cases of government institutions using social media to consult, to deliver information or services, to manage workflows more efficiently. However, practices so far result mainly in incremental changes. Only in few places have institutions embraced social media in a way that actually transforms policy-making, decision-making or service delivery processes. The risk of governments being slow about using new channels to open up is that citizens, civic entrepreneurs, non-established organisations and others step in to build platforms that "bypass" traditional means of participation. This can contribute to adverse long-term effects, e.g. further declining voter turnout rates among young people.

Despite the many changes provoked by social media, traditional power networks and known political realities still limit the actual influence that crowd-based efforts have on government actions. Social media certainly help to channel diffuse opinions and create the critical mass to place issues on the agendas of decision-makers. At the same time, governments remain very hierarchical and silo-based organisations, which favours the work of traditional intermediaries such as business lobbies and trade unions (who obviously know how to utilise social media too). There is also a lack of capacity to absorb, treat and respond to the diffuse requests picked up on social media. Taken together, these factors make it that many government workflows today clash with the "flattening" and immediate structure of information on the Internet.

In the current political climate the scrutiny of government use of social media is particularly high. General confidence in government has declined in many countries and governments partly expect social media to help them regain trust of the population. The problem is that governments are not always transparent enough about if and how they use social media to derive policy intelligence, be it about individuals or about society as a whole. Resentments of the general population to have their data used by government - as well as for commercial or research purposes - are relatively high in some places and can have a negative impact on the perception of other uses of social media by public sector institutions. 
Finally, access and use challenges need to be addressed to make social media an effective channel for reaching out to specific parts of the population. Today, low levels of education and income are hampering factors for uptake of social in many countries. This limits the inclusion potential of using these channels to encourage participation or improve public service delivery.

Moreover, the fact that almost all young people in OECD countries are active social media users does not yet make social networks a means for government to reach those young people. Current statistics indicate extremely low levels of interest for using social media to engage in any discussions of political or civic issues on the Internet. Coupled with relatively high voter abstention rates among young people, several countries face a major challenge in making sure young people are not excluded from participation in policy processes.

In this rapidly evolving field the full and detailed value proposition for social media use in government institutions has yet to emerge. It is necessary to clearly identify and state the added value for any institution in the public sector whose main purpose is not to raise its profile through communications but to deliver better services and to develop better policies.

\section{Next steps towards better guidance and data collection}

Governments can hardly afford to sit back and wait for that value proposition to emerge. In the current social media-rich context, government institutions are expected to use social media and adapt their workflows to make best use of the new opportunities. This means taking an active role and managing the change taking place in public sectors. A checklist of issues to raise and address is proposed in Table 13.

Table 13. A checklist for purpose-oriented social media use in government

\begin{tabular}{|c|c|}
\hline Issue & Questions to be raised and answered \\
\hline $\begin{array}{l}\text { Objectives and } \\
\text { expectations }\end{array}$ & $\begin{array}{l}\text { What is the core mission of my institution? } \\
\text { - What are the most important information and services provided by my institution? } \\
0 \text { How important is public communication for achieving my institution's core objectives? } \\
\text { - How can social media support my institution's core mission? What are examples from similar } \\
\text { institutions domestically or internationally? } \\
\text { Can social media enable outside actors to support selected activities of my institution, e.g. } \\
\text { intermediaries or individuals for which my institution can provide a platform for collaboration? }\end{array}$ \\
\hline $\begin{array}{l}\text { Governance } \\
\text { modes and } \\
\text { guidelines }\end{array}$ & 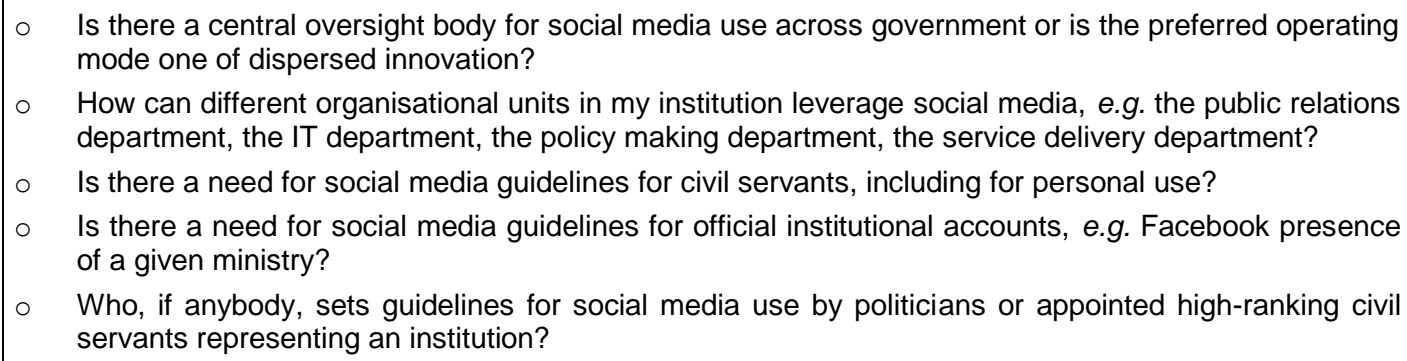 \\
\hline $\begin{array}{l}\text { Legal } \\
\text { compliance }\end{array}$ & $\begin{array}{l}\text { What are the specific legal and regulatory provisions that may have an impact on how my institution } \\
\text { uses social media? } \\
\text { - Are social media covered or excluded from official record-keeping? } \\
\text { What disclaimers should be added to the social media presence? } \\
\text { What information is my institution allowed to re-use when it comes to privacy protection or } \\
\text { compliance with intellectual property laws? } \\
\text { How to ensure that my institution's social media use meets requirements for accessibility of } \\
\text { information and services? }\end{array}$ \\
\hline
\end{tabular}




\begin{tabular}{|c|c|}
\hline Issue & Questions to be raised and answered \\
\hline $\begin{array}{l}\text { Skills and } \\
\text { resources }\end{array}$ & $\begin{array}{l}\text { What human resources are available or can be mobilized to achieve sustainable impacts? } \\
\text { Are social media skills addressed by wider (digital) skills strategies at my institution or government? } \\
\text { How are social media expenses accounted for? Can they be extracted from overall communications } \\
\text { expenses in order to calculate specific costs? }\end{array}$ \\
\hline $\begin{array}{l}\text { Collaboration } \\
\text { and community- } \\
\text { building }\end{array}$ & $\begin{array}{l}\text { Do government communities exist where I can exchange social media experiences? } \\
\text { What coordination or collaboration mechanisms would help my institution understand and maximize } \\
\text { the impact of social media? }\end{array}$ \\
\hline $\begin{array}{l}\text { Managing risks } \\
\text { of social media } \\
\text { use }\end{array}$ & $\begin{array}{l}\text { How damaging would reputational risks be for my institution? } \\
\text { Does my institution need to worry about unintentional disclosure of information? } \\
\text { What share of civil servants uses social media in their personal capacity? } \\
\text { Are social media risks addressed by overarching strategies for managing risks in my institution or } \\
\text { government? }\end{array}$ \\
\hline $\begin{array}{l}\text { Monitoring and } \\
\text { measuring social } \\
\text { media impacts }\end{array}$ & $\begin{array}{l}\text { How advanced are my social media indicators? What do they actually measure: presence, popularity, } \\
\text { penetration, perception or purpose? } \\
\text { Does my institution use indicators that evaluate the contribution to actual core objectives? } \\
\text { - What would be an ideal set of metrics for my institution's use of social media? } \\
\text { What information sources can I use to move from the current indicators to an ideal set of purpose- } \\
\text { oriented indicators? }\end{array}$ \\
\hline
\end{tabular}

Indicators are needed to accompany this change but take time to develop. This paper proposes a set of metrics that range from simple measures of social media presence and popularity to indicators that more closely relate to the mission and purpose of government institutions (see Table 11 earlier). Additional context information need to complement these indicators, e.g. information on national policy priorities and resources dedicated to social media (see Table 12).

The OECD's analytical work in this area has three main objectives: taking stock, assessing and guiding decision makers. Both quantitative and qualitative data is necessary to achieve those objectives, albeit to different degrees in each phase (see also Figure 29):

- Taking stock is mainly driven by empirical analysis as done in the second chapter. The wealth of data and tools to describe Internet and social media trends is growing exponentially and much of the Internet-generated data is readily available and can be harmonised for international comparisons. Some qualitative information is instrumental to understand the context in which social media use takes place. Government surveys such as the one used here provide an overview of efforts and resources dedicated to social media use.

- Impact assessments use a more balanced mix of quantitative and qualitative data. It is important to generate more empirical information to analyse whether social media practices in governments contribute to the core mission objectives. But qualitative analysis is very important here too, e.g. to discuss individual government initiatives and study their impacts. This can include cases of using social media to deliver public services, as well as their use to improve internal workflows and processes.

- Guidance for governments derives from comparative benchmarks, possibly even composite indicators. But policy-relevant guidance is also obtained from targeted case studies that clearly line up the success and risk factors of selected good practices. In-depth analyses allow testing the transferability of those practices to context that show comparable features, as identified during stock-taking. 
Figure 29. Analytical and data collection framework for government use of social media

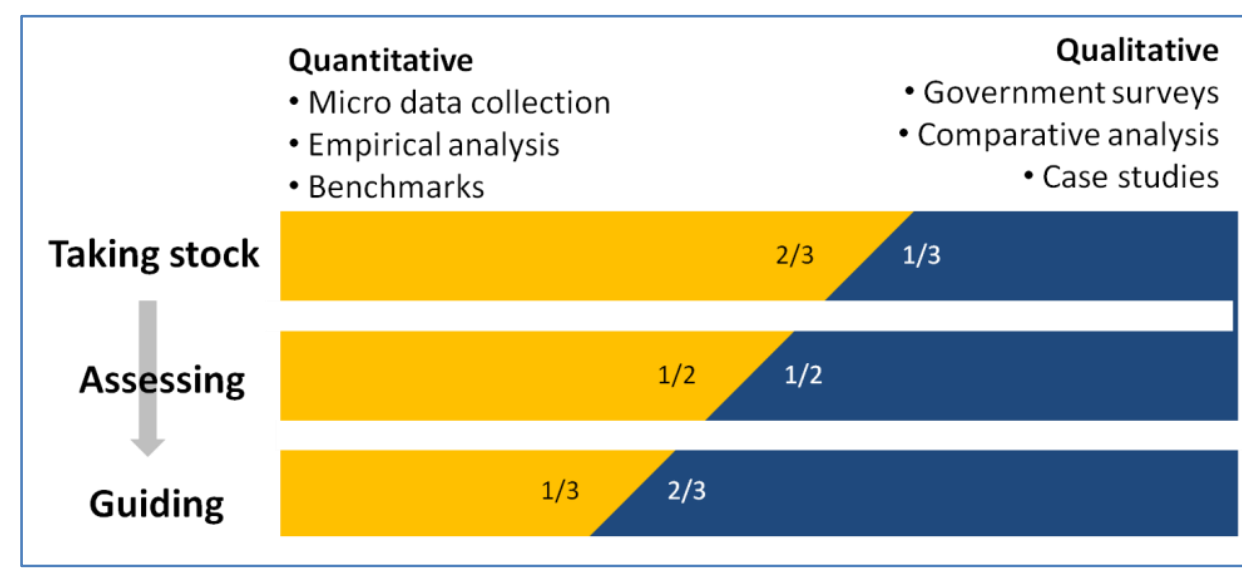

This framework for the analysis of government use of social media is relatively flexible. It can be used to analyse and collect data on social media use in specific government sectors, e.g. to expand the discussion of opportunities and challenges in the healthcare and public employment services in Chapter 3.

Similarly, the framework enables identification and analysis of good social media practices to transform internal government workflows. Chapter 3 pointed to ways in which social media enhance collaboration and foster productivity in public sector institutions.

Finally, there is great potential in applying this framework to sub-national levels of government. Regional and municipal authorities are the places where citizens most frequently interact with the state, and it is also where a lot of social media innovation takes place. At the same time, budget and other pressures to become more effective and efficient are probably hardest felt at those levels. This increases the need for solid value propositions and good practices that can be transferred to this part of government. 


\section{BIBLIOGRAPHY}

Ahn, M.J. (2010), "Adoption of e-communication applications in US municipalities: The role of political environment, bureaucratic structure and the nature of applications", in American Review of Public Administration, 41 (4), pp. 428-452.

Andersen, K., Medaglia, R. and H. Z. Henriksen (2012), "Social media in public health care: Impact domain propositions", in Government Information Quarterly, 29(4), pp. 462-469.

Bekkers, V., Edwards, A. and D. de Kool (2013), "Social media monitoring: Responsive governance in the shadow of surveillance?", in Government Information Quarterly, 30(4), pp. 335-342.

BDO (2012), "From Housing and Litter to Facebook and Twitter", BDO Local Government.

BDO (2013), "Following the trends", BDO Local Government.

Bonsón, E., Torres, L., Royo, S. and F. Flores (2012): "Local e-government 2.0: Social media and corporate transparency in municipalities", in Government Information Quarterly, 29 (2), pp. 123-132.

Bouckaert, G. (2012), “Trust and public administration”, in Administration, 60(1). pp. 91-115.

Fernández Guerra, C. (2014), @ policía: las historias de un éxito, Aguilar Press, Madrid.

GovLoop (2013), "The Social Media Experiment in Government: Elements of Excellence", www.govloop.com/profiles/blogs/the-social-media-experiment-in-government-elements-ofexcellence-.

ICMA (2011), "E-Government 2011 Survey Summary", http://icma.org/en/icma/knowledge network/documents/kn/Document/302947/EGovernment 2 011_Survey_Summary.

Jobvite (2014), "Jobvite Job Seeker Nation Study. An authoritative survey of the social, mobile job seeker”, http://blog.jobvite.com/2014/02/2014-jobvite-job-seeker-nation-study.

Livingstone, S. et al. (2007), "Youthful Steps towards Civic Participation: Does the Internet Help?", in B. Loader (ed.), Young Citizens in the Digital Age: Political Engagement, Young People and New Media, Routledge, London.

McKinsey (2012), "The social economy: Unlocking value and productivity through social technologies", www.mckinsey.com/insights/high_tech_telecoms_internet/the_social_economy.

Mergel, I. (2010), "Government 2.0 revisited - Social Media Strategies in the Public Sector", http://inesmergel.wordpress.com/2010/07/06/pa-times-government-2-0-revisited-social-mediastrategies-in-the-public-sector.

Mergel, I. (2013a), “A framework for interpreting social media interactions in the public sector”, in Government Information Quarterly, 30(4), pp. 327-334. 
Mergel, I. (2013b), "Social media adoption and resulting tactics in the U.S. federal government", in Government Information Quarterly, 30(2), pp. 123-130.

MIC (2013), Statistical Handbook of Japan 2013, Ministry of Internal Affairs and Communications.

Mickoleit, A. (2013), "Do you 'Like' your government as much as Chileans Like theirs?", blog post on OECD Insights, 16 September, http://oecdinsights.org/2013/09/16/do-you-like-yourgovernment-as-much-as-chileans-like-theirs.

Mickoleit, A. (2014), "Using social media to innovate service delivery - one size does not fit all”, blog post on OECD Observatory of Public Sector Innovation, 9 July, www.oecd.org/governance/observatory-public-sectorinnovation/blog/page/usingsocialmediatoinnovateservicedeliveryonesizedoesnotfitall.htm.

OECD (2014), OECD Recommendation on Digital Government Strategies, adopted by the OECD Council on 15 July, www.oecd.org/gov/public-innovation/recommendation-on-digitalgovernment-strategies.htm.

OECD (2013a), Government at a Glance 2013, OECD, Paris.

OECD (2013b), "Survey on government use of social media".

OECD (2012a), OECD Internet Economy Outlook 2012, OECD, Paris.

OECD (2012b), Restoring Public Finances, 2012 Update, OECD, Paris.

OECD (2011), Together for Better Public Services: Partnering with Citizens and Civil Society, OECD, Paris.

OECD \& ITU (2011), M-Government. Mobile Technologies for Responsive Governments and Connected Societies, OECD, Paris.

OECD (2008), Public-Private Partnerships: In Pursuit of Risk Sharing and Value for Money, OECD, Paris.

OECD (2001), Citizens as Partners, OECD, Paris.

O’Reilly, T. (2010), “Government as a platform”, in Lathrop, D. and L. Ruma (eds.), Open Government. Collaboration, Transparency, and Participation in Practice. O'Reilly Media.

PewInternet (2012), "Social Media and Political Engagement”, 19 October.

PewInternet (2012), "Senior citizens and digital technology", www.pewinternet.org/2012/09/15/senior-citizens-and-digital-technology.

Reddick, C. and M. Turner (2012), "Channel choice and public service delivery in Canada: Comparing e-government to traditional service delivery", in Government Information Quarterly, 29(1), pp. $1-11$.

Reddick, C. and D. Norris (2013), "Social media adoption at the American grass roots: Web 2.0 or 1.5?”, in Government Information Quarterly, 30(4), pp. 498-507. 
Saleh et al. (2012), "Effect of social media in health care and orthopedic surgery", in Orthopedics, 35(4), pp. 294-297.

SocialMediaToday (2013), "10 Examples of Social Media ROI [INFOGRAPHIC]”, 30 September, http://socialmediatoday.com/pamdyer/1777136/10-examples-social-media-roi-infographic.

TNS (2013), "European Youth: Participation in Democratic Life", Flash Eurobarometer 375, requested by the European Commission.

Twiplomacy (2014), Twiplomacy Study 2014, full dataset available at http://twiplomacy.com.

Twiplomacy (2013), Twiplomacy Study 2013, full dataset available at http://twiplomacy.com.

Ubaldi, B. (2013), “Open Government Data. Towards Empirical Analysis of Open Government Data Initiatives", OECD Working Papers on Public Governance, No. 22.

UK Prince's Trust (2013), "Digital literacy survey 2013”, www.princestrust.org.uk/about the trust/what we do/research/digital literacy research 2013.aspx.

Wendling, C., J. Radisch and S. Jacobzone (2013), "The Use of Social Media in Risk and Crisis Communication”, OECD Working Papers on Public Governance, No. 25.

Volpe, R. et al. (2013), “Googling a patient”, Hastings Center Report, 43(5), pp. 14-15. 